Portland State University

PDXScholar

Fall 12-9-2015

\title{
Thinking About Work at Home: Implications for Safety at Work
}

Frankie Guros

Portland State University

Follow this and additional works at: https://pdxscholar.library.pdx.edu/open_access_etds

Part of the Occupational Health and Industrial Hygiene Commons, and the Psychology Commons Let us know how access to this document benefits you.

\section{Recommended Citation}

Guros, Frankie, "Thinking About Work at Home: Implications for Safety at Work" (2015). Dissertations and Theses. Paper 2624.

https://doi.org/10.15760/etd.2620

This Dissertation is brought to you for free and open access. It has been accepted for inclusion in Dissertations and Theses by an authorized administrator of PDXScholar. Please contact us if we can make this document more accessible: pdxscholar@pdx.edu. 
Thinking About Work at Home: Implications for Safety at Work

by

Frankie Guros

A dissertation submitted in partial fulfillment of the requirements for the degree of

\author{
Doctor of Philosophy \\ in \\ Applied Psychology
}

\author{
Dissertation Committee: \\ Charlotte Fritz, Chair \\ Leslie Hammer \\ Ryan Olson \\ Kris Henning
}

Portland State University

2015 
(C) 2015 Frankie Guros 


\begin{abstract}
Safety at work is of the utmost importance to employees and the organizations they work for, and as such, it is a central issue for occupational health psychology. Although dramatic decreases in the number of worker injuries and fatalities have been observed over the last several decades, safety remains a principal concern for organizations. This is especially true in occupations in which employees face serious threats to their personal safety, such as correctional officers (COs). While a number of studies have identified workplace factors that contribute to worker safety, few have attempted to draw a link between employee nonwork experiences and safety at work. In the current study, a model was tested to examine whether the relationship between cognitive nonwork recovery experiences and safety performance at work was mediated by safety motivation. Specifically, the effort-recovery model (Meijman \& Mulder, 1998) and the concept of self-regulatory resources (Muraven \& Baumeister, 2000) were utilized to test these relationships. It was hypothesized that psychological detachment during nonwork time can replenish cognitive resources that employees need in order to feel motivated to be focused on safety in the workplace, and negative work reflection can drain these resources. Furthermore, drawing on Broaden-and-Build theory (Fredrickson, 1998) it was posited that positive work reflection during nonwork time would have a positive relationship with safety motivation. Additionally, it was hypothesized that the relationship between these cognitive recovery experiences and safety motivation would be moderated by individual perceptions of safety climate. The hypotheses were examined in a sample of COs $(N=166)$ from two correctional facilities in Oregon. The results
\end{abstract}


overall did not provide strong empirical support for the model. No support was found for the role of psychological detachment or negative work reflection. Additionally, perceptions of safety climate did not moderate the relationship between cognitive recovery experiences and safety. However, positive work reflection during nonwork time was significantly associated with safety participation motivation, which in turn had a positive association with safety participation. Additionally analyses revealed that this relationship was reciprocal in nature when utilizing an additional sample four months after data collection, such that safety participation motivation and safety participation predicted positive work reflection. The findings from the current study build on the research between the work-life interface and safety at work, suggesting that positive nonwork experiences can potentially be related to discretional safety performance at work. Implications for practical applications and suggestions for future research are discussed. 


\section{Acknowledgements}

In addition to the numerous peers, colleagues, lab-mates, and professors who were instrumental in the completion of my dissertation, I would like to acknowledge that this would not have been possible without the love and support from my family.

To Mom and Dad: I told you I would never go to graduate school. I guess you can't take me at my word. Thanks for your endless love, support, and belief in me. To Nick: you always inspire me with your accomplishments and overall perspective on life. Keep it up. And to LeAnna: I love you always. Thank you for supporting me through this crazy journey. 


\section{Table of Contents}

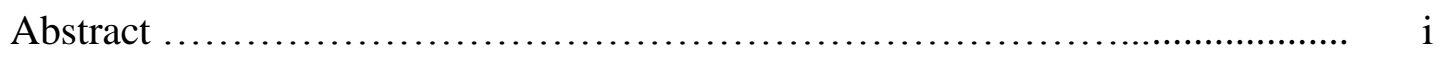

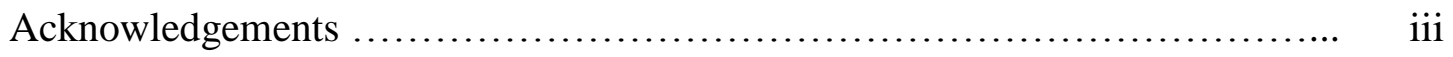

List of Tables $\ldots \ldots \ldots \ldots \ldots \ldots \ldots \ldots \ldots \ldots \ldots \ldots \ldots \ldots \ldots \ldots \ldots \ldots \ldots \ldots \ldots \ldots \ldots \ldots \ldots, \quad \mathrm{v}$

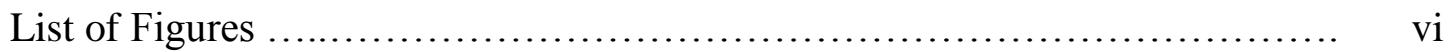

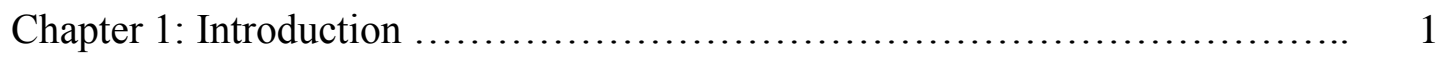

Chapter 2: Safety Motivation and Safety Performance $\ldots \ldots \ldots \ldots \ldots \ldots \ldots \ldots \ldots . . \ldots \ldots$

Chapter 3: Cognitive Recovery and Resource Replenishment ................ 26

Chapter 4: Cognitive Recovery From Work ........................... 35

Chapter 5: Perceptions of Safety Climate $\ldots \ldots \ldots \ldots \ldots \ldots \ldots \ldots \ldots \ldots \ldots \ldots \ldots, \quad 47$

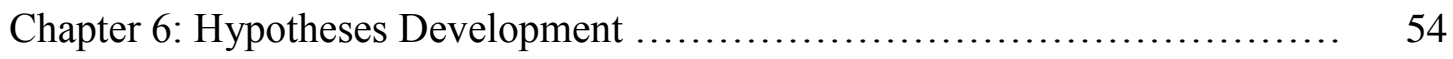

Chapter 7: Method .................................................. 73

Chapter 8: Results ...................................................... 79

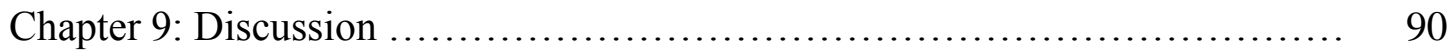

References ..................................................... 131

Appendix: List of Measures ......................................... 149 


\section{List of Tables}

Table 1: Summary of Demographics of Study Participants .................. 116

Table 2: Means, Standard Deviations, and Correlations Among Study Variables 117

Table 3: Bootstrapped Mediation Analyses ................................ 118

Table 4: Hierarchical Regression Predicting Safety Motivation From Interaction of Psychological Detachment and Perceptions of Safety Climate ...............

Table 5: Hierarchical Regression Predicting Safety Motivation From Interaction of Negative Work Reflection and Perceptions of Safety Climate ...............

Table 6: Hierarchical Regression Predicting Safety Motivation From Interaction of Positive Work Reflection and Perceptions of Safety Climate 


\section{List of Figures}

Figure 1: Final Path Model With Parameter Estimates ...................... 122

Figure 2: Distribution of Mean Scores for Psychological Detachment .......... 123

Figure 3: Distribution of Mean Scores for Negative Work Reflection ........... 124

Figure 4: Distribution of Mean Scores for Positive Work Reflection ............ 125

Figure 5: Distribution of Mean Scores for Safety Compliance Motivation ....... 126

Figure 6: Distribution of Mean Scores for Safety Compliance ................ 127

Figure 7: Distribution of Mean Scores for Safety Participation Motivation ...... 128

Figure 8: Distribution of Mean Scores for Safety Participation ............... 129

Figure 9: Distribution of Mean Scores for Perception of Safety Climate ........ 130 


\section{Chapter 1: Introduction}

Despite improvements in safety since the 1970s, workplace injuries and fatalities continue to plague organizations (Smith \& Carayon, 2011). Workplace fatalities in the U.S., which topped 5,600 in 2011, had an estimated economic impact of \$6 billion, and cost an additional $\$ 186$ billion for the nearly 8.6 million nonfatal injuries that year (Leigh, 2011). While the frequency of these accidents fluctuates each year, the numbers remain staggeringly high (4,963 fatal injuries in 2013; BLS, 2013). Additionally, these incidents cause immeasurable distress and suffering for workers and their families, friends, and coworkers (Zohar, 2000). These facts support the claim academics continue to make: occupational safety is still a crucial issue in the workplace (Zohar, 2011). Therefore, there is a critical need to identify organizational and individual factors that affect workplace safety and protect workers, given the significant prevalence and high cost of accidents in the workplace.

Furthermore, certain occupations with inherently dangerous job demands often face a higher risk of workplace accidents. One such occupation is correctional officers (COs) who work in correctional facilities for incarcerated adults. The incident rate for COs for nonfatal injuries and illnesses is among the highest of any occupation. In 2012 the Bureau of Labor Statistics (BLS) reported that correctional officers had the thirdhighest occupational incidence rate of nonfatal injuries and illnesses (459 per 10,000 workers; BLS, 2012) and the third-highest rate of these incidents resulting in missed days from work (BLS, 2012). Additionally, 17\% of all injuries and illness in state government 
jobs occurred in corrections, a rate two and a half times greater than the average rate for all government positions (BLS, 2012).

While initially the onus was placed on individuals for workplace accidents, research on occupational safety eventually shifted to focus on organizational factors rather than individual behaviors (Neal, Griffin, \& Hart, 2000). This includes assessing the work environment and organizational practices (e.g., how to eliminate hazards or redesign work environments or work practices; Smith \& Carayon, 2011), as well as examining aspects of the psychological environment at both the organization and group levels (e.g., safety climate—shared perceptions that employees have about the procedures, practices, and policies with regard to safety; Schneider, 1990; Zohar, 2010). A framework that has been utilized frequently to assess safety performance, introduced by Griffin and Neal (2000), has provided a model to examine individual and organizational predictors of individual performance. Griffin and Neal (2000) made the distinction between safety compliance, which involves adhering to safety procedures and safely carrying out work tasks, and safety participation, which refers to volitional behaviors, such as helping coworkers or promoting safety initiatives within the workplace. They additionally separated the antecedents to safety performance (i.e., motivation to engage in safe behaviors) from the outcomes (i.e., accidents resulting in bodily injury). Meta-analytic evidence utilizing this framework supports the idea that individual-level factors contribute to safety motivation, safety compliance, and even occurrences of accidents and injuries (Beus, Dhanani, \& McCord, 2015; Christian, Bradley, Wallace, \& Burke, 2009). Furthermore, numerous scholars have posited for 
years that most workplace incidents are at least partially attributed to human error (e.g., Hofmann, Jacobs, \& Landy, 1995).

Despite the extant research, our understanding of how individual-level behaviors affect safety remains incomplete. Specifically, little is known about how behaviors outside of work can influence safety at work. This is currently a general gap in the workplace safety literature; it is unclear whether experiences outside of the work domain can affect worker safety. Although research on the work-home interface has found that employees carry resources or conditions — such as their mood, energy, and stressbetween their work and their home life (i.e., spillover; Edwards \& Rothbard, 2000; ten Brummelhuis \& Bakker, 2012), this body of literature has largely not been applied to the area of workplace safety. Furthermore, one specific area of research that may help to further this pursuit is research on how individuals recover from work stress. Specifically, the study of nonwork recovery experiences, or the psychological experiences employees have while away from the workplace that help them recuperate from work stress (Sonnentag \& Fritz, 2007, 2014), can be applied to identify nonwork factors that potentially influence safety. Studies of recovery experiences have found relationships between these experiences and a number of outcomes relevant to employees, such as task performance, engagement, and well-being indicators (e.g., Binnewies, Sonnentag, \& Mojza, 2009a; Sonnentag \& Fritz, 2007, 2014). Recovery experiences are related to work-related outcomes because employees are able to use these experiences to restore personal resources (i.e., mood, attention, energy) that enable enhanced performance at work. These same factors are relevant for safety, raising a relevant question for the 
current study: Are nonwork recovery experiences related to safety in the workplace? So far, research that attempts to draw an empirical connection between recovery experiences factors and workplace safety is scarce. An exception is the study by LaPierre, Hammer, Truxillo, and Murphy (2012) in which it was found that psychological detachment during nonwork time buffered the relationship between family interference with work and workplace cognitive failure, which is a theoretical precursor to accidents at work (Wallace \& Chen, 2006). Lapierre et al.'s (2012) findings indicate that an employee's cognitive experiences outside of the workplace may in fact affect cognitions related to safety at work, although this research is in its infancy. However, a few studies have indicated that experiences in the nonwork domain may be related to safety (e.g., Cullen \& Hammer, 2007; Dai Milkman, Hofmann, and Saats, 2015; Turner, Hershcovis, Reich, \& Totterdell, 2014).

Another gap the current study addresses is motivated by the recovery from work stress literature in which findings on cognitive recovery from work stress have focused largely on psychological detachment (Etzion, Eden, \& Lapidot, 1998). Psychological detachment is mentally disengaging or refraining from work thoughts during nonwork hours (Etzion et al., 1998). Psychological detachment has emerged as a cognitive recovery experience that tends to have a robust relationship with employee outcomes. However, less is known about how the valence of work-related thoughts (when they do occur) affect employees (Sonnentag, 2012). This is important because not all employees are able to- or choose to- - psychologically detach from work. In other words, does thinking about work in a positive or negative light during off-hours either help or hinder 
employee safety performance? Negative thoughts about work may interfere with recovering from work stress, but positive thoughts could provide a positive experience for employees that may bolster their motivation (Gable Reis, Impett, \& Asher, 2004; Sonnentag \& Grant, 2012). This may be particularly important for safety performance, as it is reliant on an employee's ability to focus and make quality decisions. The thoughts employees have outside of work may have an effect on the availability of their selfregulatory resources (Baumeister, Bratslavsky, Muraven, \& Tice, 1998), which may affect their ability to focus on safety at work. However, few studies have produced evidence about how these cognitions may be related to motivation, performance, and other relevant outcomes for employees.

Finally, despite the volume of safety research, little has been done to integrate psychological measures into safety research in occupations where the job requirements create an inherently dangerous work environment. While research on safety has uncovered a great deal of knowledge of predictors of workplace safety, these studies are often conducted in only certain occupations (e.g., construction, mining, healthcare). However, correctional facilities as work environments provide unique challenges for employees from the perspective of workplace safety. Specifically, in corrections, safety involves keeping fellow officers and inmates safe from a variety of hazards in the prison environment, including physical attacks from the inmates. COs may face additional risks ranging from contracting illnesses from coming in contact with bodily fluids during an assault from inmates in the extreme case or developing musculoskeletal conditions from spending many hours on their feet while working at their post. Given the risks of working 
as a $\mathrm{CO}$, from the health risks associated with shift work to dealing with potentially dangerous inmates, more research remains to be done on the various factors, including psychological challenges, affecting workplace safety in corrections (Armstrong \& Griffin, 2004; Konda, Reichard, \& Tiesman, 2012).

Hence, the current study contributes to research on workplace safety by addressing these gaps in the literatures and creating a more complete understanding of how workplace safety is related to factors outside the workplace. In the current study, the effort-recovery model (Meijman \& Mulder, 1998) and ego-depletion model (Baumeister et al., 1998) are presented as the main theoretical frameworks that describe how cognitive recovery from work and safety are linked. Ego-depletion is a concept introduced by Baumeister and colleagues who proposed that individuals have a limited capacity for selfregulation and that engaging in tasks that require self-regulation will reduce performance on subsequent tasks. Empirical studies have widely supported the notion that an individual's capacity for self-control is like a muscle that is weakened with use over time (Hagger, Wood, Stiff, \& Chatzisarantis, 2010; Muraven \& Baumeister, 2000). The effortrecovery model posits that when employees work they exert effort, which then results in load reactions (i.e., eye strain, subjective fatigue). These load reactions can only be weakened when the employees stop working and engage in the recovery process. In the current study, it is argued that cognitive nonwork recovery experiences affect the availability of cognitive self-regulatory resources that are relevant to safety at work. When cognitive recovery replenishes, or fails to replenish, it is further assumed that these resources will be transferred with the individual from the nonwork domain to the 
workplace (Edwards \& Rothbard, 2000). As such, it is predicted that cognitive recovery during nonwork time will be associated with safety motivation and safety performance.

However, as the predictors of safety are often multifaceted, in some situations the cognitions of an individual employee may not be the only factor affecting their safety behavior. Instead, other workplace variables may intervene to affect safety as well. Therefore, in order to incorporate contextual workplace factors that may play a role in the relationship between cognitive recovery and safety, it is proposed that perceptions of safety climate will moderate the relationships between nonwork recovery experience and safety at work. Safety climate refers to perceptions about the policies, practices, and procedures in an organization related to safety (Schneider, 1990; Zohar, 2010). In the current study, these perceptions are not aggregated to represent a group-level variable, and refer to the individual's perceptions of safety climate. They will henceforth be referred to as perceptions of safety climate.

\section{Contributions of the Present Study}

This study contributes to the literature in several ways. First, this is the first study to my knowledge to directly examine the link between nonwork recovery from stress and employee safety performance. While research has made great strides in understanding what contributes to workplace safety there is still a gap in our understanding of how nonwork experiences can affect employee safety performance at work. Cognitive recovery is related to job performance (Fritz, Yankelevich, Zarubin, \& Barger, 2010), but no link has been tested for performance specifically related to safety. Therefore, a goal of 
this study is to examine how cognitive recovery experiences may enable employees to be energized and focused, and therefore perform their work duties safely.

Second, this study explicitly examines employee cognitions during nonwork recovery experiences. Specifically, mental disengagement and thoughts about work are posited as cognitive recovery during nonwork time that is associated with safety. Few studies in the nonwork recovery literature have simultaneously focused on the following three cognitive recovery experiences: psychological detachment, negative work reflection, and positive work reflection. Negative work reflection (NWR) refers to considering what one does not like about their work (Fritz \& Sonnentag, 2006). Positive work reflection (PWR) involves thinking of the favorable aspects of one's work (Fritz \& Sonnentag, 2005). Psychological detachment has been linked to positive employee wellbeing outcomes, as it provides a mental respite from work-related cognitions (Sonnentag, 2012). NWR is assumed to consume resources, increase negative affect, and decrease self-efficacy, which may theoretically spillover to the workplace as well (Fritz \& Sonnentag, 2006). In addition, research has found that negative work events may be more salient than positive ones (Baumeister, Bratslavsky, Finenauer, \& Vohs, 2001). However, the evidence of a relationship between NWR and performance is mixed (e.g., Binnewies et al., 2009a), with some studies indicating a significant link, and others indicating no association between them. PWR is assumed to be a resource-building experience that may increase positive affect or self-efficacy through positive reflections or recounting of workplace events (Sonnentag \& Grant, 2012). These resources then theoretically spill over from the home domain to the work domain to affect workplace outcomes. Empirical 
evidence has revealed, however, that the relationship between PWR and performance is mixed (Binnewies, Sonnentag, \& Mojza, 2009b; Sonnentag \& Grant, 2012), such that PWR does not consistently predict task performance. Therefore, in addition to assessing how psychological detachment predicts workplace safety, experiences in which employees do think about work will be included in the current study. While psychological detachment, PWR, and NWR may all be related to safety performance, no study has included all three to compare their relative values.

A final contribution of the study is that nonwork recovery and safety are assessed in an occupation where the requirement to be alert and maintain the capacity for decisionmaking makes cognitive recovery particularly salient. COs work in facilities in which they are responsible for breaking up inmate fights, protecting inmates from assaults, and keeping themselves and their coworkers safe (Konda et al., 2012). In addition, COs are facing a nation-wide problem in which there are too few employees to fill positions in correctional facilities, resulting in mandatory overtime (Swenson, Waseleski, \& Hartl, 2008). The job demands of the occupation have been linked to higher work-family conflict and a high prevalence of depressive symptoms (Obidoa, Reeves, Warren, Reisine, \& Cherniack, 2011). For these reasons, it is important to determine if there is utility in seeking to optimize the nonwork experiences of COs for researchers and stakeholders in corrections and other related dangerous occupations. This study is particularly informative for COs by examining the phenomena of cognitive recovery and safety within COs. In addition, this study provides context for understanding cognitive 
recovery during nonwork time among other dangerous occupations as well (e.g., firefighters, emergency responders, police). 


\section{Overview}

In this study a model was tested in which safety motivation mediates the relationship between cognitive recovery experiences during nonwork time and safety at work. Furthermore, perceptions of safety climate were examined as a moderator of the relationship between cognitive recovery and safety motivation.

In the following chapters I review the literature and explain my theoretical rationale for the model and hypotheses. Chapter 2 introduces the concept of workplace safety and reviews the constructs that have been assessed in the literature. Chapter 3 explains the theoretical framework for the current study by reviewing the concepts proposed by the effort-recovery model (Meijman \& Mulder, 1998) and ego-depletion (Baumeister et al., 1998). Additionally, a third framework is introduced-Broaden-andBuild theory (Fredrickson, 1998)—offering a theoretical rationale to explain how positive thoughts about work during nonwork time may benefit employees. Chapter 4 reviews the literature on nonwork cognitive recovery from work, including psychological detachment, PWR, and NWR. Chapter 5 introduces perceptions of safety climate as a moderator and reviews literature related to the current study. Chapter 6 integrates the information from the previous chapters and presents specific hypotheses. Chapter 7 provides details as to the sample, study procedure, and measures being used in the current

study. Finally, Chapter 8 summarizes the results of the data analysis, and Chapter 9 offers a discussion in which the limitations, implications for practical applications, and future research directions are considered. 


\section{Chapter 2: Safety Motivation and Safety Performance}

For many years safety in the workplace was primarily evaluated by accident frequency and severity (Smith \& Carayon, 2011). However, over the last several decades, researchers shifted their focus from examining these outcomes of safety to assessing individual antecedents to workplace safety outcomes. This had resulted in a closer examination of the processes through which individual and organizational factors are associated with the frequency and severity of workplace accidents. From this movement a model of safety performance has emerged as the dominant framework in the literature. Griffin and Neal (2000) created their model utilizing existing theories of work performance from industrial/organizational psychology (i.e., Borman \& Motowidlo, 1997; Campbell, McCloy, Oppler, \& Sager, 1993). Griffin and Neal (2000) applied these theories to safety performance in two ways. First, they argued that safety performance should be conceptualized similarly to how Campbell et al. (1993) proposed conceptualizing performance. Campbell and colleagues posited that distinctions should be made between the components of performance, the determinants of performance, and the antecedents of performance. Second, Griffin and Neal (2000) proposed that safety performance should be separated into two components to align with Borman and Motowidlo's (1997) performance schema. The authors proposed task performance as work behaviors related to the core tasks of one's job, and contextual performance as behaviors that do not directly contribute to core task performance but improve the contextual or social environment of the workplace. 
Using these two established models of work performance, Griffin and Neal (2000) theorized that safety performance is separate from other related safety concepts (e.g., safety climate, safety knowledge), which they argued were antecedents or determinants of safety performance, rather than actual safety performance. Furthermore, the authors named two components of safety performance. Safety compliance refers to the core safety activities required by individuals in order to maintain a safe working environment, and parallels Borman and Motowidlo's (1997) definition of task performance. Safety participation refers to behaviors that support a safe workplace such as attending safety meetings, participating in voluntary safety activities, or providing support to coworkers for safety-related tasks. Safety compliance and safety participation refer to individual behaviors that constitute performance, which aligns with Campbell et al.'s (1993) definition of work performance. Specifically, performance is conceptualized as behaviors, not results (in the context of safety, performance is equated with employee behaviors, not accidents or incidents where an employee suffers an injury). Furthermore, Griffin and Neal (2000) proposed that antecedents of performance should be distinguished from performance behaviors. One such antecedent is safety motivation, defined as an employee's willingness to put forth effort and engage in safety behaviors (Neal \& Griffin, 2006). To align with their definition of safety performance, Griffin and Neal (2000) proposed that safety motivation should be separated into safety compliance motivation and safety participation motivation. Finally, they proposed safety motivation as a proximal antecedent of safety performance based on theories of workplace 
motivation and employee behavior (e.g., Kanfer \& Ackerman, 1989; Locke \& Latham, 2002).

The literature on safety performance has greatly expanded since Griffin and Neal (2000) put forth their framework for assessing safety performance. For example, a current PsycINFO search of "safety performance" returns 415 studies, and 367 of these studies were published in 2000 or later. In addition to Griffin and Neal's model, several other theoretical frameworks that assess safety performance have been created (e.g., Burke, Sarpy, Tesluk, \& Smith-Crowe, 2002; Hofmann et al., 1995). Some studies have taken a grounded theory approach and created their own measures based on the context of the sample (e.g., Snyder, Krauss, Chen, Finlinson, \& Huang, 2011). For example, Burke et al. (2002) collected supervisory and coworker reports of safety and used confirmatory factor analysis to demonstrate a four-factor model of safety performance: using personal protective equipment, engaging in work practices to reduce risk, communicating health and safety information, and exercising employee rights and responsibilities. However, the most robust empirical support thus far exists for Griffin and Neal's (2000) framework and thus this model is the theoretical framework for the present study.

The following sections review the empirical literature on safety performance and safety motivation by distinguishing the antecedents and outcomes of these constructs.

Distal antecedents. The antecedents of safety performance examined in the literature range from organizational to supervisory to individual factors. A number of meta-analyses have been conducted that include safety performance as an outcome (Beus 
et al., 2015; Burke et al., 2011; Christian et al., 2009; Clarke, 2006, 2012, 2013;

Nahrgang, Morgeson, \& Hofmann, 2011; Ng \& Feldman, 2008). The majority of the meta-analyses of safety performance have focused on aspects of the working environment related to safety, such as safety climate, as predictors of safety performance. For example, the results of Clarke's (2006) meta-analysis of 28 studies indicated that safety climate was an antecedent to both safety compliance and safety participation. In addition, the meta-analysis found that the relationship between participation and climate $(\rho=.50)$ was stronger than the relationship between compliance and climate $(\rho=.43)$. This was noteworthy as it is comparable to the finding of Neal and Griffin (2006), who found that safety climate had no relationship with safety compliance, but a lagged effect on safety participation. However, Christian et al. (2009) found that group-level safety climate was in fact related to both components of safety performance (i.e., compliance, participation). Some researchers have applied existing I/O psychology theories to synthesize the research on workplace safety. For example, Nahrgang et al. (2011) utilized the Job Demands-Job Resources model (Demerouti, Bakker, Nachreiner, \& Schaufeli, 2001) as a theoretical framework for examining safety in the workplace and classified safety climate as a job resource within the model. They found that safety climate explained the greatest percentage of variance in safety compliance $(34 \%)$ compared to the other resources in the study (i.e., knowledge, autonomy, social support, leadership). Finally, occupational stressors at work are another type of antecedent that can affect safety performance, depending on the type of stressor. Clarke (2012) found that while hindrance stressors (such as situational constraints, hassles, organizational politics) were 
related to lower safety compliance and safety participation, challenge stressors (stressors appraised by employees as opportunities to grow or expand personal resources) were not significantly associated with safety performance. The findings from these studies indicate that workplace factors, especially safety climate, are related to safety performance, although the magnitude and pattern of the relationships between safety climate and the performance components may vary.

Supervisory practices and leadership traits account for another large portion of the examined antecedents of safety performance (Zohar, 2003). The results of Christian et al.'s (2009) meta-analysis revealed that leadership had a moderate relationship with safety performance, specifically with both safety compliance $(\rho=.24)$ and safety participation $(\rho=.35)$. Christian et al. (2009) additionally found that management commitment and supervisor support had moderate positive relationships with safety compliance. In a recent meta-analysis, Clarke (2013) found that transformational leadership, transactional leadership, and active transactional leadership were all significant predictors of safety compliance and safety participation. Additionally, the findings indicated that transformational leadership might be more strongly related to participation behaviors, while active transactional leadership may be more important for compliance behaviors. Similarly, Inness, Turner, Barling, and Stride (2010) found that transformational leadership predicted safety participation, but not safety compliance, in a sample of 159 moonlighters, or employees who regularly worked two different jobs. In another article that examined aspects of leadership as predictors of safety performance, the authors focused on leader behaviors that related directly to safety, or leader support 
for safety (LSS; Kaufman et al., 2014). They found that LSS predicted safety performance across two independent studies of construction workers $(N=249$ and 230). In the same article Kaufman et al. (2014) additionally found that safety behavior was predicted by a moderating relationship between LSS and safety-specific leader justice such that safety behavior was highest under conditions of strong LSS and strong safetyspecific leader justice. The findings from these articles indicate that leadership and supervisory practices are often linked to greater safety performance.

Several individual factors are related to safety performance in addition to the aforementioned organizational and supervisory factors. For example, $\mathrm{Ng}$ and Feldman (2008) conducted a meta-analysis of 13 studies and found that age was positively related to safety compliance. Other studies have examined personality traits and their relationships with safety performance. A recently published meta-analysis by Beus et al. (2015) included Big 5 personality traits and some of their facet-level traits as predictors of unsafe behaviors. The authors found that extraversion was positively, though weakly $(\rho=.10)$, related to unsafe behavior. Agreeableness and conscientiousness were negatively associated with unsafe behavior, as was neuroticism to some degree $(\rho=.13)$. Furthermore, the authors used relative weights analysis to determine that agreeableness was the largest factor in explaining variance in unsafe behavior. In addition, certain facetlevel traits had strong relationships with unsafe behavior. Altruism, a facet of agreeableness, had a strong correlation with unsafe behavior $(\rho=-.35)$, as did sensationseeking, a facet of extraversion (sensation-seeking; $\rho=.27$ ). In a separate study of how personality traits affect safety at work, Hogan and Foster (2013) used archival validation 
data $(K=46)$ and found that a battery of facet-level personality scales predicted selfreported and supervisor-reported safety performance, lending support to the idea that employee personality is a contributing factor to safety performance. The relationship between other individual-level factors and safety performance has been examined with less frequency than the personality-safety link, but a few have. For example, Salanova, Lorente, and Martínez (2012) compared workers with higher self-efficacy to workers with lower self-efficacy in a sample of 223 construction workers in Spain. In a seemingly counterintuitive finding, the results indicated that the workers with lower self-efficacy had higher safety performance metrics than the workers with higher self-efficacy. However, although the benefits of self-efficacy have been widely demonstrated (Bandura, 1997) this is consistent with some scholars who have argued that there may be a dark side to self-efficacy at high levels (e.g., Vancouver, Thompson, Tischner, \& Putka, 2002), and this may be particularly relevant in the context of safety. In summary, in addition to the organizational and supervisory factors that have previously been linked to safety performance, individual factors such as personality and self-efficacy are also related to safety performance.

Proximal antecedents. Safety motivation has been most consistently linked to safety performance as a proximal antecedent. In Griffin and Neal's (2000) original examination of safety motivation and safety performance, they found that compliance motivation predicted safety compliance, and participation motivation predicted safety participation. Building on their original findings, Neal and Griffin (2006) found that a composite measure of overall safety motivation had a lagged effect on safety 
participation over a two-year span. Meta-analytic findings support the proposition that safety motivation is related to safety compliance. Christian et al. (2009) found that safety motivation had a correlation of $\rho=.44$ with safety compliance across four studies. Earlier findings from Neal et al. (2000) further support this research. In a sample of 525 hospital workers from 32 work groups, Neal et al. (2000) found that safety motivation predicted both safety compliance and safety participation. Additionally, a study of 1,566 industrial employees in India found that safety motivation predicted both safety performance components (Vinodkumar \& Bhasi, 2010). In addition to safety motivation, other authors have examined other types of individual motivation in relation to safety performance. Wallace and Chen (2006) used Higgins' (1997) promotion and prevention motivation framework in a study of 254 employees across 50 work groups and found prevention focus was associated with increased safety performance, while promotion focus predicted lower safety performance. Overall, findings from these studies generally support the proposition by Griffin and Neal (2000) that safety motivation is a proximal antecedent to safety performance, although the results for compliance and participation may be different depending on whether a general or specific measure of motivation is being used.

Of particular relevance to the current study, it should be noted that only rarely do studies related to safety performance include nonwork factors as antecedents to safety performance. In the first study to examine work-family conflict and safety simultaneously, Cullen and Hammer (2007) found that family-to-work conflict, in which family or nonwork duties interfere with work role responsibilities, was associated with decreased safety compliance and less willingness to participate in discretionary safety 
meetings. Additionally, Turner et al. (2014) conducted two studies using U.K. health workers $(N=645)$ and manufacturing and service employees $(N=128)$ and found that psychological distress mediated the effect of work-to-family conflict to workplace injuries. Smith and Dejoy (2012) additionally identified work-family interference as a risk factor for occupational injury using data from the General Social Survey. Recently, Dai et al. (2015) examined safety performance in a large sample of hospital caregivers $(N$ $=4,157)$ using hand hygiene compliance (i.e., washing hands when protocol demands this is done) as a proxy for safety performance. The results of the study indicated that compliance decreased over the length of a 12-hour shift and was exacerbated by increased frequency of patient interaction and time spent in a patient's room; but time off work was associated with increased hand hygiene compliance, such that taking an additional half day off between shifts increased the odds an employee would comply with hygiene standards when the opportunity arose. Based on the findings of these studies, the available evidence suggests that nonwork factors may influence safety performance that occurs at work.

Outcomes. One of the main reasons that safety performance has emerged in the literature as a well-studied construct is that it is assumed it can predict the occurrence of accidents and injuries stemming from incidents in the workplace (Zohar, 2000). Therefore, several of the studies that have been published on safety performance have included accidents and injuries as a main outcome. Clarke (2006) found that safety compliance and safety participation were related to accidents and injuries, although the meta-analytic relationships were small $(\rho=-.06$ for compliance; $\rho=-.09$ for 
participation). However, other studies have found the true relationship may be more robust. Christian et al. (2009) included a path model in which safety performance had a moderate, negative relationship with accidents and injuries $(\rho=-.31)$. Nahrgang et al.'s (2011) meta-analysis found a slightly different relationship between safety performance and safety outcomes. The results indicated that safety compliance did have a negative, direct relationship with adverse events, which were coded as near misses, safety events, and errors, but the direct relationship between compliance and a composite of accidents and injuries was not significant in the author's path model. Additionally, longitudinal research by Neal et al. (2000) found that safety performance predicted accidents and injuries at one year later and two years later.

Although the research on outcomes of safety performance is dominated by a focus on accidents and injuries, other outcomes have been included in other studies as well. For example, Fernández-Muñiz, Montes-Peón, and Vázquez-Ordás (2012) found that safety performance predicted employee satisfaction and job commitment. Overall, it appears that safety performance often directly predicts workplace accidents and injuries, although more research may be needed to draw more finite conclusions about how the type of performance affects this relationship.

Safety motivation as a mediator. When Griffin and Neal (2000) proposed their model of safety performance they posited that safety climate was a distal antecedent to safety performance, while knowledge and motivation were proximal antecedents to safety performance. The underlying assumption behind the model is that the relationship 
between broader organizational factors — such as safety climate — and safety outcomes are at least partially mediated by safety motivation (Neal et al., 2000). Therefore, a number of studies have examined safety motivation as a mediator between organizational factors and safety performance. Griffin and Neal's (2000) original findings supported this, such that safety motivation mediated the relationship between safety climate and safety performance in a sample of 326 employees from three manufacturing organizations. Neal et al. (2000) additionally found that safety climate predicted safety performance through the mediational effect of safety motivation. In another study, Vinodkumar and Bhasi (2010) found that safety motivation mediated the relationship between an organizational safety training and employee safety performance. In addition to studies that focused on organizational factors, other authors have tested models in which safety motivation mediates the relationship between individual factors and safety performance. For example, Probst and Brubaker (2001) found that job satisfaction predicted safety compliance, though safety motivation mediated this effect in their structural equation model from a longitudinal study of food processing plant employees $(N=72)$. In summary, the findings in the literature have begun to accumulate in support of safety motivation as a mediator between organizational or individual factors and safety performance in the workplace.

\section{Safety in Corrections}

Safety is a primary concern for security staff that work in correctional facilities. This is supported by national statistics that put corrections as the occupation with the 
third-highest rate of nonfatal workplace incidents and illnesses (BLS, 2012, 2013). Interestingly, Griffin and Neal's (2000) measures of safety motivation and safety performance have not yet been utilized in studies involving COs. There are several factors related to their occupational requirements that may expose COs to exceptional risk of injury. Unlike most occupations, COs are responsible for controlling and supervising inmates who may be a danger to other inmates and staff. The risk of being assaulted is both an immediate danger to COs and additionally can negatively impact their reported levels of stress and well-being (Armstrong \& Griffin, 2004). In addition, COs can be classified as shift workers in which they may be asked to work back-to-back eight-hour shifts, evening/night shifts, or rotating shifts. Shiftwork may impact their sleep and have further implications for their ability to focus and their well-being. COs may be on their feet for many hours at a time with few breaks and may be working alone among dozens of inmates, which presents additional risks to their safety (Konda et al., 2012). One consequence for COs may be that they experience high levels of conflict between their work role and their family role due to the demands of their job and the psychological effect it may have on them in transitioning between roles. One study found that work-family conflict was positively associated with symptoms of depression among COs, and that about $31 \%$ of the sample reported experiencing symptoms of serious psychological distress (Obidoa et al., 2011). Overall, these factors may negatively impact the ability of a CO to stay healthy and safe while performing their job duties inside correctional facilities.

\section{Summary}


Empirical research has indicated a number of antecedents to safety performance at the organizational, supervisory, and individual level. Several meta-analyses have found that a variety of these factors predict safety motivation and in turn both components of safety performance. Consistent with the model proposed by Griffin and Neal (2000), safety performance in turn is a predictor of workplace accidents and injuries. These findings indicate the importance of examining safety in the workplace, and examining the factors that predict safety in order to improve the safety of workplaces. Particularly relevant to the current study, the findings from Cullen and Hammer (2007), Dai et al. (2015), and Turner et al. (2014) lend support to the idea that nonwork factors have the potential to influence safety performance at work. Although few studies have examined nonwork-to-work relationships in the context of safety, the current study builds on these initial findings to observe how cognitions during nonwork recovery time affect safety performance. The following chapter (Chapter 3) discusses the theoretical rationale behind the hypothesized relationships in the current study. 


\section{Chapter 3: Cognitive Recovery and Resource Replenishment}

In the following chapter, I discuss the theoretical frameworks relevant to the present study. This begins with a discussion of how cognitive resources may be depleted at work, specifically through the lens of the ego-depletion model (Baumeister et al., 1998). The ego-depletion model provides an initial framework to describe the process in which employees use cognitive resources at work under the assumption that these resources are limited and will eventually be depleted. Next, the effort-recovery model (Meijman \& Mulder, 1998) is introduced to bolster the explanation of how work can be depleting for employees while detailing how cognitive willpower or self-control can be replenished when employees are removed from their work demands. The effort-recovery model and ego-depletion framework are particularly relevant for the hypotheses involving psychological detachment and negative work reflection (NWR). Finally, Broaden-and-Build theory (Fredrickson, 1998, 2001) is introduced as a theoretical framework that is utilized to describe how positive work reflection (PWR) invokes processes which theoretically contradicts the depleting effects described by the effortrecovery model and ego-depletion. Broaden-and-Build theory provides a rationale for how PWR during nonwork time can be a positive affective experience that is associated with employee motivation.

Ego-depletion. The first theoretical framework that will be utilized in the current study is the idea of ego-depletion proposed by Baumeister and colleagues (1998). Egodepletion describes a process in which acts of self-regulation draw on some limited 
resource (referred to by some as the 'ego') such that a sustained demand on this resource will result in a diminished ability to self-regulate over time (Hagger et al., 2010). This is likewise referred to as self-control or willpower (Hagger et al., 2010). The central proposition behind the idea of ego-depletion is similar to how a muscle in the body becomes fatigued over time of extended use, as does an individual's ability to engage in volitional behaviors that require self-regulation (Baumeister, Vohs, \& Tice, 2007). Since Baumeister et al. (1998) conducted four original experiments to introduce the idea of egodepletion, several others have followed and their findings have accumulated to suggest that ego-depletion can have detrimental effects on performance. Hagger et al. (2010) conducted a meta-analysis of these studies $(K=83)$ and found support for an effect of ego-depletion on numerous outcomes. The authors found that ego-depletion had a negative overall effect on performance for tasks requiring self-control. Specifically, they found significant relationships of ego-depletion on effort, perceived difficulty, negative affect, subjective fatigue, and blood glucose levels. The results of the meta-analysis generally support the proposition that ego-depletion is associated with a variety of outcomes.

Several researchers have extended the basic concepts of ego-depletion to the workplace (e.g., Hahn, Binnewies, Sonnentag, \& Mojza, 2011; Trougakos \& Hideg, 2009) by focusing on how work may deplete regulatory resources. The underlying assumption is that work requires effortful behaviors from employees who use their selfregulatory resources to complete work tasks. Over time (e.g., one work day, one week, or chronically) these resources become depleted and influence employee's performance and 
well-being. For example, Dai et al. (2015) found that over the course of a 12-hour shift compliance with hand hygiene protocols decreased among hospital nurses. Findings such as this suggest that working exhausts self-regulatory resources and affects performance tasks that may be effortful but are be vital to workplace safety.

The theoretical rationale behind ego-depletion has also been described from the perspective of self-control. From this perspective, refraining from behaviors requires an individual to exert self-control over their impulses to behave in another manner (Muraven \& Baumeister, 2000). Self-control, Muraven and Baumeister theorized, is the finite resource that individuals use when engaging in undesirable behaviors. In particular, the authors noted that tasks that require an individual to be vigilant may require a great deal of self-control and would be particularly taxing on the individual's self-regulatory resources. When an individual is vigilant they must ignore distractions, mentally block thoughts unrelated to the task at hand, and regulate emotions that could interrupt their focus (Muraven \& Baumeister, 2000). Applying this logic to the workplace it can be argued that employees who are required to focus on a high priority task that requires vigilance and self-control may face expending their self-regulatory resources and experiencing consequences for performance when these resources become depleted.

The common idea that links ego-depletion, self-regulatory resources, self-control, and other terms used to describe resource depletion from a theoretical standpoint is that different effortful tasks draw from the same limited resource (Trougakos \& Hideg, 2009). This limited, cognitive resource is thought to have a direct influence on everyday 
behaviors (Baumeister et al., 2007). In other words, the evidence suggests that cognitively exerting willpower or self-control over physical behaviors is taxing on an individual so much so that the outcomes manifest themselves through decrements in performance, interpersonal relationships, and well-being (Baumeister et al., 1998; Hagger et al., 2010). In the context of the workplace, employees may inherently be using selfregulatory resources during working hours based on the nature of their work. If their work requires them to engage in tasks that may be particularly draining on self-control, such as those that require vigilance or periods of extended focus, they may be at a greater risk of the effects of ego-depletion. Therefore, combined with the evidence in support of ego-depletion, it is likely that this phenomenon is relevant to employees in the workplace and may be an explanation for decreases in performance or well-being, such as burnout (Baumeister et al., 1998).

While the discussion of ego-depletion is focused on how resources are lost, there has been progress made on how the limited capacity an individual has for self-regulation can be restored. For example, in two experiments Tyler and Burns (2008) found that allowing participants to take a break or relax between tasks alleviated the ego-depletion effect on subsequent tasks. Specifically, participants who received a break between tasks requiring self-regulation performed equally as well as a control group who completed tasks that did not require self-control. These results support an earlier proposition by Muraven and Baumeister (2000) who suggested that ego-depletion effects could be ameliorated by allowing for periods of rest between episodes of self-control. 
Effort-recovery model. The second relevant theoretical framework for this study is the effort-recovery model (Meijman \& Mulder, 1998). The effort-recovery model was developed to describe the simultaneous physical and psychological processes that occur when employees cycle through their workday. This model is useful for the current study as it explains both how work is cognitively effortful for employees and how they can recover cognitive strength after exerting themselves at work. The effort-recovery model explains that when employees expend effort at work their internal psychophysiological systems generate load reactions (i.e., eye strain, subjective fatigue) in reaction to the effort expenditure. At the same time employees lose resources (i.e., energy, ability to focus) by completing their work tasks. Oppositely, the recovery aspect of the model proposes that the only way for these load reactions to subside is by removing the employee from work-related tasks, in essence halting the production of load reactions and allowing employees to recover to their pre-work state (Meijman \& Mulder, 1998). An example of this model at work is illustrated by the case of an employee whose work requires them to look at a computer for the majority of their day. Staring at a computer screen continuously will likely produce a load reaction — eye strain — which can only be alleviated when the employee no longer is required to look at a computer screen. This process unfolds for psychological phenomena as well. The same employee may be expending self-regulatory resources in order to focus on their work and stay at their work station and this may produce a weakened state of self-control by the end of the work day. In order to replenish their self-regulatory resources the employee would need to participate in an enjoyable behavior that would not draw upon their self-control. In 
essence, the effort-recovery model can be used to describe a process in which employees expend self-regulatory resources at work that are only replenished by non-working experiences in which self-control can be restored.

The effort-recovery model has been used in the majority of studies of cognitive recovery from work stress to explain how cognitions during nonwork time can replenish employee resources and improve work outcomes. For example, Sonnentag, Binnewies, and Mojza (2008) found that in a sample of public administration employees $(N=166)$ surveyed twice per day over the course of one working week that psychological detachment experienced in the evening predicted lower levels of negative affect and lower fatigue in the morning. The findings are consistent with the effort-recovery model such that to the extent that employees refrained from work-related thoughts in the evenings they felt subjectively more energized and refreshed in the mornings. While these findings and others from the literature are consistent with the model, the processes through which recovery occurs are often inferred and not directly assessed. However, ten Brummelhuis and Bakker (2012) aimed to resolve this by directly assessing the entire process proposed by the effort-recovery model. In further support of the model, they found that low-effort activities, social activities, and physical activities after work increased next-morning vigor, and that this relationship was mediated by psychological detachment. Importantly, these findings support the idea that the process of recovery occurs at least partially through a cognitive mechanism (i.e., psychological detachment) that theoretically restores self-regulatory resources, which may affect subjective feelings of well-being or engagement. Findings such as these generally support the tenets of ego- 
depletion and the effort-recovery model in that continually calling upon self-regulatory resources will deplete the individual's limited ability for self-control (Baumeister et al., 1998; Meijman \& Mulder, 1998).

Broaden-and-Build theory. A final theoretical framework that is essential to the current study is Broaden-and-Build theory (Fredrickson, 2001). Broaden-and-Build theory suggests that positive emotions have the ability to temporarily broaden an individual's thought perspective in the moment, and furthermore than these experiences build upon one another and expand a person's enduring personal resources. The theory proposes that positive emotional experiences motivate individuals to engage in their environment and expose themselves to activities that enhance their well-being, performance, self-efficacy, and self-identity. Studies from the cognitive recovery from work literature have used Broaden-and-Build theory to explain how positive experiences during nonwork time can have a positive impact on work outcomes. Binnewies et al. (2009b) used a longitudinal design with two surveys separated by six months and found that among a group of employees who worked with individuals with special needs $(N=$ 358) that PWR at Time 1 was related to proactive work performance (i.e., personal initiative), creativity, and organizational citizenship behavior (OCB) at Time 2 (6 months later). Specifically, the authors argued that reflecting upon positive work events during nonwork time should be seen through the lens of capitalizing on positive events (Gable et al., 2004) such that recalling or thinking about these positive occurrences may be beneficial to an individual. It appears that recalling positive events allows an employee to relive moments in which they were positively engaged in their environment, and this act 
of recall is part of the building process proposed by Fredrickson (2001) that may lead to self-improvement through improving self-efficacy (Fritz \& Sonnentag, 2006).

Broaden-and Build theory hails from the positive psychology movement, which aims to understand the conditions under which individuals flourish and optimize their well-being. Specifically, the theory suggest that positive affect may be an indication that an individual is performing at the peak of their abilities and is reaping some benefit to their overall well-being. In the context of the workplace, experiencing more positive emotions may be associated with greater motivation and performance. Therefore, Broaden-and-Build theory is a necessary addition to the current study because it offers a perspective that makes predictions that oppose those described by the ego depletion and the effort-recovery model in regards to cognitive recovery from work stress. Specifically, it is essential because the current study includes PWR as a predictor of safety performance. PWR can be viewed through two lenses. First, PWR involves thinking about work, which may mimic thoughts that employees have during working hours. From the perspective of ego-depletion these thoughts may be effortful and may continue to drain cognitive resources during nonwork time. Similarly, from the perspective of the effort-recovery model, simply thinking about work may halt the recovery process and load reactions may persist if these work-related thoughts persist. Alternatively, the propositions offered by Broaden-and-Build theory can be applied to suggest that because these work-related thoughts have a positive valence they may be less effortful and may afford the employee an opportunity to further benefit from these positive events by the associated positive affective states they experience through recalling them. In summary, 
Broaden-and-Build theory offers a more complex and complete assessment of the process of cognitive recovery.

\section{Summary}

The present study examines how cognitive recovery experiences during nonwork time are related to safety performance at work by utilizing the theoretical frameworks proposed by ego-depletion, the effort-recovery model, and Broaden-and-Build theory. These three frameworks are the basis through which I develop my hypotheses. Each offers a unique, distinguishable perspective on the process of cognitive recovery from work. Ego depletion defines self-regulatory resources and describes how effortful activities can drain the source of these limited resources (Baumeister et al., 1998). The effort-recovery model outlines the recovery from work process in which load reactions created by effortful behavior at work are reduced during nonwork hours when work demands cease to exist (Meijman \& Mulder, 1998). Finally, Broaden-and-Build theory is used to describe how a nonwork cognitive experience involving thinking about work may actually be beneficial if an employee uses this time to recall positive work events (Fredrickson, 1998). In the following chapter (Chapter 4) I describe three cognitive recovery experiences that occur when employees recover from work stress. 


\section{Chapter 4: Cognitive Recovery from Work}

An area of research that holds great promise for identifying nonwork factors that may be related to safety performance is the study of nonwork recovery experiences, or the psychological experiences employees have while away from the workplace that help them recuperate from work stress (Sonnentag \& Fritz, 2007, 2014). Evidence has been mounting over the last decade that employees can use their time away from work to psychologically recuperate from stress they experience at work such that they can improve their well-being and subsequent experiences at work (Fritz, Ellis, Demsky, Lin, \& Guros, 2013; Sonnentag \& Fritz, 2014). Specifically, findings from a growing body of studies within this literature suggests that whether an employee thinks about work-and the valence of their thoughts if they do think about work - is an important aspect of the recovery process.

Recovery from work stress has been defined as the process through which employees recuperate from the stressors and subsequent load reactions that occur as a result of effortful behavior at work (Meijman \& Mulder, 1998; Sonnentag \& Fritz, 2007). The effort-recovery model (Meijman \& Mulder, 1998) is the framework most often applied in studies of recovery from work stress to explain how the recovery process. Specifically, the assumption proposed by the model is that employees exert effort at work to complete tasks, which creations load reactions (i.e., tired muscles, subjective feelings of fatigue) within the employee. In order to allow these load reactions to diminish during nonwork time in order to avoid chronic strain reactions the employee must cease their 
exposure to the demands of their workplace (Geurts \& Sonnentag, 2006). In other words, the model has been used to explain that recovery from work occurs when an employee is no longer participating in work behaviors and avoiding work-related thoughts or cognitions. The present study focuses on this cognitive aspect of the recovery from work stress process; specifically, the aim of the study is to focus on how employee cognitions contribute to, or interfere with, recovery from work stress. Specifically, I will examine three different cognitive experiences that employees may have during their nonwork time. These experiences are discussed in the following sections.

The most frequently studied type of cognitive recovery is psychological detachment. Psychological detachment has been defined as an “individual's sense of being away from the work situation" (Etzion et al., 1998, p. 579). This definition captures the principle that both job-related activities and job-related thoughts are absent when an employee is psychologically detached (Sonnentag, 2012). The assumption implied by the concept of psychological detachment is that employees cannot constantly work and think about work; rather, they need an opportunity to refrain from work-related thoughts to allow load reactions to diminish and allow their psychophysiological systems to return to the state they were in before working (Meijman \& Mulder, 1998). Psychological detachment is thought to be beneficial for employees because of the cognitive respite it provides them from their job demands. Although some researchers have examined whether psychological detachment and related phenomena, from the literature on coping with stress, for instance, may not be beneficial in all situations (i.e., Cheng \& McCarthy, 2013), the empirical evidence for the benefits of psychological detachment to recover 
from work stress is plentiful (e.g., Binnewies, Sonnentag, \& Mojza, 2010; Fritz et al., 2010; Park \& Fritz, 2015; Sonnentag \& Bayer, 2005). The research supports the proposition that detachment during nonwork time can positively contribute to mood, motivation, well-being, performance, and even crossover to well-being of employee's spouses.

The other types of cognitive recovery employees can experience involve thinking about or reflecting upon events or experiences at work. However, researchers have argued that simply because an employee is thinking about work does not necessarily mean this will be harmful for recovery. Rather, it has been suggested that cognitions should be differentiated base on their valence, or whether the thoughts are positive or negative (Segerstrom, Stanton, Alden, \& Shortride, 2003). Researchers in the recovery from work stress literature have applied this rationale to employee cognitions about work and have identified two types of reflecting thinking during nonwork time. The first is negative work reflection (NWR), which refers to considering what one does not like about their work (Fritz \& Sonnentag, 2006). An employee who engages in NWR may recall failures or negative events at work or may consider work experiences in a negative light (Binnewies et al. 2009a). The second is positive work reflection (PWR), which involves thinking of the favorable aspects of one's work (Fritz \& Sonnentag, 2005). An employee who engages in PWR may reflect back on their workday and think about the positive and meaningful moments of their day, and recall these events from a positive perspective (Sonnentag \& Grant, 2012). 
While findings on psychological detachment indicate that mentally disengaging from work during nonworking hours is beneficial for employees and not detaching may contribute to chronic stress reactions (Sonnentag, 2012), less is known about the link between NWR, PWR, and employee health, well-being, and performance. In a review of the literature, Sonnentag (2012) recommended that more research should be conducted to elucidate whether not detaching (i.e., reflecting on work, positively or negatively) is detrimental for all employees in all situations. In other words, it appears that while psychological detachment is beneficial, not detaching from work may not necessarily be detrimental, and the outcome may depend on the valance of the work-related thoughts.

Several existing theoretical frameworks and empirical studies offer competing rationale for if and how NWR and PWR may influence employee performance. For instance, PWR may be associated with positive affective states from reflecting on positive events at work during nonworking hours, which could help strengthen personal resources such as self-efficacy (Binnewies et al., 2009b). Oppositely, the effort-recovery model suggests that any type of work-related experience may hinder an employee's ability to cognitively recover from work stress, which may leave them fatigued and unable to perform at the necessary level for their job. Similarly, Mood as Information theory (Schwarz \& Clore, 2003) could be used to explain that NWR as a negative affective experience provides employees with information that they are not happy with aspects of their job. This may motivate them to pursue goals or redirect energy at work to address this discrepancy between their ideal and actual work experiences (Kanfer \& Ackerman, 1989). Additionally, NWR may halt the cognitive recovery process and the 
negative thoughts during nonwork time may spillover to the workplace and distract an employee during subsequent work shifts (Edwards \& Rothbard, 2000; Meijman \& Mulder, 1998). In summary, it appears there are several competing frameworks that can be used to explain how the valences of employee cognitions affect work outcomes.

Though there are a far greater number of studies on psychological detachment or lack of detachment (i.e., rumination, repetitive thought) during nonwork time, there are a small number of empirical studies that examine PWR and NWR. The following sections review the literature on the antecedents and outcomes of psychological detachment, PWR, and NWR during nonworking hours.

\section{Empirical Findings: Cognitive Recovery from Work}

Antecedents. Several studies have examined workplace factors that predict psychological detachment outside of the workplace. For example, Sonnentag and Bayer (2005) had 87 employees fill out surveys twice per day for a span of three consecutive days to assess how their workload affected their ability to detach in the evenings after work. The authors found that both day-specific workload and chronic workload (i.e., workload throughout the study period) predicted detachment in a negative direction, such that higher workload was associated with lower levels of evening detachment. Similarly, in another study Sonnentag, Kuttler, and Fritz (2010) found that workload and emotional dissonance predicted lower detachment in a sample of protestant pastors $(N=136)$. Sonnentag et al. (2010) additionally found that spatial boundaries_-working in one location and experiencing off-work time at another location-were associated with 
psychological detachment, such that to the extent to which employees had spatial boundaries between work and home they were able to mentally disengage from work. Overall, the findings suggest that several work-related factors can either facilitate or hinder psychological detachment during nonworking hours. Recently, Sonnentag, Arbeus, Mahn, and Fritz (2014) found that exhaustion predicted psychological detachment one month later, but only when high time pressure at work was present. This study is a rich addition to understanding how both work factors and individual indicators of fatigue may interact to predict whether employees enjoy psychological detachment experiences during nonwork time, yet more studies are needed to create a clearer picture of the antecedents of detachment during nonwork time.

To date, few studies have examined the antecedents to PWR and NWR. This is not a major revelation, as research is still scare on the outcomes of work reflection as well, which likely contributes to there being fewer arguments available for including PWR and NWR as outcome variables in a peer-reviewed publication. In regards to NWR, Volmer, Binnewies, Sonnentag, and Niessen (2012) utilized a sample of civil service agents $(N=98)$ in which surveys were distributed twice daily over 5 consecutive work days and found that customer conflicts at work were significantly related to increased NWR during nonwork time. In regards to antecedents of PWR, Sonnentag and Grant (2012) used a daily diary study design among 68 fire and rescue workers to examine the effects of perceived prosocial impact, PWR, and positive activation. Their findings indicated that PWR at the end of the workday was predicted by perceived prosocial impact, and perceived prosocial impact at work was associated with positive activation 
before bed partially through the effect of PWR. Daniel and Sonnentag (2014) found that work engagement was a positive predictor of PWR, suggesting that employees who are highly engaged at work may reflect positively about work during non-working hours. So far, the results of these studies suggest that positive events or feelings at work may contribute to more PWR during nonworking hours, while negative events (e.g., conflicts with customers) may spur more NWR at the end of the workday. However, with so few studies that assess antecedents to PWR and NWR, more research is needed in this area.

Outcomes. Many studies of cognitive recovery from work have focused on the outcomes of psychological detachment from work during nonworking hours. Furthermore, a large number of these studies were designed to shed light on psychological detachment's relationship with health and well-being outcomes. For example, Sonnentag and Bayer (2005) found that psychological detachment after work predicted higher self-reports of well-being at bedtime, and furthermore that the effect of detachment on self-reported fatigue was present on days where employees faced high time pressure demands at work. These findings suggest that detachment is associated with employee well-being, especially when work demands are high. The association between detachment and well-being appears to be fairly consistent across well-being indicators. Illustrative of this is the study by Sonnentag and Fritz (2007) in which they found that psychological detachment was negatively associated with health complaints, emotional exhaustion, disengagement, depressive symptoms, need for recovery, and sleep problems, and positively associated with life satisfaction. For the most part, studies have found that detachment is an antecedent to employee well-being (for an exception, see 
Sonnentag et al., 2014). An example is the study by Sonnentag et al. (2008) that utilized a weeklong diary study design with two daily surveys among 166 public administration employees. The authors found that psychological detachment in the evening was significantly related to negative activation and fatigue in the morning. These results are consistent with the propositions of the effort-recovery model, such that detachment allows an employee's load reactions to diminish in the evening, and this leaves them feeling energized and motivated for work in the mornings. In addition to predicting wellbeing, psychological detachment is additionally related to other employee outcomes at home. Recently, Demsky, Ellis, and Fritz (2014) found that psychological detachment had a negative relationship with work-family conflict, and that detachment mediated the negative effect of workplace aggression on work-family conflict among a sample of 107 administrative university employees. Psychological detachment has also been associated with some health behaviors. Pereira and Elfering (2014) used actigraphy devices to assess sleep among 60 Swiss employees. Their results indicated that social stressors at work affected sleep onset latency and sleep fragmentation, but detachment mediated this relationship and had positive relationships with both sleep indicators (i.e., faster to fall asleep, less fragmented sleep).

While there are fewer studies in the literature that have assessed the link between psychological detachment and performance, there is evidence to suggest this link does exist. For example, Binnewies et al. (2010) used a within-person design among 133 employees and had participants fill out a survey at the beginning of the week for four consecutive weeks to examine the link between psychological detachment and several 
performance indicators. Their findings indicated that psychological detachment indirectly predicted higher task performance, personal initiative, organizational citizenship behaviors (OCB's), and lower perceived effort at work through its relationship with feelings of recovery at the beginning of the week. In other words, the findings suggest that employees use weekends to psychologically detach and their subjective feeling of being recovered at the beginning of the week predicts their performance levels for the week. Other studies have corroborated this pathway of detachment to feeling recovered to performance. Volman, Bakker, and Zanthopoulou (2013) found that detachment in the evening predicted daily performance through the effect of feeling recovered in the morning in a sample of 65 Dutch employees. It may additionally be the case that psychological detachment has a nonlinear effect on performance. For example, Fritz et al. (2010) found that psychological detachment had a curvilinear association with task performance and proactive behavior, such that detachment at low or high levels was less beneficial for performance than detachment at medium levels. The authors argued that too little detachment may not be enough to restore an individual's resources needed to perform at work, and too much may make it difficult to transition from home back to a working mindset that an employee needs to have to meet performance expectations.

While there have been a few published studies that examined NWR as a predictor, the findings so far paint an unclear picture of the relationship between NWR and performance. Fritz and Sonnentag (2006) examined NWR during a vacation period and found that it was related to more health complaints and higher burnout levels after vacation. However, although NWR was significantly related to higher perceived effort at 
work two weeks after vacation, it was unrelated to several performance indicators. In another study, Binnewies et al. (2009a) found that NWR predicted performance under only circumstances; for example, NWR predicted task performance when self-efficacy was included in the regression equation, but not when it was excluded. As with the research on the antecedents of NWR, more studies are needed to more clearly elucidate the outcomes related to NWR.

Several studies have indicated that PWR may be more strongly related to wellbeing and possibly performance, especially when the performance is volitional or extrarole in nature. For instance, Sonnentag and Grant's (2012) study found that PWR at the end of the workday predicted activated positive affect before bed. Daniel and Sonnentag (2014) found that PWR mediated the relationship between work engagement and workto-life enrichment. In Binnewies et al.'s (2009b) aforementioned study the authors found that PWR predicted personal initiative, creativity, and OCB's in a longitudinal study of 358 employees working with adults with special needs. However, as with NWR, PWR did not predict core task performance in the 6 month gap between surveys. In a study in which the results mirrored the pattern found by Binnewies et al. (2009b), Fritz and Sonnentag (2005) found that PWR over the weekend was associated with decreased burnout after the weekend. Furthermore, PWR was not significantly associated with task performance after the weekend, but it was positively associated with pursuit of learning at work in a sample of 87 emergency workers. Although these studies indicate at least initially the value of PWR during nonwork time for some outcomes, the results of another study by Fritz and Sonnentag (2006) presented findings that reveal this relationship may 
not be so clear. The authors conducted a study with 221 university employees before, during, and after vacation and found that PWR during vacation was unrelated to health complaints, burnout, and performance after vacation. In other words, these results support the idea that at least during vacation PWR may neither be helpful or harmful to employee outcomes when they return to work.

\section{Summary}

The research that has been conducted on cognitive recovery experiences has identified several antecedents and outcomes both at work and at home. Overall, there are a few conclusions that can be made about the literature on psychological detachment, NWR, and PWR. First, psychological detachment appears in far more studies than NWR and PWR and appears to be consistently predicted by workplace factors and predictive of employee outcomes. Second, although all three cognitive recovery experiences have been linked in at least one study to well-being indicator, so far the pattern of results are less clear when performance is the outcome. Particularly relevant to the current study are the findings where cognitive recovery experiences are predictors of employee outcomes. Psychological detachment has been linked to performance through the mediating effect of subjective feelings of recovery and one study found a curvilinear direct relationship between detachment and performance (Fritz et al., 2010). When NWR and PWR have been included as predictors of performance, the results indicate that PWR may be a more salient cognitive recovery experience than NWR such that the relationships between PWR and performance are stronger and more consistent than between NWR and 
performance. Finally, there is some evidence to suggest that cognitive recovery experiences are stronger predictors of behaviors at work that have stronger volitional components, such as extra-role behaviors or proactive work behaviors. Based on the empirical findings in the literature up to this point and the theoretical rationale described in Chapter 3 there is reason to predict that safety at work may be associated with employee nonwork cognitive recovery from work stress. However, it may additionally be that this relationship may be dependent on other aspects of the work environment, such as perceptions of safety climate. Next, in Chapter 5 the idea of perceptions of safety climate will be introduced and the literature relevant to the current study will be reviewed. 


\section{Chapter 5: Perceptions of Safety Climate}

Classic models of safety at work have differed in many aspects, but one aspect of safety that researchers appear to have agreed upon is the multifaceted nature workplace safety. In other words, it is difficult to argue that one factor (e.g., work conditions, equipment design, fatigue) is fully culpable for failed safety performance at work. Rather, safety appears to be determined by a combination of factors, much as general work performance is (Campbell et al., 1993). Based on this rationale and past research, I will introduce and review the literature on a specific contextual workplace factorperceptions of safety climate - that is related to safety and safety performance in a variety of ways.

Employee perceptions of support for safety in their workplace have often been studied as perceptions of safety climate. Safety climate has been defined as the shared perceptions of employees in an organization with regard to policies, procedures, and practices related to workplace safety (Schneider, 1990; Zohar, 1980, 2000). This line of research branched from the literature on organizational climate that focuses on employee perceptions of certain features or characteristics of their environment (Schneider, 1990; Zohar, 2010). The argument for studying safety climate in the workplace is that employees will prioritize safety behaviors based on their perceptions of how important safety is to their supervisor, coworkers, and organization (Zohar, 2003). In other words, employees take cues from their surroundings that affect, in part, how closely they follow safety procedures and how they prioritize safety needs over other work requirements 
(e.g., productivity). In order to accurately capture the phenomenon of shared perceptions among employees, individual responses across work groups are often aggregated to the group- or organization-level based on whether significant variance exists in the perceptions between work groups and agreement within groups (e.g., Bliese \& Jex, 2002; Zohar \& Luria, 2005). However, this is not always feasible, and when the focus of the research is not at the group or organization level but rather on individual perceptions, the label for these perceptions vary (e.g., referred to as psychological safety climate; Beus, Payne, Bergman, \& Arthur Jr., 2010; referred to as leader support for safety; Kaufman et al., 2014). Therefore, in the present study I will refer to these perceptions as perceptions of safety climate in order to include research on both individual perceptions and aggregated perceptions of safety climate at work. This is meant to include any research in the current study that specifically relates to perceptions of support for safety from the individual employee's perspective.

In the following sections the literature on perceptions of support for safety is reviewed with a discussion of the antecedents and outcomes of these perceptions, followed by the empirical findings of studies in which perceptions of support for safety was found to be a moderator between two variables.

\section{Nomological Net of Perceptions of Safety Climate}

Antecedents. Zohar (1980) first introduced the idea of safety climate as an important organizational phenomenon that should predict accidents and injuries in the workplace. As a likely result of this original conceptualization most studies have 
examined the outcomes of safety climate perceptions. However, a few studies, including meta-analyses, have found some predictors of perceptions of support for safety. One predictor that has been examined is the overall organizational climate. For example, Neal et al. (2000) found that organizational climate was positively associated with safety climate perceptions in a study of 525 hospital workers in 32 work groups. Another factor that Zohar (2000) theorized should predict safety perceptions within a work group are the perceptions of organizational safety climate. Zohar and Luria (2005) tested this proposition and indeed found that organizational safety climate perceptions were positively associated with group-level safety climate perceptions. Their findings suggest that safety climate is a top-down phenomenon in which broader, more distal organizational policies around safety trickle down to employee perceptions of safety climate (Zohar, 2000).

It may be the case that these perceptions are additionally influenced by the behaviors of leaders. For example, the findings a recent meta-analysis indicated that leadership perceptions may be associated with perceptions of support for safety. Clarke (2013) examined 32 studies on leadership and safety climate and found that both transformational leadership and active transactional leadership had significant, positive correlations with safety climate $(\rho=.45$ for transformational leadership; $\rho=.52$ for active transactional leadership. However, the findings of another meta-analysis indicate that safety climate may not be influenced by solely organizational or leadership variables. Beus et al. found (2010) that injuries were the strongest predictor of organizational safety climate perceptions and were additionally associated with psychological safety climate 
perceptions (i.e., individual perceptions). These results indicate that the number of injuries occurring in the workplace may signal to an employee how important safety is to their organization. If more injuries occur the employees may evaluate their workplace as unsafe because of a low prioritization of safety by management, as one possibility. Taken together, these findings suggest that perceptions of safety climate might be influenced by some top-down processes from management at the organizational and supervisory levels, but other factors such as the frequency of workplace accidents may additionally be associated with these perceptions.

Outcomes. Zohar (2000) posited the idea of safety climate in the hope that researchers would have a framework for examining organizational safety factors. In response, a number of studies have been published that suggest safety climate perceptions are related to several work-related safety outcomes. For example, Zohar (2000) used a two-factor model of safety climate consisting of perceptions of supervisory actions and supervisory expectations and found that these perceptions both predicted minor accidents that required medical attention. Other studies have produced results that support the proposition that perceptions of safety climate predict workplace accidents. For example, Christian et al. (2009) examined a number of predictors of accidents and injuries in their meta-analysis and found that group-level safety climate was the strongest indicator of accidents and injuries in the workplace. However, not all studies of perceptions of safety climate have found such a clear link between safety climate and accidents and injuries. For example, the findings from Beus et al.'s (2010) meta-analysis indicated that safety climate predicted accidents, although this association was not as strong as the reverse 
relationship (i.e., accidents predicting safety climate). Additionally, a previous metaanalysis by Clarke (2006) found that safety climate predicted safety performance, but safety climate was not significantly associated with accidents and injuries. Furthermore, the results indicated that the relationship between safety climate and incidents were moderated by study design, such that climate perceptions were more strongly associated with accidents and injuries in prospective designs compared to cross-sectional designs. These findings from Clarke (2006) may suggest that the relationship between perceptions of support for safety and incidents may more frequently be observed when there is temporal separation between assessment occasions. Overall, the research on the outcomes of safety climate have revealed that perceptions of support for safety is related to a number of safety-related outcomes, though the mixed results beg the question of what the true nature of these relationships look like. Based on this state of the literature, researchers have additionally posited that safety climate perceptions may be a moderating factor between predictors and safety performance. Next, a discussion of these studies follows.

\section{Perceptions of perceptions of safety climate as a moderator. Employees'}

perceptions of safety climate have been conceptualized as being a contextual factor that directs employee attention and focus towards behaviors related to safety. For example, Ford and Tetrick (2011) reasoned that supervisors can signal what direction employees should focus their energy and attention towards. They tested this hypothesis in a sample of hospital employees from 21 work groups $(N=171)$ and found that perceptions of supervisor safety practices moderated the effect of feelings of psychological 
empowerment on use of personal protective equipment (PPE). When perceptions of supervisor safety practices were low there was no relationship between empowerment and PPE use. However, when perceptions were high there was a positive relationship between empowerment and PPE use, suggesting that when employees viewed safety as a priority of their supervisor they directed their feelings of empowerment towards wearing their proper safety gear. This study may indicate that the presence of supervisory support for safety can create a positive relationship between employee characteristics and safety behavior. It has additionally been demonstrated in the literature that safety climate perceptions can enhance positive relationships between predictors and outcomes. For example, Jiang, Yu, Li, and $\mathrm{Li}$ (2010) found a positive relationship between perceived colleague's safety knowledge/behavior and safety performance. Furthermore, safety climate moderated this relationship such that the positive effect on safety compliance was enhanced under high levels of safety climate perceptions. Other studies have produced a similar pattern of results. Using two independent samples of construction workers Kaufman et al. (2014) found that leader support for safety moderated the effect of general leader justice on safety performance in a sample of construction workers in their Study 1 $(N=249)$. The results indicated that under low levels of general leader justice that leader support for safety had no effect on performance. However, when general leader justice was high, the presence of high leader support for safety were associated with increased safety performance, while low levels for leader support for safety were associated with a decrease in safety performance. The findings from their Study 2 of a separate sample of construction workers $(N=230)$ found a similar pattern of results when safety specific 
leader justice was the predictor. Overall, the findings in the literature so far suggest a strong likelihood that perceptions of safety climate can moderate relationships between organizational or individual factors and safety performance.

\section{Summary}

The literature of perceptions of safety climate in the workplace has examined these perceptions as an antecedent, outcome, and moderator. Studies in this area of research have often examined these perceptions as either individual or aggregated safety climate measures, but other similar constructs have been used as well. Leadership and organizational-level factors appear to be some of the antecedents to perceptions of support for safety, while the outcomes include safety behavior and accidents and injuries in some cases. Furthermore, these perceptions have been positioned as a moderator in some theoretical models, and several empirical studies have supported this proposition for a number of variables. The current study adds to these findings by examining perceptions of safety climate as a moderator that directs an organization's employees to focus on safety. In the following section (Chapter 6) the development of the hypotheses is presented and the argument will be made that these perceptions can moderate the relationship between cognitive recovery and workplace safety. 


\section{Chapter 6: Hypotheses Development}

This chapter presents the specific arguments for the hypothesized relationships between the variables in the current study. The arguments for the hypotheses were formed based on the empirical findings and theoretical rationale presented in the previous chapters. The overall rationale for these arguments was first briefly presented in the introduction (Chapter 1). Chapter 2 presented a review of the literature on safety performance and Chapter 3 introduced and reviewed the major theoretical frameworks relevant to the current study. The concept of cognitive recovery from work stress was introduced and the literature reviewed (Chapter 4), and the same was done for perceptions of safety climate in Chapter 5.

\section{Relationship between Safety Motivation and Safety Performance}

According to Griffin and Neal (2000) the motivation to engage in safe behavior precedes safety performance behaviors. Their rationale was based on established models of work performance that posit motivation as a key antecedent to individual performance. This proposition was supported in the context of workplace safety such that safety compliance motivation predicted safety compliance, and safety participation motivation predicted safety participation. Similarly, the findings from several other studies have supported the proposition that safety motivation is a proximal antecedent to safety performance (e.g., Christian et al., 2009; Neal \& Griffin, 2006). Therefore, the link between safety motivation and safety performance will not be the focus of the present study. Instead, the hypothesis of this study is that nonwork cognitive recovery 
experiences will predict safety motivation, which in turn will predict safety performance. Given the previously established link between safety motivation and safety performance, it is argued that safety motivation will fully mediate the relationship between nonwork cognitive recovery experiences and safety performance. The following sections describe the specific hypotheses in detail.

\section{Psychological Detachment and Safety}

Based on research that has established a link between nonwork experiences and work outcomes (Edwards \& Rothbard, 2000) it is assumed that cognitive nonwork recovery experiences are related to workplace safety. Specifically, I propose that psychological detachment during nonwork time will be related to safety motivation at work. Refraining from work-related thoughts during off-hours is a cognitive recovery experience in which employees can reverse the cognitive strain they experience during work (e.g., Fritz et al., 2010; Pereira \& Elfering, 2014; Sonnentag, 2012). The positive associations between psychological detachment and employee outcomes have most often been explained through the lens of the effort-recovery model (Binnewies et al., 2010; Meijman \& Mulder, 1998; Sonnentag et al., 2008). Specifically, the effort-recovery model proposes that task demands and conditions of the workplace elicit responses from employees in order to meet demands and complete tasks. In the course of meeting these demands the employee's psychobiological systems develop reactions to addressing the workload on the employee (i.e., load reactions, such as eye strain or reduced ability to focus). The model further proposes that these load reactions will be reduced when the 
employee stops working or stops having work-related experiences, such as thinking of work. Therefore, when employees refrain from work-related thoughts during nonworking hours they allow their psychobiological systems to return to their baseline levels (i.e., where they start before work begins). Not thinking about work helps to decrease an employee's general level of arousal and contributes to their ability to unwind from work stress (Sonnentag, 2012). Psychological detachment allows employees load reactions to diminish during nonwork time.

In addition, psychological detachment may help employees recover the cognitive energy they expended through work tasks requiring self-regulatory effort. Work tasks often require employees to use their self-regulatory, attentional, and self-monitoring resources (Kanfer \& Ackerman, 1989). When these personal resources have been completely expended, the performance capabilities of the employee will be limited or diminished. However, when employees psychologically detach during nonwork time they can rebuild their attentional energy and cognitive willpower 'muscle' (Muraven \& Baumeister, 2000). Not thinking about work does not require the same resources that an employee uses at work for completing tasks. In other words, psychological detachment can help an employee feel energized and cognitively prepared for the tasks and demands of the workday because they have allowed their self-regulatory resources to be replenished through mental disengagement from work tasks. Overall, psychological detachment during nonwork time serves the employee by protecting them from the effects of fatigue and ego-depletion that occur when prolonged effort is not interspersed with periods of rest. 
Based on the propositions of the effort-recovery model and ego-depletion, psychological detachment during nonwork time should have a positive association with safety motivation. While motivation can be dependent on a great number of factors, Kanfer and Ackerman (1989) have specified that motivation for self-regulatory activities is partially dependent on the availability of cognitive resources. In other words, if employees lack the sufficient resources to regulate their behaviors at work then their motivation will be low to engage in these activities. The presence of cognitive resources plays a role in determining whether employees can use self-regulation to complete work tasks. Additionally, the effort employees put forth may depend on the salience of the goals they are striving for. Motivation scholars generally agree that motivation for goals are hierarchically arranged; that is, there are needs and goals that are superordinate to goals of lower perceived importance (Diefendorff \& Chandler, 2011). Employees with low cognitive self-regulatory resources may perceive that they only have enough resources to be motivated to complete only the most basic, essential tasks, and will not feel motivated to complete tasks they view as requiring more effort or self-regulation, such as safety-related behaviors (Olson, 2010).

Specifically, psychological detachment will be associated with safety compliance motivation. While compliance motivation infers being motivated to complete required or mandatory tasks related to safety, safety tasks often inherently require motivation for self-regulation because individuals view these tasks as effortful (Dai et al., 2015; Olson, 2010). Employees who cannot, or choose not to, focus on these tasks may struggle to find motivation for compliance behaviors. The results from the literature so far have indicated 
that in some instances psychological detachment is positively related to task performance (e.g., Binnewies et al., 2010). In the present study I propose that psychological detachment is related to safety compliance through the effect of compliance motivation. While the link between psychological detachment and safety compliance has not been explicitly tested, there is theoretical rationale to predict that a positive relationship exists between these phenomena. A shortage of cognitive resources available to the employee may result in these mandatory performance tasks going unfulfilled as employees with low energy and low focus are unmotivated to complete them, as even compliance motivation requires some self-regulation and focus.

In addition, the argument that psychological detachment may help diminish load reactions and replenish cognitive resources may be even more salient for safety participation motivation. Safety participation motivation is defined as being volitional in comparison to compliance behaviors (Griffin \& Neal, 2000). Safety participation behaviors can be volunteering for safety committees or other activities that may not directly contribute to workplace safety, but can improve the overall safety of the workplace. If employees have a shortage of cognitive resources they will be especially unlikely to feel like they can put in the extra effort required for participatory behaviors. Oppositely, if employees have detached during nonwork hours such that cognitive resources have been replenished then they will more likely be motivated and energized to perform participatory safety behaviors. While the valence of these behaviors may be strong for employees, the instrumentality (i.e., whether they believe that completing them will yield productive results) of the activities may be perceived as low to employees, as 
putting effort into these voluntary activities is not guaranteed to result in improved workplace safety (Vroom, 1964).

In summary, it is argued that a positive relationship exists between psychological detachment and safety compliance through the effect of safety compliance motivation, and safety participation through the mediating effect of safety participation motivation. In line with past studies, safety compliance motivation is viewed as a proximal antecedent to safety compliance, and safety participation motivation is a proximal antecedent to safety compliance. Therefore, based on past empirical findings and the process of cognitive recovery, it is hypothesized that safety compliance motivation will mediate the relationship between psychological detachment during nonwork time and safety compliance (a). Specifically, psychological detachment will be related to higher safety compliance motivation, and safety compliance motivation will be related to higher safety compliance. Similarly, it is hypothesized that safety participation motivation will mediate the relationship between psychological detachment during nonwork time and safety participation (b). Specifically, psychological detachment will be related to higher safety participation motivation, and safety participation motivation will be related to higher safety participation.

Hypothesis 1a: Safety compliance motivation mediates the relationship between psychological detachment and safety compliance.

Hypothesis 1b: Safety participation motivation mediates the relationship between psychological detachment and safety participation. 


\section{Negative Work Reflection and Safety}

While psychological detachment is theorized to diminish load reactions and replenish cognitive resources, negative work reflection (NWR) may interfere with these processes and have a negative relationship with safety motivation. NWR is a cognitive recovery experience that has been associated with negative employee outcomes (Fritz \& Sonnentag, 2006; Sonnentag \& Bayer, 2005). From the perspective of the ego-depletion model, NWR further draws on the same cognitive resource that is being called upon by the employee during the workday. In other words, by reflecting on the days' work an employee does not allow their self-regulatory resource to recover as the reflection process may be effortful and requires the attentional resources of the employee. NWR interferes with the employee's ability to rest their self-regulatory muscle during nonwork time (Muraven \& Baumeister, 2000). Furthermore, by reflecting on negative events or experiences employees are likely simultaneously experiencing increased psychophysiological activation that prevents employees' systems from returning to prework, baseline levels. For example, reflecting on negative events at work may stir up negative emotions associated with the event that the employee was trying to forget or let go of. These negative emotions can interfere with recovery by being distracting and continuing to consume cognitive resources that would have been used to focus on other thoughts.

In addition, NWR is likely associated with negative affect and negative job attitudes. From the perspective of job attitude research (e.g., Harrison, Newman, \& Roth, 
2006) NWR can be viewed as an affective evaluation of the workplace that occurs during nonworking hours. This is significant, as a large body of literature has indicated that job attitudes can be related to a wide variety of organizational phenomena, including motivation and performance (Harrison et al., 2006; Judge, Thorensen, Bono, \& Patton, 2001; Meyer, Stanley, Herscovitch, \& Topolnytsky, 2002). NWR may be associated with negative job attitudes such as low organizational commitment (Meyer et al., 2002) and low job satisfaction (Judge et al., 2001). An employee who has a negative evaluation of their job and lacks commitment will likely have ample negative thoughts and reflections about work that may occur during nonworking hours. Organizational commitment and job satisfaction all have established relationships with motivation and performance (Christian et al., 2009; Harrison et al., 2006; Kinicki, McKee-Ryan, Schriesheim, \& Carson, 2002) and NWR may be an indicator that employees are dissatisfied with their organization. Although NWR occurs outside of working hours, research suggests that negative attitudes experienced in the nonwork domain can be associated with outcomes in the workplace (Edwards \& Rothbard, 2000). This is important as the findings from the literature suggest that negative affective states may be associated with lower performance. Research suggests that performance can be determined by moods, emotions, and dispositional affect (Barsade \& Gibson, 2007). Employees who are not able avoid work-related cognitions during nonwork time have less energy and subsequently do not perform as well at work (e.g., ten Brummelhuis \& Bakker, 2012). In other words, the negative job attitudes and affective states that may be associated with NWR may have detrimental consequences for work motivation. 
I propose that NWR is negatively related to safety compliance motivation. Motivation may be significantly influenced by a number of factors, such as affect (Barsade \& Gibson, 2007), job attitudes (Christian et al., 2009), and the availability of resources (Rothbard \& Wilk, 2011). Employees who consider their work in a negative light may be doing so for several reasons. For example, an employee may work at a job in which many negative events often occur during a typical workday. For that reason the employee may be likely to consider the negative events that occurred because of the frequency of the negative events. Thinking about these negative effects may spur negative emotions within the employee, and these negative emotions may become more salient for the employee (Baumeister et al., 2001). Salient negative emotions may build up and spillover with the employee from their nonworking cognitions to thoughts they have at work, and may be distracting or detrimental to their motivation at work. Negative events related to safety at work may be especially distracting for employees due to the importance of safety and salience of safety-related incidents or actions. NWR may additionally occur when an employee is not satisfied with their job or does not feel committed to their organization. An employee with low job satisfaction or low organizational commitment may reflect on the negative aspects of their job because of how they perceive their workplace, coworkers, or job responsibilities. Low organizational commitment and low job satisfaction are predictive of low employee motivation (Harrison et al., 2006), and the associated NWR that occurs simultaneously is likely an additional correlate of low motivation. 
NWR will additionally be negatively associated with participation motivation. Although safety is effortful in general, safety participation motivation is especially volitional (Griffin \& Neal, 2000). Being motivated to participate in voluntary events related to safety or assist a coworker with safety-related tasks is theorized to be perceived by the employee as requiring additional effort to engage in. This effort may be stifled if an employee lacks the necessary resources to feel motivated to engage in participatory activities. NWR may contribute to an inadequate resource level by interfering with the recovery process. The motivation to participate in voluntary or extra-role safety behaviors may be insufficient when negative thoughts about the workplace prevent load reactions from subsiding during nonworking hours. In addition, it is likely that employees who are generally dissatisfied with their job and reflect upon this evaluation during nonworking hours will be unlikely have a sense of obligation to engage in safety participation behaviors. Negative job attitudes have been associated with lower contextual performance (Harrison et al., 2006). In addition, these attitudes eventually manifest themselves through withdrawal behaviors. Overall, it appears that employees who have negative evaluations of their job are less motivated to contribute to the overall effectiveness of workplace through volitional performance behaviors.

In summary, it is argued that a negative relationship exists between NWR and safety compliance through the mediating effect of safety compliance motivation, and safety participation through the mediating effect of safety participation motivation. Consistent with the previous hypotheses, safety compliance motivation is viewed as a proximal antecedent to safety compliance, and safety participation motivation is a 
proximal antecedent to safety compliance. Therefore, based on past empirical findings and the process of cognitive recovery, it is hypothesized that safety compliance motivation will mediate the relationship between NWR during nonwork time and safety compliance (a). Specifically, NWR will be related to lower safety compliance motivation, and safety compliance motivation will be related to lower safety compliance. Similarly, it is hypothesized that safety participation motivation will mediate the relationship between NWR during nonwork time and safety participation (b). Specifically, NWR will be related to lower safety participation motivation, and safety participation motivation will be related to lower safety participation.

Hypothesis 2a: Safety compliance motivation mediates the relationship between negative work reflection and safety compliance.

Hypothesis 2b: Safety participation motivation mediates the relationship between negative work reflection and safety participation.

\section{Positive Work Reflection and Safety}

While the effort-recovery model and ego depletion framework can be used to argue that reflecting on work during nonwork time will be depleting and result in diminished subsequent performance for employees, another theoretical perspective offers a competing view when the reflection is positive in valence. Broaden-and-Build theory (Fredrickson, 1998) can be applied to the current study to describe how PWR during nonwork time may be associated with positive motivational states. When employees 
consider their work in a positive light or think about positive work events they experience positive emotional states. The act of reflecting on positive events at work may be pleasurable and provide a satisfactory experience for employees (Binnewies et al., 2009b). A proposition of broaden and build theory is that positive experiences broaden an employee's thought-action repertoire and is an experience that builds personal resources and builds motivation (Fredrickson, 2001). The theory emphasizes the role that positive emotional states can play in affecting optimal psychological functioning. In some ways, this process is in opposition to the tenets of the effort-recovery model and ego depletion framework, such that the Broaden-and-Build framework is utilized to argue that thinking about positive work events can be associated with increased work motivation. In other words, the counterargument (utilizing the effort-recovery model and ego-depletion framework) could be applied to argue that PWR during nonwork time may have a draining effect on employee cognitive resources because thinking about work in any way interferes with the recovery of cognitive self-regulatory resources. However, in the present study it is argued that PWR has a positive association with motivation by providing a positive affective experience for employees that is associated with higher motivation (Fredrickson, 1998).

Two additional perspectives can be applied to present arguments as to why PWR will be positively linked to safety performance through safety motivation. First, from a motivational perspective PWR is a process in which there is great potential for building cognitive resources related to motivation. PWR may broaden employee's perspective and strengthen their self-regulatory "muscle", which has been suggested to be one of two 
methods (in addition resting) to combat ego-depletion effects (Muraven \& Baumeister, 2000). PWR may actually build sustainable and durable resources for employees and this may be positively associated with employee motivation. PWR may be beneficial for employee motivation and performance through the employee's positive reappraisal reinterpretation of work circumstances. The process of broadening employee perspective may contribute to positive attitudes towards their job, their self-efficacy surrounding work, or their positive affect, all of which have the potential to positively affect motivation and performance. For example, PWR may involve reflecting on tasks or projects that were completed to the employee's satisfaction, which may build their selfefficacy for completing future tasks. Second, PWR can be seen through the lens of job attitudes research as an evaluation of one's work situation (Harrison et al., 2006). Through this perspective PWR is an indication of a positive evaluation of one's work that occurs during nonworking hours. As research indicates attitudes such as job satisfaction and organizational commitment are related to higher job performance, PWR should likewise be positively related to safety motivation and performance.

It is therefore argued using the propositions from Broaden-and-Build theory and research on work motivation and job attitudes that there is a significant positive association between PWR safety compliance motivation. Although the findings for PWR and task performance have been mixed (Binnewies et al., 2009b; Fritz \& Sonnentag, 2005; Sonnentag \& Grant, 2012), there are several theoretical perspectives that provide reason to propose a significant relationship between PWR and safety motivation. The tenets of Broaden-and-Build theory can be used to suggest that PWR may be positively 
associated with safety compliance motivation by providing a positive nonwork experience for employees. Positives thoughts and cognitions during nonwork time may improve employee motivation, and perhaps higher self-efficacy. Employees who view the positive aspects of their job may feel they have the adequate cognitive resources to engage in effortful safety compliance behaviors. Additionally, as PWR may indicate general satisfaction with one's job situation, a positive job attitude should contribute to motivation to engage in routine safety behaviors.

Therefore, I further propose that PWR will be positively related to safety participation motivation. The findings from the literature suggest that PWR may be likely to affect volitional performance behaviors, such as OCB's or proactive work behaviors (Binnewies et al., 2009b; Fritz \& Sonnentag, 2005; Sonnentag \& Grant, 2012). These studies have found consistent relationships between PWR and volitional performance. Volitional job performance behaviors or attitudes such as safety participation motivation or safety participation theoretically are dependent on the presence of cognitive resources. Employees choose whether to volunteer for safety committees or assist coworkers in their safety tasks. They are not mandated to do so, and it is because of this that safety participation is likely affected by the availability of cognitive resources. PWR may additionally be positively associated with the attitudes of employees towards their job, or it may be an indication of their commitment to their work. As with compliance motivation, this is significant because of the previously established relationship between positive job attitudes and contextual performance (Harrison et al., 2006). Finally, PWR may be associated with the strengthening of the 'muscle' for self-regulation. The process 
of broadening one's perspective may provide cognitive resources that are vital for allowing employees to feel as though they have the energy to engage in participatory behaviors. Through these processes, employees may experience heightened motivation to give their resources back to the organization by participating in voluntary safety behaviors, and they may in fact follow through in doing so.

In summary, it is argued that a positive relationship exists between PWR and both safety compliance through the mediating effect of safety compliance motivation and safety participation through the mediating effect of safety participation motivation. As was proposed in the previous hypotheses, safety compliance motivation is viewed as a proximal antecedent to safety compliance, and safety participation motivation is a proximal antecedent to safety compliance. Therefore, based on past empirical findings and the process of cognitive recovery, it is hypothesized that safety compliance motivation will mediate the relationship between PWR during nonwork time and safety compliance (a). Specifically, PWR will be related to higher safety compliance motivation, and safety compliance motivation will be related to higher safety compliance. Similarly, it is hypothesized that safety participation motivation will mediate the relationship between PWR during nonwork time and safety participation (b). Specifically, PWR will be related to higher safety participation motivation, and safety participation motivation will be related to higher safety participation.

Hypothesis 3a: Safety compliance motivation mediates the relationship between positive work reflection and safety compliance. 
Hypothesis 3b: Safety participation motivation mediates the relationship between positive work reflection and safety participation.

\section{Moderator: Perceptions of Safety Climate}

While individual cognitive recovery experiences during nonwork time may be associated with safety performance, safety at work is likely determined by a combination of factors. What an employee thinks about during nonwork time may be important, but contextual workplace factors will likely be associated with safety as well (Nahrgang et al., 2011). One such factor that has a strong potential for channeling the effect of cognitive recovery during nonwork time on safety motivation is employee perceptions of safety climate. Supervisory practices are assumed to have an effect on employee outcomes by being the link between organizational policies and implementation in the workplace (Zohar, 2000, 2003). In the present study, supervisors may play a directive role in urging employees to direct their attention and focus towards safety. Support for safety sends a message to employees that the supervisor and organization value safety and encourage their employees to prioritize safety behaviors (Zohar, 1980). For example, a supervisor with a high priority for a strong safety climate will help an employee focus on safety, even if they are fatigued. Perhaps more importantly, a deficiency of supervisor support for safety may be particularly salient in the workplace and may indicate to employees that the organization is not concerned with their safety at work. Overall, it is argued that higher-quality relationships, based on mutual trust and genuine care, will result in a greater emphasis on safety (Zohar, 2003). 
Neal et al. (2000) found empirical support that employee perceptions of safety climate are antecedents to safety motivation. In the present study it is proposed that cognitive nonwork recovery experiences are additional antecedents to safety motivation. It may be such that these antecedents to motivation may interact to predict safety motivation. Perceptions of safety climate are present during working hours while recovery experiences occur outside of work. Theoretically, each may occur in different domains but they may interact within an employees' cognition to predict safety performance. In other words, the theoretical processes through which cognitive recovery experiences are associated with safety motivation may differ from the processes in which perceptions of safety climate are associated with safety motivation, but ultimately their collective influence may produce the highest safety motivation. Further, while cognitive recovery is argued to be associated with cognitive resource availability outside of work that spills over to working hours, perceptions of safety climate may be viewed as a contextual work resource that enhances employee engagement with their work (Demerouti, Mostert, \& Bakker, 2010). Under these assumptions, the employee who has the highest levels of safety motivation is both adequately equipped with cognitive resources and perceives a high level of safety support from their supervisor. Therefore, I propose that perceptions of safety climate enhance the previously hypothesized relationships between cognitive recovery experiences and safety motivation.

Specifically, perceptions of safety climate can enhance the relationship between psychological detachment and safety motivation. While employees who can detach and allow their internal systems to be restored are likely to be motivated to engage in safety 
behaviors, the addition of perceiving that the employee's supervisor prioritizes safety can provide further motivation. An absence of safety support can additionally enhance the negative relationships between NWR and safety motivation. Employees who perceive negative events at the workplace and additionally do not feel that their supervisor prioritizes safety may expend less effort on both mandatory and optional safety behaviors in response. In other words, if engaging in NWR depletes their cognitive resources, and they do not feel they have the support to direct their focus to safety behaviors at work, then there is a danger of lower safety compliance motivation and lower safety participation motivation. Conversely, when the employee perceives high support for a safe work environment from their supervisor, the negative thoughts about work may encourage them to correct this discrepancy through higher safety performance. In other words, the supervisor's behaviors towards safety in the workplace may motivate employees to direct their attention towards making improvements to safety rather than letting their own performance slip. Finally, the perception of safety support from the supervisor may additionally enhance the positive relationship between PWR and safety motivation. Perceptions of safety climate can direct employees who are focused and have a positive attitude about their job to aim their efforts towards safety. For example, an employee may be energized at work (as a result of reflecting positively about their job, thus aiding their cognitive recovery from work stress) but they are likely faced with competing demands and multiple goals to pursue (Locke \& Latham, 2002). However, the presence of a supervisor who prioritizes safety can signal to an employee that their effort should be prioritized towards essential workplace safety functions. 
In summary, it is hypothesized that perceptions of safety climate will enhance the previously hypothesized relationships between cognitive recovery experiences and safety motivation.

Hypothesis 4a-b: Perceptions of safety climate will moderate the relationship between psychological detachment and safety compliance motivation (a) and safety participation motivation. (b) Specifically, the magnitude of the positive relationship between psychological detachment and safety motivation will be stronger under conditions of high perceptions of safety climate.

Hypothesis 5a-b: Perceptions of safety climate will moderate the relationship between negative work reflection and safety compliance motivation (a) and safety participation motivation. (b) Specifically, the magnitude of the negative relationship between negative work reflection and safety motivation will be weaker under conditions of high perceptions of safety support.

Hypothesis 6a-b: Perceptions of safety climate will moderate the relationship between positive work reflection and safety compliance motivation (a) and safety participation motivation. (b) Specifically, the magnitude of the positive relationship between positive work reflection and safety motivation will be stronger under conditions of high perceptions of safety climate. 


\section{Chapter 7: Method}

\section{Study Context \& Procedure}

The data being utilized for this study were collected with funding from the Oregon Healthy Workforce Center, a NIOSH Center of Excellence in Total Worker Health $^{\circledR}$, in collaboration with the Oregon Department of Corrections (ODOC). I was the sole graduate student funded to work on this project and took a major role in the project management tasks, research design planning, data collection, data management, data analysis, and collaborating with the ODOC. Prior to distributing surveys, our research assistant and I visited the two facilities in which the study was conducted and met with supervisory staff, security staff, and superintendents there to discuss the purpose and logistics of the study. We explained that the study was a step in seeking to understand, and ultimately improve, factors related to security staff health and well-being. We then took a tour of the facilities to learn more about the specifics of each facility. Finally, we conducted several interviews with superintendents and union representatives to discuss any concerns in regards to the study logistics. These actions were taken in an effort to encourage commitment to the study and maximize participation among staff.

After visiting the facilities and gaining approval for the project from the ODOC we created a survey that provided the data that the current study will utilize. These surveys were distributed to the participants in January 2014 in both facilities over the course of three weeks. We sent the surveys in a package to the facilities and they were handed to security staff via Master Control, which is the main entrance to the facilities 
through which all security staff pass through at the beginning or end of their shift. The survey envelopes were addressed individually to each potential participant but the surveys did not contain any identifying information. In addition, each envelope contained a stamped envelope addressed to the PI of the project so participants were able to mail their envelopes back to us. We asked supervisors to identify themselves by name, but we allowed the COs' responses to remain anonymous. An email announcement soliciting participation in the study was sent from the research team, facility superintendent, and a representative from the union that represented the staff at the facility. Each week during data collection reminders were sent from these groups to encourage participation. There were two survey forms: CO (staff) and Supervisor. The forms were identical with the exception of the frame of reference for certain items (e.g., perceptions of supervisory behaviors) and several questions about workplace characteristics related to supervisory status (e.g., how many subordinates they supervised).

\section{Participants}

Participants were security staff from two correctional facilities in Oregon. The facilities were selected for the study based on similarities in the security level of the facility and the geographic region in which they were located. Both were classified as medium security correctional facilities and were located in Northeastern Oregon. We recruited security staff of all ranks (i.e., Correctional Officer, Corporal, Sergeant, Lieutenant, Captain) to participate in the study. 
At the time the surveys were distributed there were a total of 596 COs working at the facilities. Surveys were returned by 166 participants, resulting in a response rate of 28\%. Participants who completed the survey were emailed a \$10 Amazon gift card. Of these participants, 44 (27\%) were classified as supervisors (i.e., sergeant, lieutenant, captain). The average number of employees that supervisors oversaw was 30.17 ( $S D=$ 28.75). On average, participants were 45.43 years old $(S D=11.50)$ and the majority were male $(81 \%)$. The majority of the sample identified their ethnicity as White $(85 \%)$, followed by $7 \%$ who identified as Hispanic or Latino. Most participants (82\%) had an education beyond high school. Approximately three quarters (78\%) of the sample reported that they were married, followed by $10 \%$ who indicated they were currently divorced. Almost half (44\%) indicated they usually worked a day shift, followed by $35 \%$ who typically worked a swing shift, and $25 \%$ who typically worked a night shift. Participants reported working an average of 43.18 hours per week $(S D=7.90)$. One quarter $(25 \%)$ of the participants reported they were Veterans. The average tenure as a CO was 12.04 years $(S D=8.22)$. Demographic information for the participants can be found in Table 1.

\section{Measures}

Cognitive recovery experiences. Three measures were used to assess nonwork cognitive recovery experiences. Psychological detachment was measured using the 4item subscale from the Recovery Questionnaire (Sonnentag \& Fritz, 2007). A sample item was, "Outside of work, in the past month I didn't think about work at all." 
Cronbach's alpha for this scale was .87. Positive work reflection was measured using 3 items from Fritz and Sonnentag (2005). A sample item from this scale was, "Outside of work, in the past month I thought about the positive aspects of my job." Cronbach's alpha for this scale was .96. Negative work reflection was measured using 3 items from Fritz and Sonnentag (2006). A sample item from this scale was, "Outside of work, in the past month I considered the negative aspects of my work. Cronbach's alpha for this scale was .86. For all items, participants were asked to what extent they agreed with each statement. Participants responded on a scale from 1 (Not at all) to 5 (Very much).

Safety motivation. Safety compliance motivation was measured using a 5-item scale from Neal et al. (2000). A sample item was, "In the past month, I felt that adhering to safe procedures was important for my job. Cronbach's alpha for this scale was .93. Safety participation motivation was measured using a 6-item subscale from Neal et al. (2000). A sample item was, "In the past month, I felt it was important to encourage others to use safe practices." Cronbach's alpha for this scale was .89. Participants were asked to respond to what extent they agreed with each statement. Participants responded on a scale from 1 (Strongly disagree) to 5 (Strongly agree).

Safety performance. Safety compliance was measured using a 3-item subscale from Neal et al. (2000). A sample item was, "In the past month, I ensured the highest levels of safety when I carried out my job.” Cronbach's alpha for this scale was .93. Safety participation was measured using a 3-item subscale from Neal et al. (2000). A sample item was, "In the past month, I put in extra effort to improve the safety of the 
workplace." Cronbach's alpha for this scale was .87. Participants were asked to respond to what extent they agreed with each statements. Participants responded on a scale from 1 (Strongly disagree) to 5 (Strongly agree).

Perceptions of safety climate. Perceptions of safety climate were assessed using 6 items selected from Zohar and Luria’s (2005) Group-Level Safety Climate scale. The frame of reference for the scale varied depending on whether the participant was a $\mathrm{CO}$ (staff) or a Supervisor. A sample item from this scale for the CO version of the survey was, "In the past month, my direct supervisor was strict about working safely even when we were tired or stressed." The same item from this scale for the Supervisor version of the survey was, "In the past month, I was strict about working safely even when my employees were tired or stressed." Cronbach's alpha for this scale was .88 for CO perceptions of safety climate, and .89 for Supervisor perceptions of safety climate. Participants were asked to respond to what extent they agreed with each statement they were presented. Participants responded on a scale from 1 (Strongly disagree) to 5 (Strongly agree). Finally, as perceptions of safety climate were modeled at the individual level, the responses were not aggregated to the group level.

All of the items from the scales used in this study are located in the Appendix.

Control variables. Several variables were examined to determine their potential inclusion as control variables. Control variables were included if there was a previously established empirical relationship with the proposed predictors and outcomes, or if there was a theoretical reason to expect a relationship. 
First, the findings from a meta-analysis revealed that age has a significant bivariate relationship with safety performance. Specifically, age has a positive relationship with safety compliance and a negative relationship with accident and injury frequency ( $\mathrm{Ng} \&$ Feldman, 2008). Second, tenure may additionally be related to safety performance. Theoretically, employees who have worked for more years at an organization may perform job duties differently depending on their experience and perceptions, and may additionally work more favorable shifts or be assigned more desirable duties. Third, rank may be related to safety performance. As employees advance in rank they will often shifted towards supervisory duties due to their experience and the needs of the organization and will have fewer opportunities to perform safetyrelated tasks. Therefore, age, tenure, and rank were included as control variables in the analyses conducted for this study. Several other variables were considered as additional control variables, but were not included due to a deficiency of empirical and/or theoretical rationale for their inclusion (Bernerth \& Aguinis, 2015). 


\section{Chapter 8: Results}

\section{Descriptive Statistics}

Means, standard deviations, and correlations are reported in Table 2. Overall, some of the study variables were correlated with one another at low to moderate levels. Psychological detachment was not associated with safety motivation $(r=.02, p=.78$ compliance, $r=-.04, p=.58$ participation), and had weak associations with safety performance $(r=.10, p=.20$ compliance, $r=.07, p=.38$ participation $)$ in the expected directions. The results indicate that psychological detachment has a weak bivariate relationship with both safety compliance and safety participation. NWR was not associated with safety motivation $(r=.00, p=.99$ for compliance, $r=.00, p=.96$ participation) or safety performance $(r=-.01, p=.90$ for compliance, $r=-.01, p=.88$ participation). The results indicate that NWR is not related to safety motivation or safety performance, as it is not significantly correlated with any of the four safety variables. PWR was weakly associated with safety compliance motivation $(r=.06, p=.43)$ and safety compliance $(r=.10, p=.20)$, and moderately associated with safety participation motivation $(r=.24, p<.01)$ and safety participation $(r=.25, p<.01)$ in the expected direction. The results indicate that while PWR has a weak relationship with safety compliance (motivation and performance), it has a moderate positive bivariate relationship with safety participation (motivation and performance).

\section{Analytic Strategy: Hypotheses 1-3}


To evaluate Hypothesis 1-3 path analysis was used. Path analysis is a type of structural equation model (SEM) that utilizes ordinary least squares regression to test a causal set of relationships among a set of variables (Billings \& Wroten, 1978). The path analysis was conducted using the lavaan package in $\mathrm{R}$.

Model fit was assessed by examining the chi-square $\left(\chi^{2}\right)$ statistic. Since this statistic is sensitive to sample size, several other fit indices were examined: the comparative fit index (CFI), the Tucker-Lewis Index (TLI), the root mean square error of approximation (RMSEA), and the standardized root mean square residual (SRMR). The CFI and TLI above .90 and the RMSEA and SRMR below .08 indicate acceptable model fit (Hu \& Bentler, 1999). Maximum-likelihood (ML) estimation was used to estimate the model fit statistics.

In addition, bias-corrected bootstrapping (Preacher \& Hayes, 2004) was used to assess the indirect effects between the predictors (detachment, NWR, PWR) and outcomes (safety performance) through the mediator (safety motivation). Bias-corrected bootstrapping provides a confidence interval (CI) to determine the magnitude of the relationship between two variables. If the $95 \%$ CI does not include zero then this provides support for a statistically significant mediation effect. This method has been proposed as a more accurate way to assess mediation when compared with existing methods designed for use in large samples (e.g, Sobel, 1982), especially in small samples (Shrout \& Bolger, 2002). This is noteworthy as tests for indirect effects such as Sobel's (1982) test assume the data are normally distributed, which is not always the case with 
smaller data sets. Bootstrapping creates a pseudo-sample by taking a number of random observations, with resampling, from the original data, and this process is repeated usually thousands of times. The lavaan package in $\mathrm{R}$ was used to obtain 1,000 resamples of the data for the analyses.

\section{Model Specification and Results}

To examine whether the three cognitive recovery experiences could be analyzed in the same model and treated as three separate constructs, a three-factor CFA was specified. The model provided a good fit for the data $\left(\chi^{2}=43.29, d f=32, \mathrm{CFI}=.99\right.$, TLI $=.99, \mathrm{RMSEA}=.05, \mathrm{SRMSR}=.05)$. Furthermore, the cognitive recovery experiences were weakly to moderately related to one another. Psychological detachment was moderately related to $\operatorname{NWR}(p=-.38)$ and weakly related to $\operatorname{PWR}(p=.10)$, while NWR and PWR were weakly correlated $(p=-.04)$. Therefore, the CFA confirmed that a threefactor structure fit the data appropriately and that the three cognitive recovery experiences are empirically distinguishable from one another.

Age, tenure, and rank were included as control variables by including them in the equations for the paths between the cognitive recovery experiences (psychological detachment, NWR, PWR) and the safety motivation variables, and between safety motivation and safety performance. Additionally, paths were specified to indicate the covariance between the cognitive recovery experiences. Finally, there was a path specified to indicate the covariance between the two safety motivation indicators (safety compliance motivation and safety participation motivation), and to indicate the 
covariance between the two safety performance indicators (safety compliance and safety participation).

\section{Hypothesis Testing}

The hypothesized model fit the data adequately $\left(\chi^{2}=26.66, d f=18, \mathrm{CFI}=.98\right.$, $\mathrm{TLI}=.95, \mathrm{RMSEA}=.06, \mathrm{SRMSR}=.04)$. Figure 2 shows the path model with standardized coefficients.

Table 3 displays the results of the mediation hypotheses. Hypothesis 1 stated that safety motivation would mediate the relationship between psychological detachment and safety performance. Hypothesis 1 was not supported. Safety compliance motivation did not mediate the path from psychological detachment to safety compliance $($ Est. $=-.004$, $S E=.035,95 \%$ CI: $-.067, .072)$, nor did safety participation motivation mediate the path from psychological detachment to safety participation (Est. $=.035, S E=.037,95 \% \mathrm{CI}$ : $.034, .109)$, as the 95\% CI's contained zero.

Hypothesis 2 was not supported. Safety compliance motivation did not mediate the path from NWR to safety compliance (Est. $=.010, S E=.029,95 \% \mathrm{CI}:-.048, .069)$, nor did safety participation motivation mediate the path from psychological detachment to safety participation (Est. $=-.033, S E=.051,95 \% \mathrm{CI}:-.132, .070)$, as the $95 \%$ CI's contained zero.

Hypothesis 3 was partially supported. Safety compliance motivation did not mediate the path from PWR to safety compliance (Est. $=.032, S E=.054,95 \% \mathrm{CI}:-.073$, 
.139 ), as the $95 \%$ CI contained zero. Safety participation motivation did mediate the path from PWR to safety participation (Est. $=.136, S E=.049,95 \%$ CI: .046, .236), as the 95\% CI did not contained zero.

In addition, an alternate model was specified to assess whether a partial mediation model was a better fit for the data. Paths were specified from the cognitive recovery experiences (psychological detachment, NWR, PWR) to the safety performance outcomes (safety compliance, safety participation). This model fit the data adequately $\left(\chi^{2}\right.$ $=20.48, d f=12, \mathrm{CFI}=.98, \mathrm{TLI}=.93, \mathrm{RMSEA}=.07, \mathrm{SRMSR}=.04)$. A chi-square difference test was conducted to determine whether the partial mediation model fit the data significantly better than the hypothesized full mediation model. The results indicated that the partial mediation model did not significantly improve the model fit $\left(\chi^{2}\right.$ difference $=6.19, d f=6, p=.40)$. Therefore, the full mediation model was retained.

\section{Analytic Strategy: Hypotheses 4-6}

To evaluate Hypothesis 4-6 ordinary least squares (OLS) regression was used to test whether perceptions of safety climate moderated the relationship between cognitive recovery and safety motivation. The predictor variables (psychological detachment, NWR, PWR) and the moderator (perceptions of safety climate) were mean-centered to improve the interpretability of the results. Interaction terms were created by multiplying the mean-centered predictors with the mean-centered moderator variable. The control variables (age, tenure, rank), predictor, moderator, and interaction term were entered together into separate OLS models for each of the two outcome variables (safety 
compliance motivation, safety participation motivation) and the interaction term was evaluated for statistical significance at $p<.05$. A total of six models were specified to test Hypothesis 4-6.

\section{Hypothesis Testing}

The results for Hypothesis 4-6 are displayed in Tables 3-5. Hypothesis 4 proposed that perceptions of safety climate would moderate the relationship between psychological detachment and safety motivation. Hypothesis 4 was not supported. Controlling for age, tenure, and rank, the interaction of psychological detachment and perceptions of safety climate was not significant for safety compliance motivation $(\mathrm{H} 4 \mathrm{a} ; \beta=-.01, p=.96)$ or for safety participation motivation $(\mathrm{H} 4 \mathrm{~b} ; \beta=.05, p=.56)$.

Hypothesis 5 proposed that perceptions of safety climate would moderate the relationship between NWR and safety motivation. Hypothesis 5 was not supported. Controlling for age, tenure, and rank, the interaction of NWR and perceptions of safety climate was not significant for safety compliance motivation $(\mathrm{H} 5 \mathrm{a} ; \beta=-.01, p=.93)$ or for safety participation motivation $(\mathrm{H} 5 \mathrm{~b} ; \beta=-.04, p=.68)$.

Hypothesis 6 proposed that perceptions of safety climate would moderate the relationship between PWR and safety motivation. Hypothesis 6 was not supported. Controlling for age, tenure, and rank, the interaction of PWR and perceptions of safety climate was not significant for safety compliance motivation $(\mathrm{H6a} ; \beta=-.07, p=.46)$ or for safety participation motivation $(\mathrm{H} 6 \mathrm{~b} ; \beta=-.11, p=.19)$. 
In addition, Hypothesis 4-6 were re-analyzed using safety performance as the dependent variable. However, none of the interactions were significantly associated with safety performance.

\section{Additional Analyses}

Several additional sets of analyses were conducted to further examine the relationship between cognitive recovery experiences and workplace safety.

Multilevel. Research in organizations should take into account the nested aspect of the workplace, such employees are naturally separated or 'nested' into different work groups, or they work under different supervisors within the organization. By excluding specifications in the analyses that account for variance due to group membership there may be unexplained variance in the dependent variable, which may affect the accuracy of the estimates (Bliese \& Jex, 2002).

In the present study, we asked employees to identify their supervisor in order to group them by which supervisor they worked under. However, two problems arose. First, the supervisory structure of working in corrections is similar to a matrix organization such that employees have multiple supervisors of different ranks. Furthermore, COs work double shifts, different posts, and many hours of overtime, and therefore may interact with multiple supervisors over the course of a month (e.g., they may report to a Sergeant most days, but may report to a different Lieutenant if they are covering a coworker's post). Therefore, we asked employees to report which supervisor they interacted with the 
most over the last month. Second, even with this change, there was significant underreporting of which supervisor an employee worked with. There were $124 \mathrm{COs}$ who participated in the survey, but only 84 reported which supervisor they worked under most often in the past month. Furthermore, of these 84 participants, they identified working with 40 different supervisors, and $12(14 \%)$ of these participants indicated they worked with multiple supervisors equally, and 20 of the 40 supervisors (50\%) were only identified by one employee. Therefore, due to the small overall sample size, small group sizes, and quality of the data, multilevel analyses were not pursued in the present study.

Alternative Model: How Does Burnout Affect Safety? Research on workplace safety has revealed that employee burnout may directly or indirectly relate to safety at work (Nahrgang et al., 2011). Therefore, several alternate models were tested in which exhaustion was added to the model. A 7-item scale was used to measure exhaustion, a component of burnout (Demerouti, Bakker, Vardakou, Kantas, 2003). ${ }^{1}$

First, a model was specified in which exhaustion mediated the relationship between cognitive recovery experiences and safety motivation. This explores the possibility that employees who feel fully mentally recovered from work will be less exhausted, and subsequently will experience higher levels of safety motivation. However, the resulting model did not provide an adequate fit of the data $\left(\chi^{2}=42.74, d f=12, \mathrm{CFI}=\right.$ $.85, \mathrm{TLI}=.74, \mathrm{RMSEA}=.13, \mathrm{SRMSR}=.07)$.

\footnotetext{
${ }^{1}$ The Demerouti et al. (2003) scale originally had 8 items, but an error occurred while creating the surveys, resulting in one item appearing twice, leaving 7 unique items.
} 
Second, exhaustion was added a control variable to the path model to determine if safety motivation mediated the relationship between cognitive recovery and safety performance while controlling for employee's levels of exhaustion. However, the resulting model fit the data poorly $\left(\chi^{2}=111.06, d f=17, \mathrm{CFI}=.70, \mathrm{TLI}=.40, \mathrm{RMSEA}=\right.$ $.19, \mathrm{SRMSR}=.11)$.

Finally, six moderated regression analyses were tested in which exhaustion moderated the relationship between cognitive recovery and safety motivation. This was done to examine the hypothesis that employees experience higher levels of safety motivation only under the condition of high cognitive recovery and low levels of exhaustion. However, none of the interactions were significantly related to safety motivation, thereby not providing support for the moderating role of exhaustion.

Relationships with Accidents and Injuries. One question in the area of workplace safety that has not yet been clearly answered is whether self-reported performance measures are valid indicators of safety at work. When possible it is ideal to assess objective measures of workplace safety in addition to self-report measures in order to provide criterion and construct validity evidence for self-reported safety performance. While actual objective data were not collected in the present study, participants were asked about their involvement in workplace incidents in which they suffered some type of injury. Two 1-item measures were assessed: the number of work days missed as a result a major injury at work, and whether the participant had filed a worker's compensation claim in the past three months. 
The accident data were first examined at the descriptive level. About $90 \%$ of the sample indicated they had not missed any days in the past three months due to a major injury at work. Three percent responded they had missed one day, $4 \%$ missed two days, and $3 \%$ missed at least three days of work in the past three months. Additionally, $3 \%$ of the sample indicated they had filed a worker's compensation claim. Finally, it should be noted that $19 \%$ of the participants indicated they had been involved in a physical confrontation with an inmate in the past month. Interestingly, being involved in a physical confrontation was not correlated with the measure of major injuries $(r=-.01)$ and only had a low correlation with the measure of worker's compensation claims $(r=$ $.09)$.

The accident data were then examined further using Poisson regression. Poisson regression is used when the frequency of the dependent variable is low and contains many zeros, as is often the case with accident or injury data. Four models were analyzed in which safety performance predicted major accidents or worker's compensation claims, as this aligns with theoretical models in which performance predicts actual behaviors or incidents (Campbell et al., 1993; Griffin \& Neal, 2000). Safety performance did not predict days missed due to major accidents or worker's compensation claims.

Specifically, safety compliance was not related to workdays missed $(\beta=-.04, p=.68)$ or worker's compensation claims $(\beta=-.01, p=.89)$, and safety participation was not related to workdays missed $(\beta=-.04, p=.53)$ or worker's compensation claims $(\beta=.00, p=$ $.99)$. 
Power Analysis. A post hoc power analysis was conducted to determine the power available in the present study to detect significant effects. Two separate power analyses were conducted: one power analysis was conducted for Hypothesis 1-3, and one power analysis was conducted for Hypothesis 4-6. G*Power 3.1 was used to calculate power. For Hypothesis 1-3, a small effect size was assumed based on the findings from the current study. With a sample size of $N=166$, the achieved power in the present study was $\beta=.30$ to detect significant linear regression effects. For Hypothesis 4-6, a small effect size was assumed based on existing empirical evidence and the probability for detecting interactions in the social sciences. With a sample size of $N=122$, the observed power in the present study was $\beta=.22$ to detect significant interaction effects. The results of the power analysis indicate that the current study may be underpowered. Typically, power of $\beta=.80$ is considered acceptable for detecting significant effects when the null hypothesis is false using $\alpha=.05$ (Cohen, 1992). 


\section{Chapter 9: Discussion}

The overarching aim of this study was to determine if there was a relationship between cognitive experiences away from work and safety motivation and safety performance at work. While much has been uncovered about workplace factors that contribute to workplace safety, little is known about how an employee's nonwork time may be related to safety at work (for exceptions, see Cullen \& Hammer, 2007; LaPierre et al., 2012; Turner et al., 2014). It was proposed that the cognitive recovery experiences an employee has away from the workplace would impact the psychological resources they have available to them during the workday. Specifically, a model was tested in which safety motivation mediated the relationship between cognitive nonwork recovery experiences and safety performance. Based on prior research of recovery experiences during nonwork time, it was proposed that cognitive recovery experiences during nonwork time would be related to safety in the workplace. The effort-recovery model was utilized to argue that employees who refrain from work-related thoughts would recover from stress more efficiently and therefore have more cognitive resources to direct towards safety at work. In the context of self-regulation, negative thoughts about work during nonwork time may drain self-regulatory resources required to carry out safety tasks at work (Muraven \& Baumeister, 2000). Furthermore, these thoughts may have a negative relationship with performance, paralleling findings from research on negative job attitudes and general work performance (Harrison et al., 2006). Oppositely, positive thoughts about work during nonwork time may be associated with positive affective states. According to Broaden-and-Build theory such positive emotions can facilitate 
feelings of motivation that can be associated with improved work performance.

Additionally, positive thoughts during nonwork time may be reflective of positive job attitudes (or several other related concepts, discussed in this section), which have previously been linked to increased performance. Overall, it was proposed that three cognitive recovery experiences — psychological detachment, NWR, PWR — would be significantly associated with safety performance through safety motivation mediating the relationship between cognitive recovery experiences and safety performance.

Furthermore, a separate set of models was tested in which perceptions of safety climate moderated the relationship between cognitive recovery experiences (i.e., psychological detachment, NWR, PWR) and safety motivation. Scholars have previously found that safety at work is affected by a great number of factors, one in particular being the quality of the safety climate in the workplace. Zohar (2003) and others have argued that leaders may have a great influence on the climate of the workplace through their actions, messages, and how they prioritize safety. When leaders demonstrate that they prioritize safety it may affect the employees' perceptions of the importance of safety in the workplace. Therefore, when employees perceive that their supervisors are prioritizing safety in the workplace, the employees themselves may be more likely to be motivated to focus on safety as well. Conversely, when employees perceive that their supervisors pay little attention to the safety of workers, employees feel less connected to their supervisors and are less likely to experience a strong motivation to engage in safety behaviors. 
Overall, although previous research and the theoretical rationale discussed offered support for the proposed hypotheses, they received minimal empirical support in the current study. The following summarizes and details the findings from each hypothesis, and provides a context through which the results can be interpreted. Finally, potential limitations are discussed and implications for both researchers and practitioners are offered.

\section{Summary of Findings: Mediation}

The first hypothesis stated that safety motivation would mediate the relationship between psychological detachment and safety performance. Specifically, psychological detachment would have a positive association with safety performance through a positive association with safety motivation. Drawing on the effort-recovery model it was argued that psychological detachment during nonwork time would aid employees' recovery of their self-regulatory resources that are essential for the motivation to engage in safety tasks at work. However, the results did not support this hypothesis such that psychological detachment was not related to safety compliance (via safety compliance motivation) nor safety participation (via safety participation motivation). Thus, Hypothesis 1 was not supported.

A further examination of the data reveals that psychological detachment had low bivariate relationships with both types of safety motivation and both types of safety performance ( $r$ ranged from -.04 to .10 ). Contrary to the hypothesis, it appears that employees' levels of psychological detachment were not associated with their motivation 
for or performance of safety duties at work. In some ways, this finding is not entirely surprising. While past research has revealed that psychological detachment has strong, consistent relationships with employee well-being, its association with performance is less clear. For instance, in the current study an alternative hypothesis could be that psychological detachment could be related to performance in a curvilinear pattern, such that either too little or too much detachment could be related to lower performance. For example, minimal amounts of detachment may not provide an adequate mental break from work, while high levels of detachment could make it difficult for an employee to transition back into the mindset required by their work. While this has been supported by at least one prior study (i.e., Fritz et al., 2010), this was tested in the current study and the results indicated there were no significant curvilinear relationships between detachment and safety. Interpreted through the lens of the effort-recovery model, psychological detachment diminishes load reactions that occur as a response to expending effort at work and allows internal systems to return to their prework levels. This may directly affect outcomes such as reduced feelings of exhaustion, reduced health complaints, and increased feelings of vigor, but may not as clearly influence performance. In other words, as performance and motivation are determined by a number of factors, simply feeling good and healthy may not be sufficient to drive higher motivation and better performance.

Hypothesis 2 stated that safety motivation would mediate the relationship between NWR and safety performance. Specifically, NWR would have a negative association with safety performance. It was argued that NWR during nonwork hours depletes 
cognitive resources and interferes with the employee's ability to regenerate the selfregulatory resources required for safety behaviors. Through the lens of the ego-depletion model it was reasoned that NWR conjures up negative thoughts and feelings that may be similar to those experienced during work, thus continuing to draw from the limited pool of self-control that an employee possesses. Furthermore, NWR may be reflective of negative job attitudes, which can have a negative effect on both motivation and performance (Harrison et al., 2006). However, the results of the current study did not support this hypothesis. NWR was not related to safety compliance (via safety compliance motivation) or safety participation (via safety participation motivation), and thus Hypothesis 2 was not supported.

As was the case with Hypothesis 1, the bivariate relationships were weak to nonexistent between NWR and workplace safety. In the current study NWR during nonwork time appeared to have no bearing on the levels of reported safety motivation or safety performance at work. One possibility that could explain this relationship may be related to how individuals react to negative feelings stemming for workplace demands. For example, it was argued that NWR was similar to experiencing a negative evaluation of one's job situation while away from work, which would result in lower motivation and worsened performance at work. Research on job attitudes indicates that if employees do not have positive feelings about their job that they will feel less of need to meet job expectations, and may be considering leaving the job (Tett \& Meyer, 1993). However, an alternative hypothesis would be that NWR is an indication that negative events are occurring at work and that the employee should take action to correct this situation. This 
is in line with Mood as Information theory, which suggests that negative affective states signal to an individual that action should be taken to improve their situation (Schwarz \& Clore, 2003). Thus, it is possible that while some employees lower their motivation and performance in reaction to a negative work situation, others work harder and more diligently in an effort to make improvements in the workplace.

Hypothesis 3 stated that safety motivation would mediate the relationship between PWR and safety performance such that PWR would have a positive association with performance. It was stated that PWR during nonwork time would have a positive relationship with performance through increased motivation based on the tenets of Broaden-and-Build theory. The theory suggests that individuals who experience positive emotional states may enjoy improved psychological functioning in their life, including enhanced motivational states. While it was argued that PWR would be positively associated with both types of performance — compliance and participation - the results suggested this was only true for participation. Safety participation motivation mediated the relationship between PWR and safety participation, but this relationship was not significant for compliance and compliance motivation. Therefore, Hypothesis 3 received partial support.

PWR displayed moderate bivariate relationships with safety participation $(r=.24$ for motivation, $r=.25$ for performance), but had only weak correlations with compliance ( $r=.06$ for motivation, $r=.10$ for performance). This aligns with past research on PWR from the recovery from work stress literature, in which a few studies have found that 
PWR appears to be related to volitional performance outcomes, such as contextual performance or OCB's (Binnewies et al., 2009b; Fritz \& Sonnentag, 2005; Sonnentag \& Grant, 2012). These findings lend support to an existing hypothesis in the literature that task performance and contextual performance may have different antecedents from one another. This may additionally be true for safety compliance and safety participation. For example, Inness et al. (2010) found that transformational leadership was a significant predictor of safety participation, but was unrelated to safety compliance. Such findings suggest that while employees may be motivated to fulfill their obligatory safety duties and leadership or individual experiences will not change this, these factors are related to the extra effort or the completion of optional safety tasks.

Range restriction for safety outcomes. A consideration when analyzing these results is whether there was adequate variability in the dependent variables (safety motivation, safety performance) to find significant effects in the model if such relationships truly exist. One concern with asking employees in a dangerous profession about safety is that there is the strong potential for response distortion, such that participants may tend to over-report their motivation and performance (or, safety climate perceptions and performance may naturally be high when safety hazards are high). This may be associated with the notion that admitting safety is not important to you might be met with ire from coworkers. Even though the survey responses were either anonymous or confidential, participants still may not be willing to answer questions honestly. This phenomenon may result in range restriction-specifically, a ceiling effect in which participants tend to report higher agreement with positively worded survey items - in the 
safety indicators, which may consequently restrict the variance of the variable and restrict the probability of uncovering statistically significant bivariate relationships. In the current study, this concern may have been more significant for safety compliance rather than safety participation. The means for safety compliance motivation (4.42) and safety compliance (4.43) were much higher than the means for safety participation motivation (3.67) and safety participation (3.60). Additionally, there was less variance in the safety compliance measures ( $S D=.77$ motivation, .72 performance) than for the safety participation measures $(S D=.89$ motivation, 1.04) performance. While no conclusive interpretations can be made, there appears to be a potential ceiling effect and restriction in variance for the self-reported safety compliance measures.

\section{Summary of Findings: Mediation}

Hypotheses 4-6 proposed a series of moderated regressions in which employee perceptions of safety climate would moderate the relationship between cognitive nonwork recovery experiences and safety motivation. Perceptions of safety climate were predicted to act as a moderator between individual recovery and safety motivation at work based on the idea that safety is predicted by a variety of factors, and it is unlikely that a single factor will consistently have a large effect on safety. For example, the nature of accidents is multifaceted, such that a single instance could be blamed on faulty work conditions, a fatigued worker, a poorly designed system, or unlucky circumstances, or even a combination of some or all of these factors. Therefore, it was specifically proposed that motivation would be observed at the highest levels under conditions of 
high perceptions of safety climate and either high psychological detachment (H4), low NWR (H5), and high PWR (H6). However, none of the proposed interactions were found to have significant associations with either type of safety motivation. In addition, these analyses were conducted using safety performance as the dependent variable, but similarly none of the interactions were significantly related to safety performance. Thus, no support was found for Hypotheses 4-6.

Several scholars have emphasized the importance of supervisor-driven safety climate in the workplace, and findings from empirical studies have supported this hypothesis (e.g., Beus et al., 2010; Christian et al., 2009). Specifically, safety climate has additionally been observed as moderating the relationship between individual-level factors (i.e., psychological empowerment) and safety performance (i.e., Ford \& Tetrick, 2011). However, a similar moderated relationship received no empirical support in the current study. It does appear that safety climate does have a strong association with safety motivation and safety performance, though, as evidenced by its moderate bivariate relationship with safety motivation ( $r=.22$ for compliance, $r=.41$ for participation) and safety performance ( $r=.17$ for compliance, $r=37$ for participation). This evidence additionally should be taken into account when interpreting the findings of the current study. It is possible that the interaction between cognitive recovery and perceptions of safety climate did not have incremental variance over the direct relationship between perceptions of safety climate and safety, as a substantial portion of the variance in safety was already accounted for by this. 
Interestingly, safety climate was moderately correlated with age $(p=-.24)$ and tenure $(p=-.29)$ in the current study. These results appear to suggest that the longer a CO had been working in corrections they would report lower perceptions of safety climate. While this relationship is not a focal point of the study, it warrants consideration. Several reasons this relationship was found can be offered, but due to the data available they are purely speculative. It might be that COs become more cynical of the support they receive from their superiors as they work in an underfunded and understaffed occupation; or, their lower scores may be reflective of an actual decrease over their career in the safety climate they perceive. Another possibility is that given the unpredictability of the work environment in which a prison riot or attack from an inmate can occur without warning and injure a $\mathrm{CO}$, the perception of safety decreases among COs who have more experience and have observed a higher frequency of these incidents. Finally, as the perceptions of safety climate were assessed by nonsupervisory employees, it may be that employees who are not promoted or are passed over for supervisory roles harbor some ill feelings towards their supervisor or facility, and these negative job attitudes may leak into their assessment of all aspects of their workplace.

\section{Additional Analyses}

To further examine the data several additional analyses were conducted to provide an extended picture of the results of the hypothesis testing and to clarify the general research question posed as to whether cognitive nonwork recovery experiences are related to safety in the workplace 
Burnout. The current study proposed that cognitive recovery from stress away from the workplace would be related to workplace safety. However, a closely related research question is whether the state of being recovered from stress is related to workplace safety. In the current study it is argued that if employees have adequate cognitive resources and the mental bandwidth to focus on safety tasks, then increases in workplace safety would be observed. Similarly, it could be proposed if employees report low levels of subjective exhaustion then this would be associated with greater safety motivation and safety performance. In fact, this would be consistent with a meta-analysis in which the authors found employee burnout to have a negative relationship with safety performance (Nahrgang et al., 2011), and other studies in which exhaustion is linked to occupational injuries (Halbesleben, 2010). However, the results of a set of alternate models did not lend empirical support for this research question in the current data.

First, a model was proposed in which cognitive recovery predicted exhaustion, and exhaustion subsequently predicted safety motivation. This is an extension of the first part of the path model in the current study. According to the effort-recovery model, employees can recover from stress by removing themselves from work-related tasks and allow their load reactions that accumulate as a result of working to subside. The model suggests that once enough time is spent on recovery that employees will feel less of a need to recover from work, and this proposition has been supported by empirical evidence (ten Brummelhuis \& Bakker, 2012). Furthermore, employees that are less exhausted (and, likely, full of energy) may have greater resources to devote to safety at work. However, the path models that included exhaustion fit the data poorly, and 
therefore were not retained for further interpretation. Two similar questions were examined, utilizing exhaustion as either a control variable in the originally proposed path model or as a moderator between cognitive recovery and safety motivation. Since no significant results were found, it was concluded that including exhaustion in the current study did not appear to contribute any additional value to the examination of the data. In other words, in the current study the results indicate that burnout may not be a factor related to workplace safety. However, as this is not consistent with meta-analytic evidence, this finding should be interpreted carefully, as the current study has several limitations (see Potential Limitations section).

Accidents and Injuries. For workplace safety researchers one of the ultimate goals is to determine what factors predict workplace safety incidents so interventions can be designed to mitigate these factors. This study examined safety performance, which is a proximal antecedent to safety incidents (Griffin \& Neal, 2000). However, the findings from several meta-analyses have shed light on the fact that this relationship may not in fact exist. For example, Nahrgang et al. (2011) found that safety compliance did not have a significant association with a composite measure of accidents and injuries. Previous studies found that while the relationship exists the magnitude may be small (e.g., $\rho=-.06$ - .09; Clarke, 2006). Therefore, while the hypotheses for the current study did not include accidents and injuries as dependent variables, the relationship between safety performance and accidents and injuries was still analyzed to examine the criterion validity of the safety performance measures. 
The results of the Poisson regressions indicated that safety performance in the current study was not significantly associated with self-reported major injuries or selfreported worker's compensation claims. Two points should be made in regards to these findings. First, as discussed in the following section, the sample size for this study was possibly not adequate to detect significant effects between some variables. This may be especially salient for major injuries and worker's compensation claims, both of which had low base rates and therefore reduced variability. However, the Poisson regression should have provided an adequate analysis strategy to account for this. Second, if safety performance is truly unrelated to accidents and injuries then the safety performance measures may be suffering from criterion deficiency in the current study (Austin \& Villanova, 1992). In other words, if safety performance theoretically precedes actual workplace safety incidents but this relationship is not observed in the data, then the safety performance measures are not capturing all aspects or behaviors of actual workplace safety performance. While these measures were validated and used in multiple previous studies they may not completely capture the construct of safety performance in the occupation of corrections. This point, though speculative, may be a reason that no significant relationship exists between safety performance and accidents and injuries in the current study.

Reverse Causal Model: Can Safety Predict Recovery? When a path model is proposed and then analyzed using cross-sectional data, there is question as to whether the proposed relationships could be reversed. Specifically, in the current study it could be proposed that safety is an antecedent to cognitive recovery experiences. It is possible that 
if an employee performs their safety duties adequately and contributes to a safe workplace, then they are able to go home and recover from work with a clear mind. Additionally, in this example, they may simply be working a job where fewer safety incidents occur, possibly as a result of their contributions to workplace safety. Previous studies have indicated that being engaged and energized at work may predict cognitive recovery (Daniel \& Sonnentag, 2014; Sonnentag et al., 2014), and therefore, there is reason to test this proposition in this study. To examine this research question, a series of OLS regression analyses were conducted between cognitive recovery experiences and safety. Furthermore, in an attempt to overcome the cross-sectional limitation of the data, data from 4 months (Time 2) following the original survey (Time 1) were utilized $(N=$ $57)$.

The results mirrored the findings from the hypotheses testing such that the only cognitive recovery experience to be significantly related to safety was PWR, and furthermore that PWR was only associated with the participation aspect of safety. Interestingly, a pattern emerged in which PWR predicted safety, but safety predicted PWR as well. When PWR from Time 1 was entered as a predictor in the regression equation, it significantly predicted safety participation motivation at Time $1(\beta=.23, p<$ $.01)$ and at Time $2(\beta=.30, p<.05)$, and additionally predicted safety participation at Time $1(\beta=.25, p<.01)$ but not at Time $2(\beta=.25, p=.06)$, although the result approached significance. When safety participation motivation from Time 1 was entered as a predictor to examine the reverse causal pathways, it significantly predicted PWR at 
Time $1(\beta=.24, p<.01)$ and at Time $2(\beta=.38, p<.01)$. Finally, safety participation at Time 1 predicted PWR at Time $2(\beta=.25, p<.01)$ and at Time $1(\beta=.37, p<.01)$.

Overall, these findings support the possibility that PWR and safety at work are related to one another in a reciprocal manner. While the results from the path model in the current study support the recovery to safety path, the results from the additional analyses suggest that individual safety participation may be related to an increase in PWR. One explanation may be that an employee who engages in safety participation efforts at work may receive praise from coworkers or supervisors, thus leading the employee to reflect positively on the work they have done and their overall job situation. Or, engaging in these volitional performance tasks may increase an employee's authentic feelings of self-worth or efficacy beliefs tied to their job, and as a result the employee experiences positive thoughts about their work situation. These results are consistent with a recent study by Daniel and Sonnentag (2014) in which engagement at work was associated with future PWR during nonwork time. These results can be viewed through the lens of Conservation of Resources theory (Hobfoll, 1989) which describes a gain spiral that is experienced when positive experiences in one life domain spur further resource gains in another. In essence, as described in Broaden-and-Build theory, positive events or experiences build on one another in a reciprocal pattern, similar to an upward spiral in which one's personal resources grow as they have positive experiences in workplace, and vice versa.

\section{Potential Limitations}


The findings from the current study should be interpreted while considering some potential limitations associated with the study. For example, due to sample size restrictions and missing responses to the item asking employees to identify their primary supervisor, I was unable to run my analyses taking into account the nested structure of the data. By not being able to account for variance in employee constructs due to differences in which supervisor they worked under, it is possible that the estimates produced through path modeling have underestimated the true relationships between variables. Ideally, research in organizations should be conducted in such a way that the structure of the workplace is accounted for (Bliese \& Jex, 2002).

The sample size and type of data may be other potential limitations of the current study. The post hoc power analysis that was conducted revealed that the study was underpowered, thus limiting the ability to detect significant effects. Although the overall sample may have been adequate $(N=166)$ to examine some bivariate relationships, the hypotheses in the current study were focused on detecting previously unexamined relationships where it was assumed, based on past literature and theoretical rationale, that such relationships would have small effect sizes. Therefore, to detect significant small effects a larger sample size would likely be needed in future studies. In addition, the data were self-reported by security staff and were cross-sectional (except for some additional analyses using data from 4 months following the initial survey). Same-source data collected at a single time point may lead to common method bias (Podsakoff, MacKenzie, Lee, \& Podsakoff, 2003) and may overestimate true relationships between variables. However, in the current study this would only be a consideration when 
interpreting the results from Hypothesis 3, as none of the other hypotheses were supported.

Another potential limitation of the analytic strategy in particular is that path modeling was used to test several of the hypotheses, as opposed to a full SEM model. While path analysis is arguably a useful tool for examining variables in a sequential arrangement according to theoretical rationale and past literature, it suffers from the same shortcoming of OLS regression. Namely, in utilizing path analysis it is assumed that all variables are measured with no measurement error, while SEM models this error and produces estimates in which this is included (Kline, 2011). However, when I tried to run the model using the full SEM specifications (regression plus measurement model), the model did not converge, which was likely due to the inability to estimate a large number of parameters using the inadequately sized sample.

Finally, one aspect of the current study that should be considered is the appropriateness of using measures to assess safety that were developed for use in occupations with occupational requirements that are different from those faced by COs. While measures of safety have been used in various occupations in the literature, there has been a trend toward developing safety climate scales for specific industries in which the job demands are not fully captured by a general safety climate scale. For example, Zohar, Huang, Lee, and Robertson (2014) developed a scale specifically for use in the long-haul trucking industry. So, while Griffin and Neal's (2000) safety performance measures have been utilized in a variety of occupations, it may be that a measure with 
more specific references to a CO's job duties would be more appropriate when conducting safety research in corrections. Other researchers have created their own safety performance measures (e.g., Synder et al., 2011), and doing so in corrections may be a worthwhile endeavor.

One prominent example is that COs are at far greater risk of an inmate assaulting them regardless of how motivated the $\mathrm{CO}$ is to engage in safety behaviors. This may be an aspect of the CO's job of which employees in most other occupations do not worry about, and dealing with this issue may be an instance of safety performance not assessed through the measures utilized in this study. However, the correlations between whether a $\mathrm{CO}$ had a physical confrontation with an inmate and the accident indicators were small $(r$ $=.01$ for major accidents, $r=.09$ for worker's compensation claims). In the current data it appears there is not a strong link between physical confrontations with inmates and workplace injuries, but this point warrants further investigation in future studies.

Additionally, in occupations such as corrections where safety is an essential, salient job requirement, there may be little variability in reported safety compliance. Specifically, this phenomenon may result in a range restriction in the responses to safety compliance items, thus limiting the ability to detect bivariate relationships. Alternatively, it may be that safety is viewed by COs as being so important it that regardless of how burned out they feel, how many extra shifts they have worked, or how little sleep they have gotten, they pay attention to the compulsory safety duties while at work.

\section{Implications for Future Research}


The findings from the current study leave several questions unanswered that future studies should examine. First, one question that this study did not address is whether the content of work-related thoughts during nonwork time was related to workplace safety. For example, it is possible that having work-related thoughts about safety issues at work may affect an employee's future safety motivation, while thoughts about other aspects of work may be unrelated to safety performance. This is related to the compatibility principle in attitude theory, which has been applied to job attitudes by Harrison and colleagues (2006). Essentially, the principle explains that behaviors will be affected by attitudes only if there is similarity in the content between the attitude and the behavior. In the context of the current study a $\mathrm{CO}$ may have a negative experience with a coworker during a disagreement over switching schedules, causing them to have negative thoughts about work while at home, but as this experience was not related to safety then no change in safety behavior should be expected. This may be especially true for safety compliance, which may be largely a product of organizational rules and occupational requirements (Reason, Parker, Lawton, 1998). Therefore, future studies should assess the content of work-related cognitions during nonwork time to further examine whether the compatibility principle may be used to explain why few significant results were found in the current study.

Second, future studies should utilize a variety of research designs that are appropriate for examining the processes occurring between nonwork recovery experiences and safety at work (and vice versa). Daily diary studies and longitudinal studies with three or more measurement occurrences should be applied to assess how the 
relationship between recovery and safety unfold over time. Studies in which an employee responds to items several times throughout a day and a work week may allow researchers to examine how recovery and safety unfold over the course of a workday and into the evening. For example, Sonnentag and Grant (2012) found that PWR at the immediate conclusion of the work shift predicted positive affective states before bed. In the context of safety, the question is this: Would positive affect be found to be the mediator between recovery and safety motivation? A diary study would be a step toward better understanding these processes on a day-to-day level. Additionally, longitudinal studies over the course of several weeks, months, or years can help to determine the accuracy of the reciprocal relationship between PWR and safety participation. While this relationship was uncovered through additional analysis using a 4-month separation between measurement occasions, it would be sensible to examine this using various time periods between measurement occasions. Furthermore, with a sufficient sample size and at least three assessments the path model proposed in the current study could be tested with temporal separation between measures.

Third, more research is needed to better understand the perception of safety climate in occupations such as corrections. For example, perceptions of safety climate were negatively associated with age and tenure in the current study, indicating that more senior COs perceived a lower safety climate. However, this relationship may be especially difficult to interpret given the measurement of safety climate in the current study. Due to the matrix structure of corrections in which COs have various supervisors of varying ranks, it may be difficult for them to given an accurate rating of the safety 
climate in their facility. Furthermore, their perception of safety climate may be heavily dependent on the post they work. For example, consider the job of the $\mathrm{CO}$ who patrols the outside perimeter of the facility in comparison to a $\mathrm{CO}$ who works alone in a sector with 100 or more inmates. Each employee may report varying degrees of safety climate due to differences between the characteristics of their post.

Finally, the current study focused on three nonwork recovery experiences that had a strong cognitive component to them. However, three of Sonnentag and Fritz's (2007) original four experiences were not assessed here. Relaxation, mastery, and control have been assessed in various studies in the nonwork recovery from stress literature but were unexamined in this study. It was tested whether the cognitive aspects of psychological detachment, NWR, and PWR would be most related to the cognitive resources required by safety-related motivation and tasks. However, it is possible that other types of recovery experiences may be important for workplace safety, and future studies should include these in their analyses. This could help further the more general pursuit of understanding how occupational stress is related to safety. For example, Clarke (2012) found that different types of stressors (hindrance versus challenge) had different relationships with safety. A parallel in the recovery from stress literature is that other types of recovery experiences - such as relaxation (low-effort activities) and mastery (challenging activities that build self-efficacy or other personal resources)—may be associated with processes other than cognitive or self-regulatory pathways, discussed in this study, that are related to safety. 


\section{Implications for Practice}

The current study has certain implications for applying the findings to the workplace. First, if the link between PWR and safety participation can be replicated in future studies it would suggest that organizations in general should acknowledge that safety participation can be associated with how an employee reflects on their job outside of the workplace. In fact, the existence of PWR and safety participation may be signs that employees are enjoying similar positive experiences while in the workplace. Some reasons that employees may experience PWR or engage in participatory safety behaviors could be high levels of social support from coworkers, a strong experience of meaning or purpose in their work, high levels of goal achievement, perceived support from their organization, and a high-quality exchange relationship with their direct supervisor. In corrections specifically, the occupation is often characterized as a purposeful job that contributes positively to society by doing a service for the public and by helping inmates change their behavior to avoid recidivism. However, correctional facilities are currently suffering from low funding in the U.S., and COs tend to get less attention and praise than other law enforcement agencies. Therefore, it may be especially important in this occupation to have positive influences at work, because without these resources COs may not have positive experiences at work. ${ }^{2}$ In this study, PWR appeared to have a positive

\footnotetext{
${ }^{2}$ For visual representations of the levels of the study variables, see Figure 2 through
} Figure 9. 
skew when the individual responses were put in graphical form, indicating that most COs tended to report low levels of PWR.

Given the reciprocal relationship discovered between PWR and safety participation, organizations should consider ways of contributing to the overall positive experience of their employees, and avoid focusing solely on performance and work requirements. This may be especially difficult in occupations in which safety is of the highest importance. However, organizational leaders should still examine whether there are ways to recognize an employee's extra efforts in such a way that does not distract from workplace safety but also may leave the employee feeling positive about their job. For example, in corrections it may be likely that management is always looking for ways to reduce safety-related incidents by getting more COs involved in voluntary safety committees. However, they must understand that since employees may be more likely to volunteer if they have a positive perception of their job, they should consider these participation efforts as a reciprocal relationship in which COs are somehow compensated for their effort. In general, if an organization would like to increase employee participation in other types of safety participation it should be noted that the organization might need to ensure the employee is having a positive experience at work first. By showing that the organization cares for the employee, employees may feel a sense of increased perceived organizational support (Eisenberger et al., 1986) and will be more willing to participate in non-obligatory safety activities. 
Second, organizations may acknowledge that especially in occupations where safety is salient, and injuries, accidents, or even near misses occur frequently, employees will not feel positive about their job each day they go home. However, if there is not already a debriefing policy in place such that employees are given the opportunity to express their negative perception of a safety incident at work before going home, this may be a worthwhile endeavor for an organization. If negative feelings can be expressed at work, it may be less likely that an employee will express these feelings once they return home (as their concerns have been addressed), and more likely that they will experience positive feelings toward their job.

Finally, in the current study perceptions of safety climate were assessed by both employees and supervisors. There was an observable difference in the mean levels between these variables. The mean for employee perceptions of safety climate was 2.39 $(S D=.95)$ and the mean for supervisor perceptions of safety climate was $3.68(S D=.89)$. While this is merely a descriptive statistic and not necessarily a finding from the study, it does point to one area in which an organization may focus their efforts to improve safety. The importance of safety communication in organizations in a safety-sensitive occupation is crucial for maintaining employee safety, and part of this communication is the degree of agreement employees and supervisors have in regards to the current safety climate. However, there is often a discrepancy between management, supervisors, and employees in how important they perceive safety to be in their organization (Kearny, Rodriguez, Quandt, Arcury, \& Accury, 2015). Organizations may want to consider enacting policies in which employees are able to provide feedback (such as a 360-degree performance 
review) to supervisors so they can receive feedback on the quality of the safety climate they are contributing to. This could lead to further detailed discussions of the safety needs of the employees, which they may feel are being unfulfilled, thus leading to this gap between employee and supervisor perceptions of safety climate.

\section{Conclusion}

The current study examined the relationship between cognitive nonwork recovery experiences and safety motivation and safety performance at work. A mediation was tested using path analysis to determine whether safety motivation mediated the relationship between cognitive recovery and safety performance. The results indicated only one mediation of six was significant; specifically, safety participation motivation mediated the relationship between PWR and safety participation. This finding is noteworthy as it is the first indication that nonwork recovery experiences may be linked to employee safety motivation, and subsequently employee safety performance, at work. As this was not found for safety compliance, the results suggest that this relationship may only be true for volitional motivation and performance, such that having positive thoughts about work during nonwork time may be related to motivation for nonessential work tasks (i.e., participating in voluntary safety committees). Furthermore, contrary to past findings on safety climate, perceptions of safety climate had no effect on the relationship between cognitive recovery and safety motivation. However, the low estimated power to detect a significant effect in this study should be considered in light of this finding. In summary, this study suggests that while nonwork experiences may in 
some manner be related to safety motivation and safety performance, more research is needed to elucidate in what circumstances this is true and how this process unfolds over time. 
Table 1

Summary of Demographics of Study Participants

\begin{tabular}{ll}
\hline Demographic & Mean/Standard Deviation or Percentage Reported \\
\hline Age & $\mathrm{M}=45.43(\mathrm{SD})=11.50$ \\
Tenure (as a CO) & $\mathrm{M}=12.04(\mathrm{SD})=8.22$ \\
Tenure (at facility) & $\mathrm{M}=9.76(\mathrm{SD})=6.99$ \\
Hours worked per week & $\mathrm{M}=43.18(\mathrm{SD})=7.90$ \\
Gender & $81 \%$ male; $19 \%$ female \\
Marital Status & $78 \%$ married; $10 \%$ divorced; $12 \%$ other \\
Ethnicity & $85 \%$ White; $7 \%$ Hispanic/Latino \\
Rank & $65 \%$ CO; $8 \%$ Corporal; $13 \%$ Sergeant; $7 \%$ Lieutenant; \\
& $7 \%$ Captain \\
Security level & $91 \%$ medium; $5 \%$ maximum, 4\% minimum \\
Shift & $44 \%$ day; 32\% swing; 25\% night \\
Veteran & $25 \%$ Veterans of U.S. Armed Forces \\
\hline
\end{tabular}




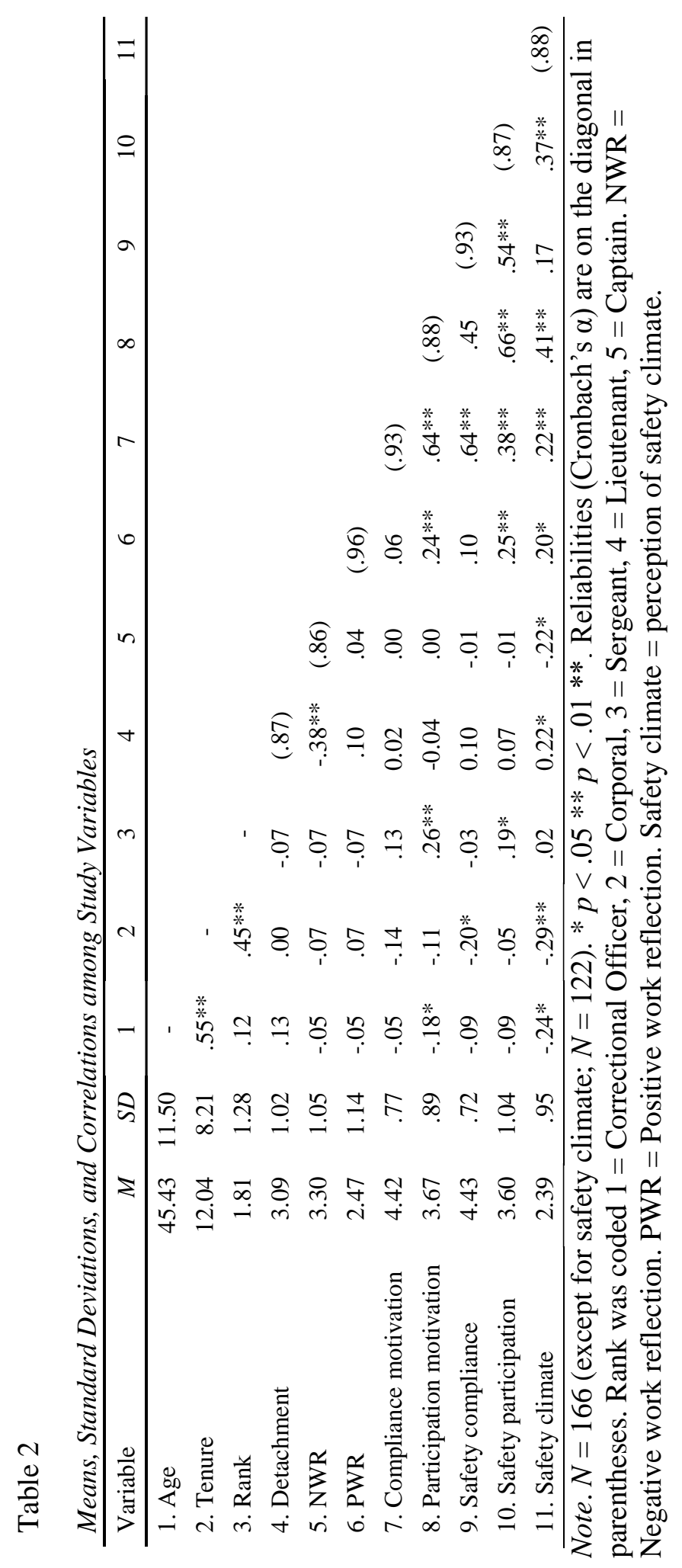




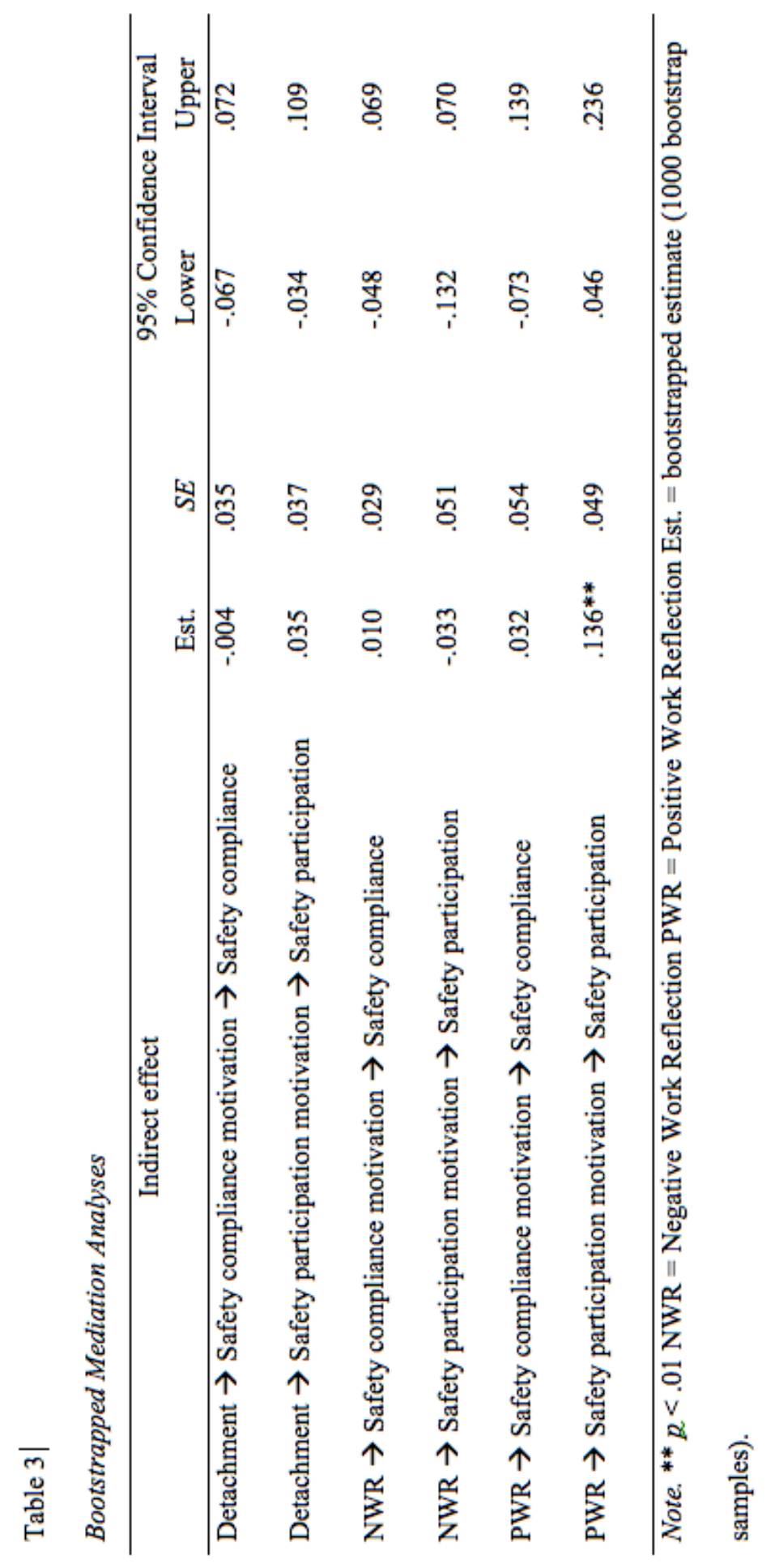




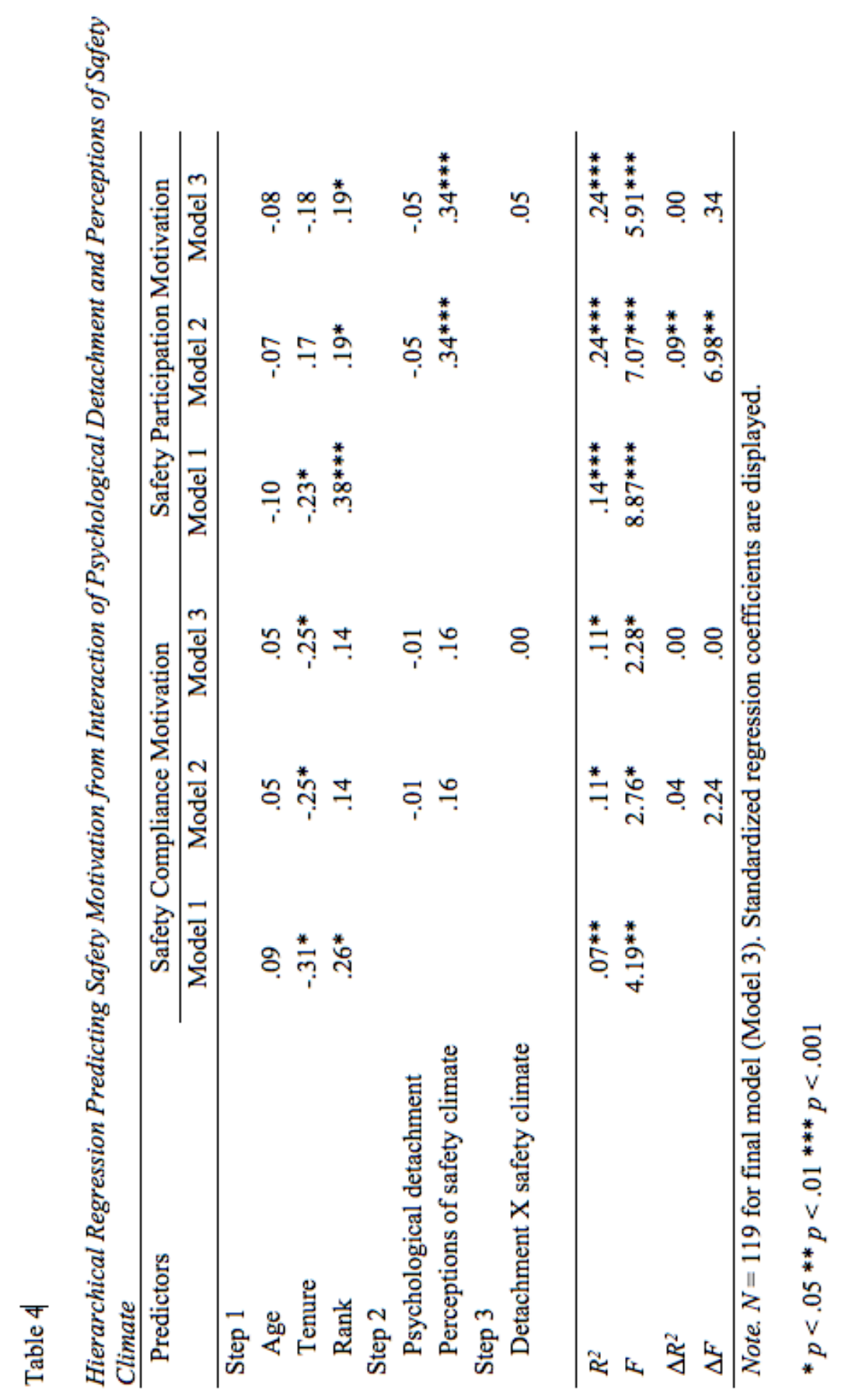




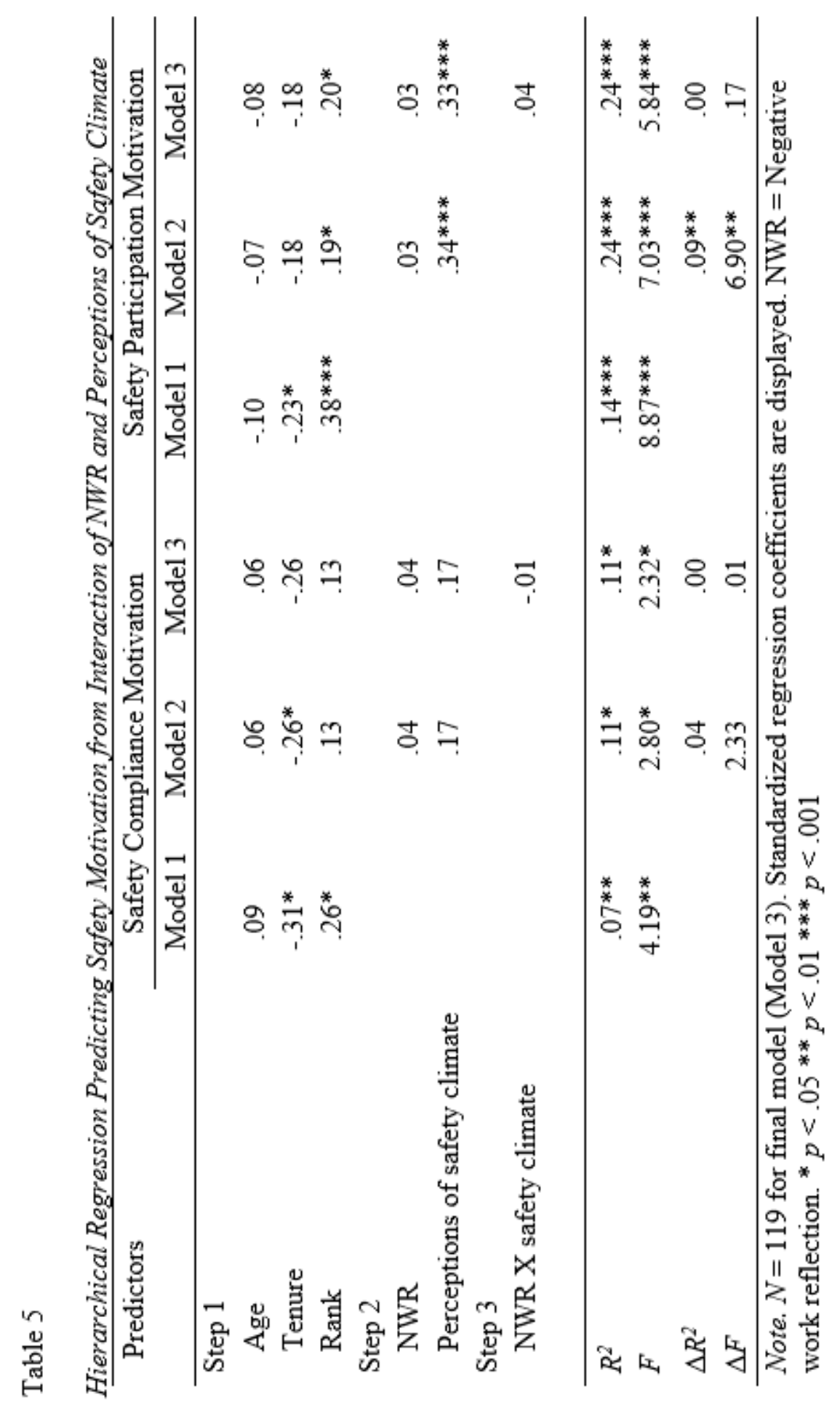




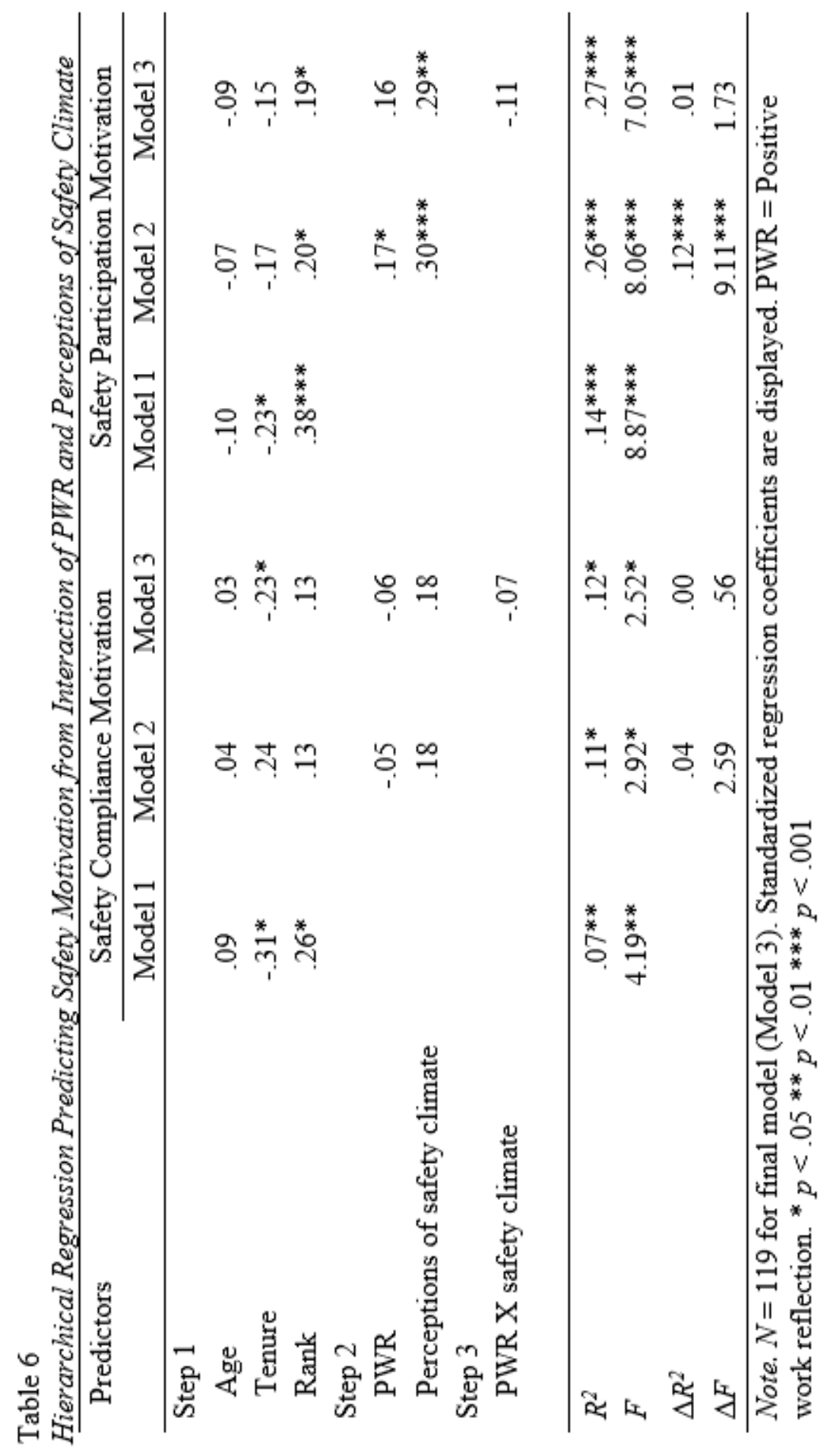




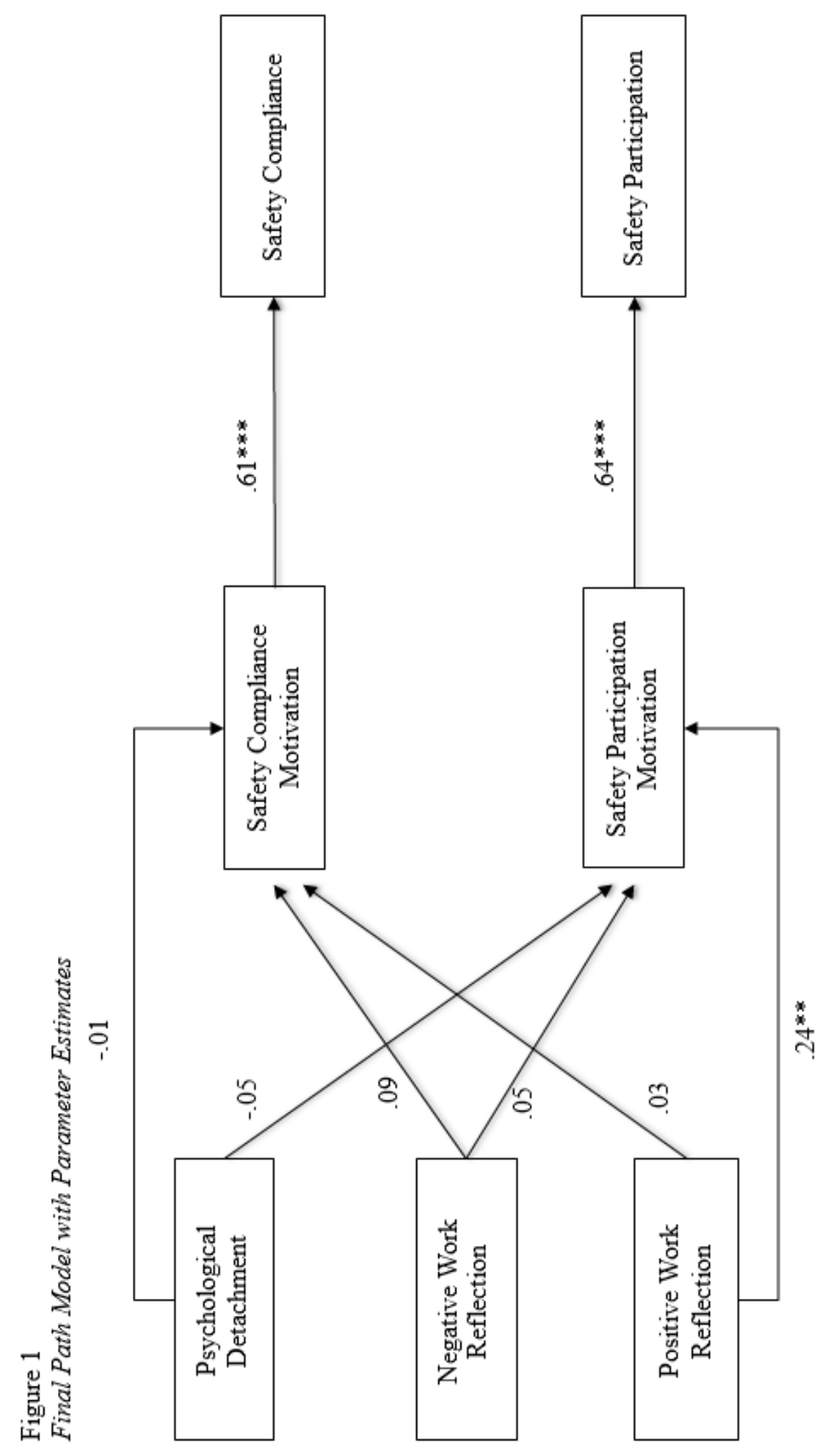


Figure 2

Distribution of Mean Scores for Psychological Detachment

\section{Psychological Detachment}

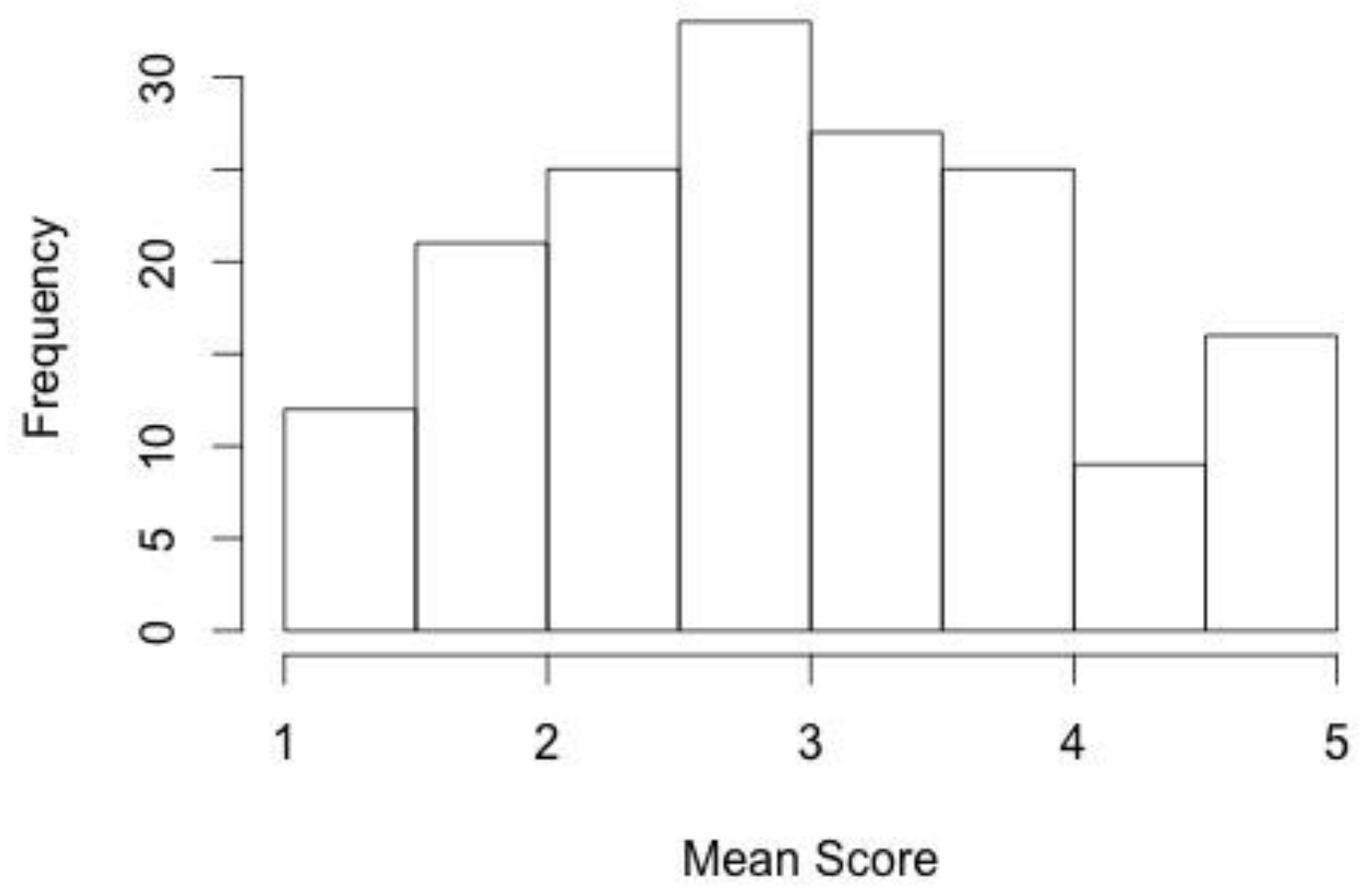


Figure 3

Distribution of Mean Scores for Negative Work Reflection

\section{Negative Work Reflection}

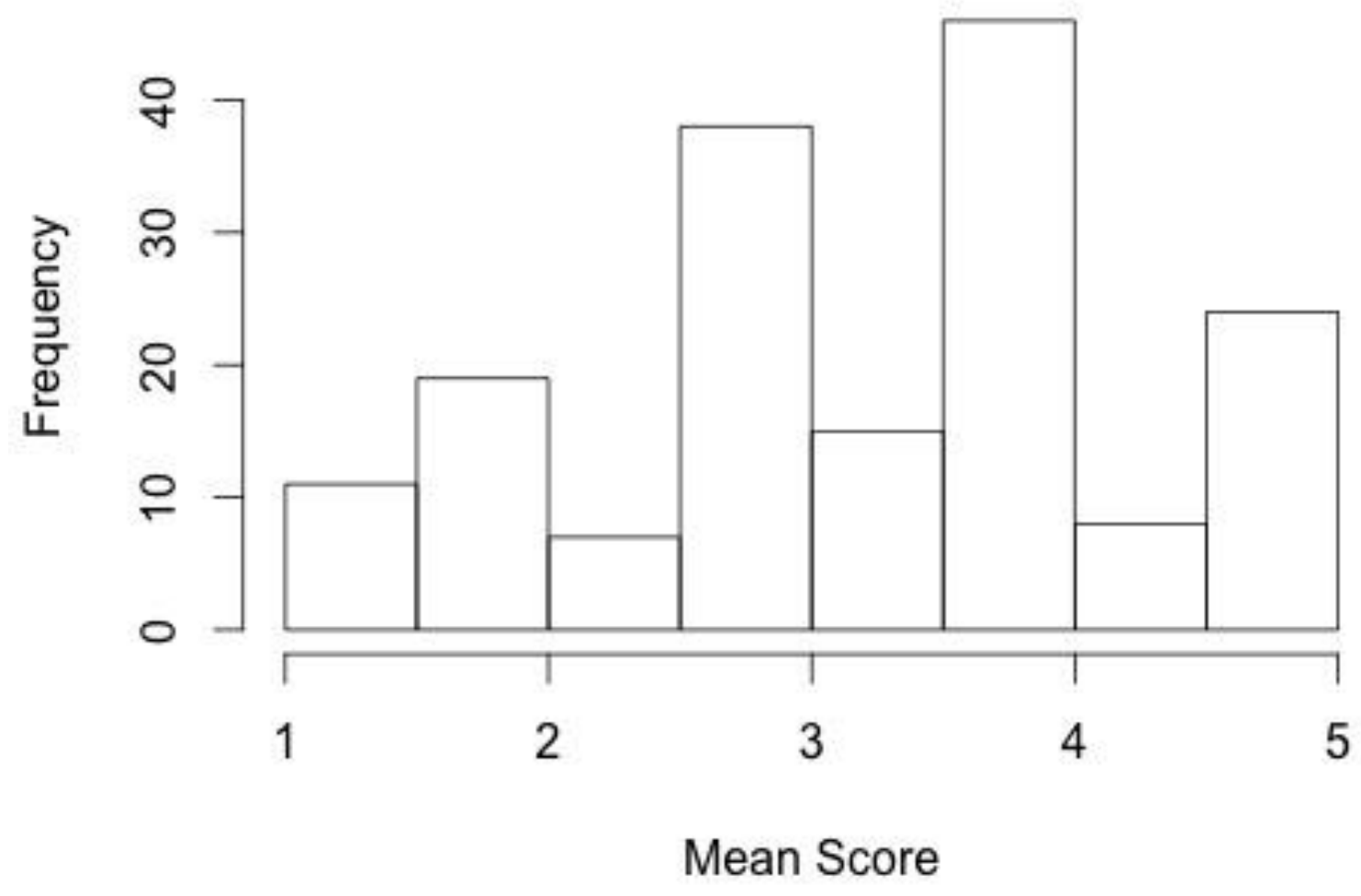


Figure 4

Distribution of Mean Scores for Positive Work Reflection

\section{Positive Work Reflection}

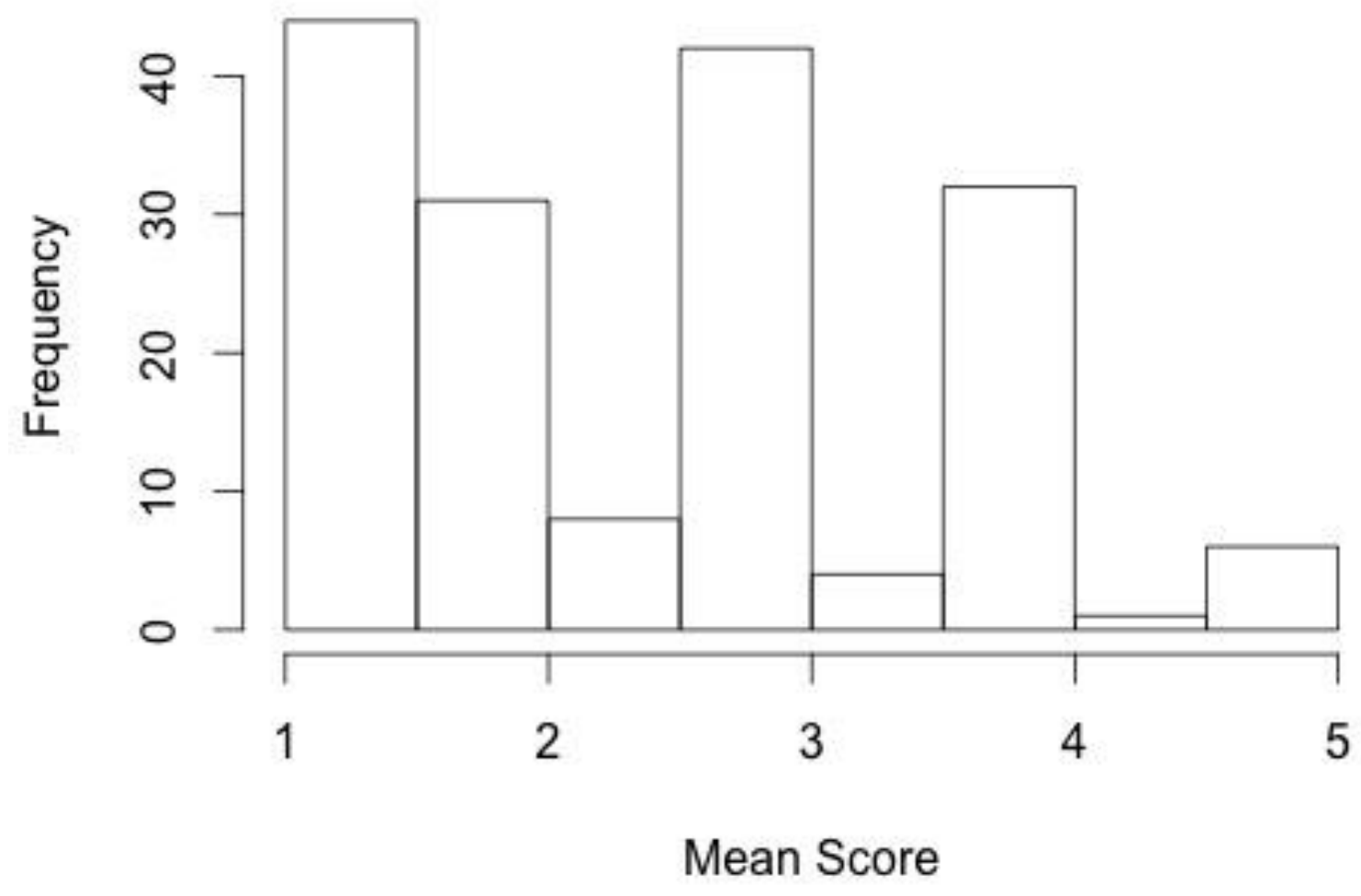


Figure 5

Distribution of Mean Scores for Safety Compliance Motivation

\section{Compliance Motivation}

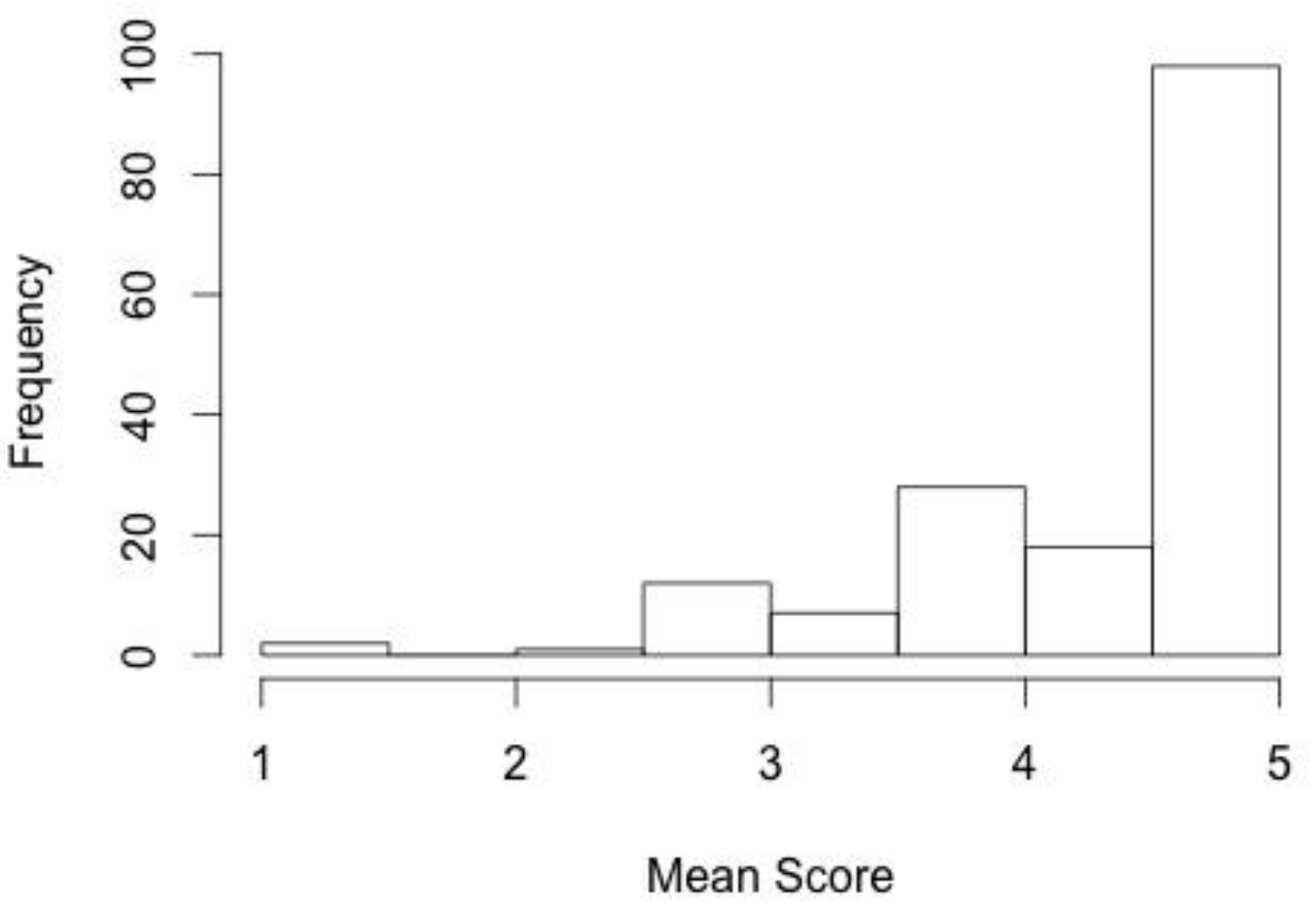


Figure 6

Distribution of Mean Scores for Safety Compliance

\section{Compliance}

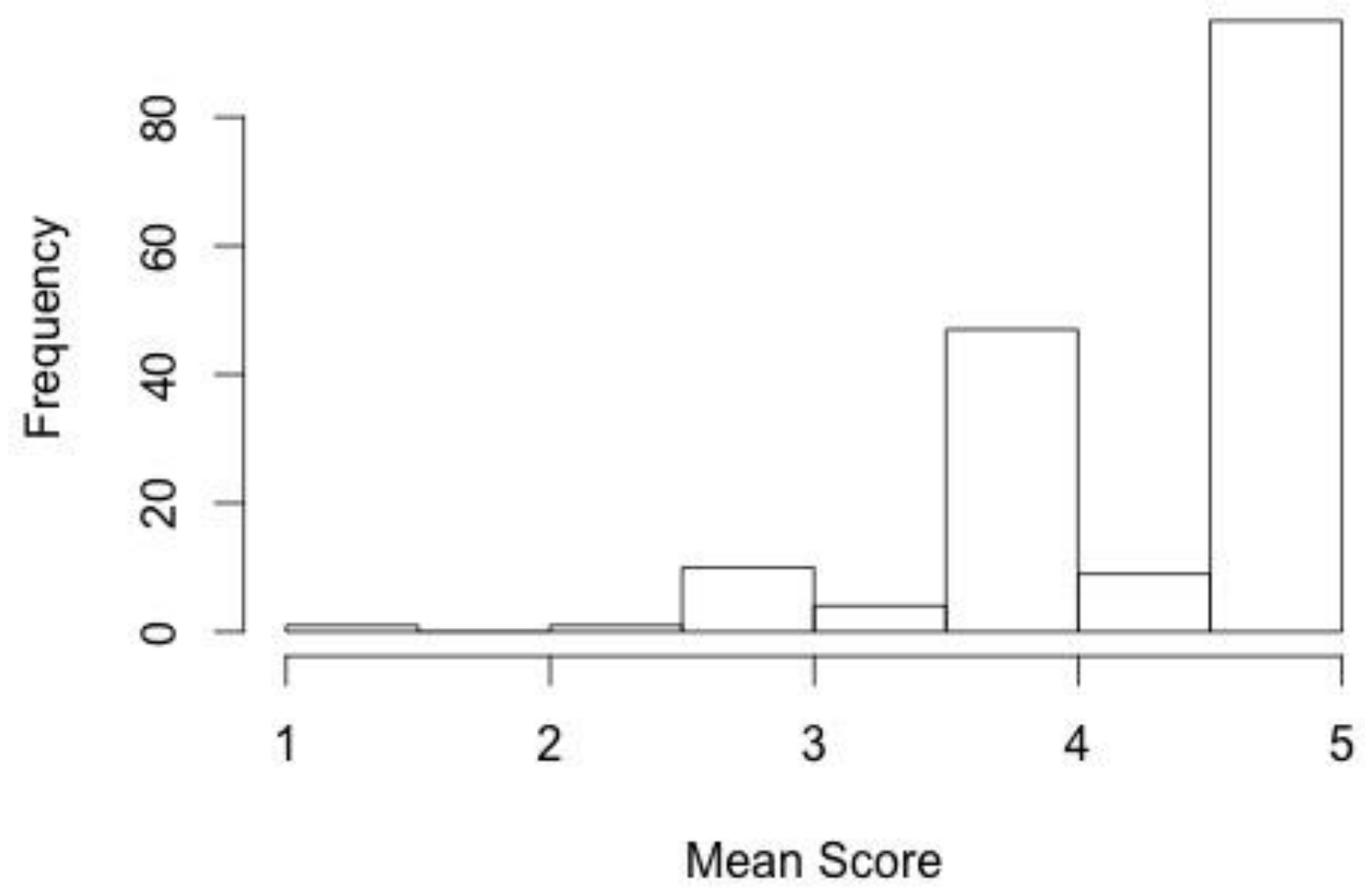


Figure 7

Distribution of Mean Scores for Safety Participation Motivation

\section{Participation Motivation}

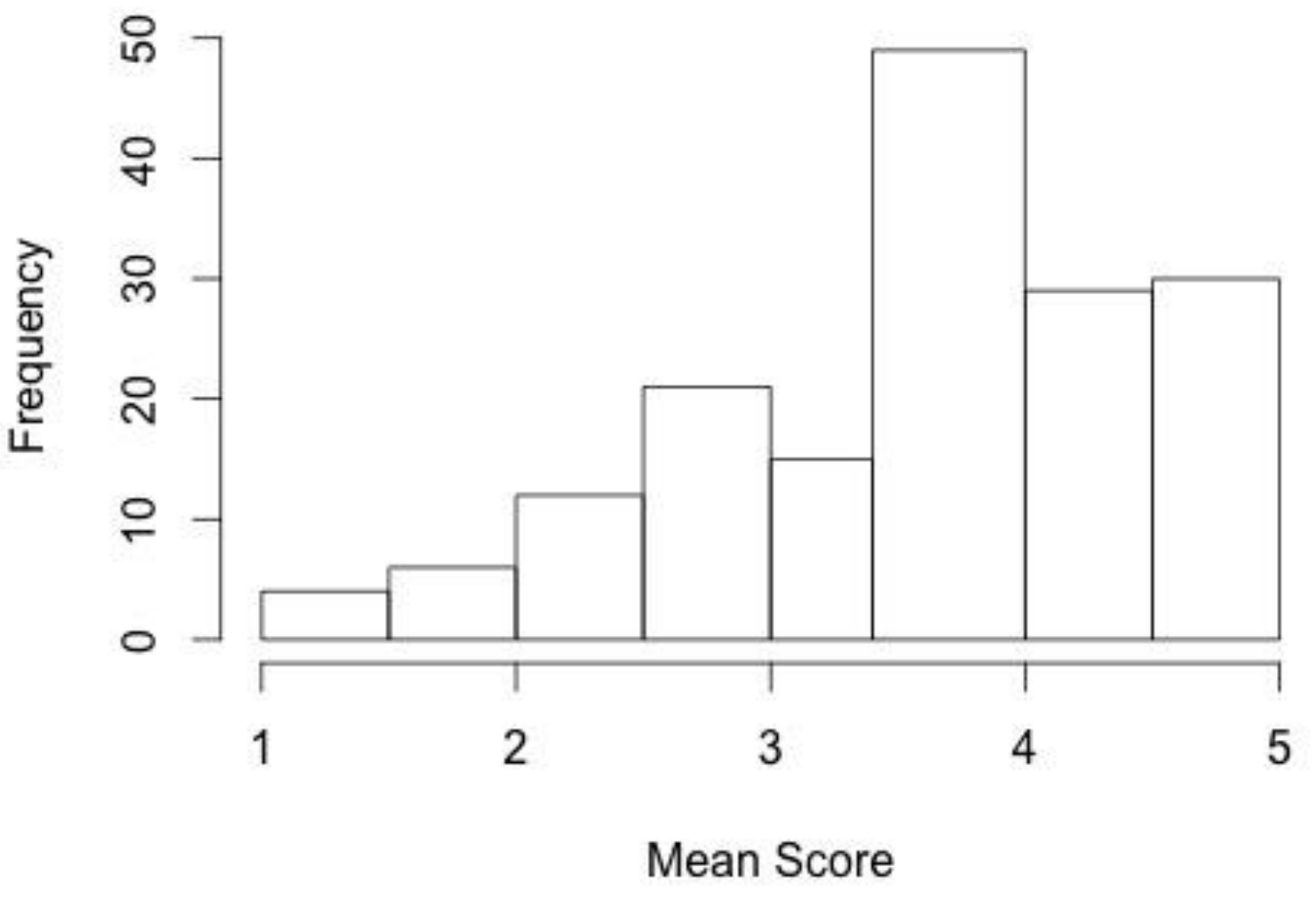


Figure 8

Distribution of Mean Scores for Safety Participation

\section{Participation}

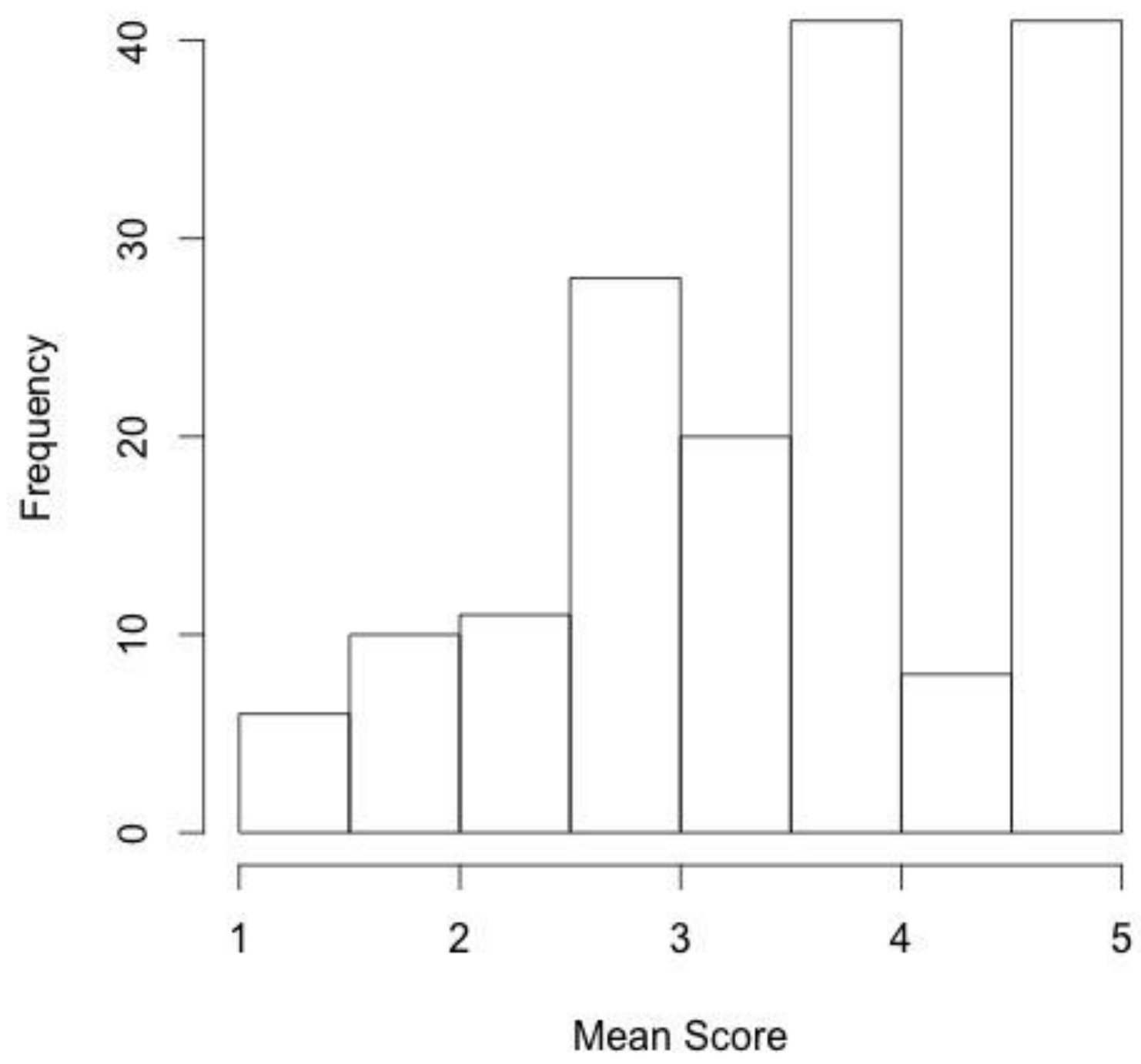


Figure 9

Distribution of Mean Scores for Perceptions of Safety Climate

\section{Perceptions of Safety Climate}

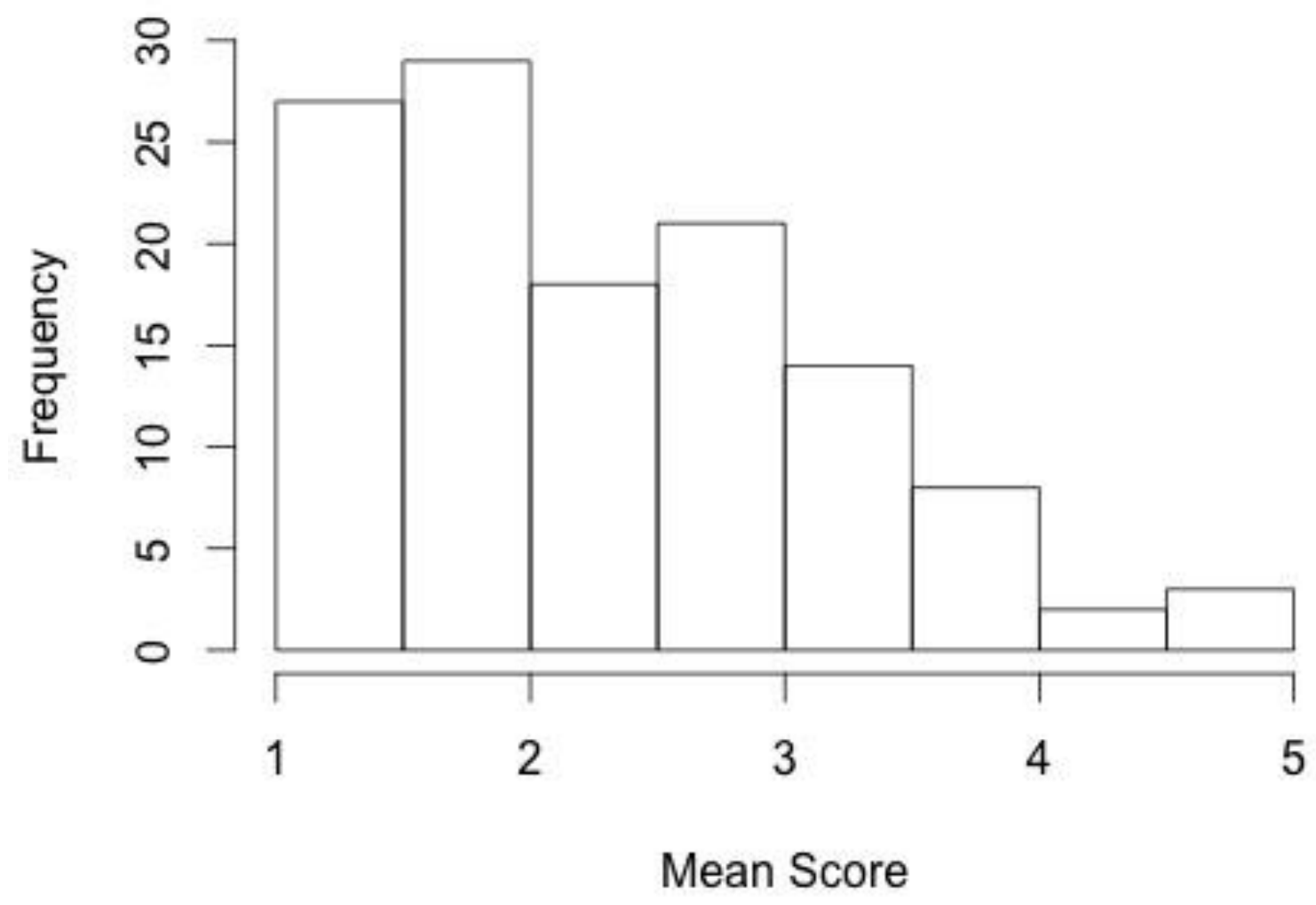




\section{References}

Armstrong, G.S., \& Griffin, M.L. Does the job matter? Comparing correlates of stress among treatment and correctional staff in prisons. Journal of Criminal Justice, 32, 577-592. doi: 10.1016/j.jcrimjus.2004.08.007

Austin, J.T., \& Villanova, P. (1992). The criterion problem: 1917-1992. Journal of Applied Psychology, 77, 836-874.

Bandura, A. (1997). Self-efficacy: The exercise of control. New York: Freeman.

Barsade, S.G., \& Gibson, D.E. (2007). Why does affect matter in organizations? The Academy of Management Perspectives, 21, 36-59.

Baumeister, R.E., Bratslavsky, E., Finkenauer, C., \& Vohs, K.D. (2001). Bad is stronger than good. Review of General Psychology, 5, 323-370. doi: 10.1037/10892680.5.4.323

Baumeister, R.E., Bratslavsky, E., Muraven, M., \& Tice, D.M. (1998). Ego depletion: Is the active self a limited resource? Journal of Personality and Social Psychology, 74, 1252-1265. doi: 10.1037/0022-3514.74.5.1252

Baumeister, R.F., Vohs, K.D., \& Tice, D.M. (2007). The strength model of self-control. Current Directions in Psychological Science, 16, 351-355. doi: 10.1111/j.14678721.2007.00534.x

Bernerth, J.B., \& Aguinis, H. (in press). A critical review and best-practice recommendations for control variable usage. Personnel Psychology. 
Beus, J.M., Dhanani, L.Y., \& McCord, M.A. (2015). A meta-analysis of personality and workplace safety: Addressing unanswered questions. Journal of Applied Psychology, 100, 481-498. doi: 10.1037/a0037916

Beus, J.M., Payne, S.C., Bergman, M.E., \& Arthur Jr., W. (2010). Safety climate and injuries: An examination of theoretical and empirical relationships. Journal of Applied Psychology, 95, 713-727. doi: 10.1037/a0019164

Billings, R.S., \& Wroten, S.P. (1978). Use of path analysis in Industrial/Organizational psychology: Criticisms and suggestions. Journal of Applied Psychology, 63, 677688. doi: 10.1037/0021-9010.63.6.677

Binnewies, C., Sonnentag, S., \& Mojza, E.J. (2009a). Daily performance at work: Feeling recovered in the morning as a predictor of day-level job performance. Journal of Organizational Behavior, 30, 67-93. doi: 10.1002/job.541

Binnewies, C., Sonnentag, S., \& Mojza, E.J. (2009b). Feeling recovered and thinking about the good sides of one's work. Journal of Occupational Health Psychology, 14, 243-256. doi: 10.1037/a0014933

Binnewies, C., Sonnentag, S., \& Mojza, E.J. (2010). Recovery during the weekend and fluctuations in weekly job performance: A week-level study examining intraindividual relationships. Journal of Occupational and Organizational Psychology, 83, 419-441. doi: 10.1348/096317909X418049

Bliese, P.D., \& Jex, S.M. (2002). Incorporating a mulitilevel perspective into occupational stress research: Theoretical, methodological, and practical 
implications. Journal of Occupational Health Psychology, 7, 265-276. doi: 10.1037/1076-8998.7.3.265

Borman, W.C., \& Motowidlo, S.J. (1997). Task performance and contextual performance: The meaning for personnel selection research. Human Performance, 10, 99-109. doi: 10.1207/s15327043hup1002_3

Bureau of Labor Statistics. (2012). Nonfatal occupational injuries and illnesses requiring days away from work, 2012.

Bureau of Labor Statistics. (2013). Workplace Injury and Illness Summary.

Burke, M.J., Salvador, R.O., Smith-Crowe, K., Chan-Serafin, S., Smith, A.S., \& Sonesh, S. (2011). The dread factor: How hazards and safety training influence learning and performance. Journal of Applied Psychology, 96, 46-70. doi: $10.1037 / \mathrm{a} 0021838$

Burke, M.J., Sarpy, S.A., Tesluk, P.E., \& Smith-Crowe, K. (2002). General safety performance: A test of a grounded theoretical model. Personnel Psychology, 55, 429-457. doi: 10.1111/j.1744-6570.2002.tb00116.x

Campbell, J.P., McCloy, R.A., Oppler, S.H., \& Sager, C.E. (1993). A theory of performance. In N. Schmitt \& W. C. Borman (Eds.), Personnel selections in organizations (pp. 35-70). San Francisco, CA: Jossey-Bass.

Cheng, B.H., \& McCarthy, J.M. (2013). Managing work, family, and school roles: Disengagement strategies can help and hinder. Journal of Occupational Health Psychology, 18, 241-251. doi: 10.1037/a0032507 
Christian, M.S., Bradley, J.C., Wallace, J.C., \& Burke, M.J. (2009). Workplace safety: A meta-analysis of the roles of person and situation factors. Journal of Applied Psychology, 94, 1103-1127. doi: 10.1037/a0016172

Clarke, S. (2006). The relationship between safety climate and safety performance: A meta-analytic review. Journal of Occupational Health Psychology, 11, 315-327. doi: $10.1037 / 1076-8998.11 .4 .315$

Clarke, S. (2012). The Effect of Challenge and Hindrance Stressors on Safety Behavior and Safety Outcomes: A Meta-Analysis. Journal of Occupational Health Psychology, 17, 387-397. doi: 10.1037/a0029817

Clarke, S. (2013). Safety leadership: A meta-analytic review of transformational and transactional leadership styles as antecedents of safety behaviours. Journal of Occupational and Organizational Psychology, 86, 22-49. doi: 10.1111/j.20448325.2012.02064.x

Cullen, J.C., \& Hammer, L.B. (2007). Developing and testing a theoretical model linking work-family conflict to employee safety. Journal of Occupational Health Psychology, 12, 266-278. doi: 10.1037/1076-8998.12.3.266

Dai, H., Milkman, K.L., Hofmann, D.A., \& Saats, B.R. (2015). The impact of time at work and time off from work on rule compliance: The case of hand hygiene in health care. Journal of Applied Psychology, 100, 846-862. doi: 10.1037/a0038067

Daniel, S. \& Sonnentag, S. (2014) Work to non-work enrichment: The mediating roles of positive affect and positive work reflection, Work \& Stress, 28, 49-66. doi: $10.1080 / 02678373.2013 .872706$ 
Demerouti, E., Bakker, A.B., Nachreiner, F., \& Schaufeli, W.B. (2001). The job demands-resources model of burnout. Journal of Applied Psychology, 86, 499512. doi: 10.1303//0021-9010.86.3.499

Demerouti, E., Bakker, A.B., Vardakou, I., \& Kantas, A. (2003). European Journal of Psychological Assessment, 19, 12-23. doi: 10.1027//1015-5759.19.1.12

Demerouti, E., Mostert, K., \& Bakker, A.B. (2010). Burnout and work engagement: A thorough investigation of the independency of both constructs. Journal of Occupational Health Psychology, 15, 209-222. doi: 10.1037/a0019408

Demsky, C.A., Ellis, A.M., \& Fritz, C. (2014). Shrugging it off: Does psychological detachment from work mediate the relationship between workplace aggression and work-family conflict? Journal of Occupational Health Psychology, 19, 195205. doi: $10.1037 / \mathrm{a} 0035448$

Diefendorff, J.M., \& Chandler, M.M. (2011). Motivating employees. In S. Zedeck (Ed.), APA handbook of industrial and organizational psychology, Vol 3: Maintaining, expanding, and contracting the organization (Vol. viii, pp. 960). Washington, DC: American Psychological Association.

Edwards, J.R., \& Rothbard, N.P. (2000). Mechanisms linking work and family: Clarifying the relationship between work and family constructs. Academy of Management Review, 25, 178-199. doi: 10.5465/AMR.2000.2791609

Eisenberger, R., Huntington, R., Hutchison, S., \& Sowa, D. (1986). Perceived organizational support. Journal of Applied Psychology, 71, 500-507. 
Etzion, D., Eden, D., \& Lapidot, Y. (1998). Relief from job stressors and burnout: Reserve service as a respite. Journal of Applied Psychology, 83, 377-585. doi: $10.1037 / 0021-9010.83 .4 .577$

Fernández-Muñiz, B., Montes-Peón, J.M., \& Vázquez-Ordás, C.J. (2012). Safety climate in OHSAS 18001-certified organisations: Antecedents and consequences of safety behaviour. Accident Analysis and Prevention, 45, 745-758. doi:

10.1016/j.aap.2011.10.002

Ford, M.T., \& Tetrick, L.E. (2011). Relations among occupational hazards, attitudes, and safety performance. Journal of Occupational Health Psychology, 16, 48-66. doi: $10.1037 / \mathrm{a} 0021296$

Fredrickson, B.L. (1998). What good are positive emotions? Review of General Psychology, 2, 300-319. doi: 10.1037/1089-2680.2.3.300

Fredrickson, B.L. (2001). The role of positive emotions in positive psychology. American Psychologist, 56, 218-226. doi: 10.1037/0003-066X.56.3.218

Fritz, C., Yankelevich, M., Zarubin, A., \& Barger, P. (2010). Happy, healthy, and productive: The role of detachment from work during nonwork time. Journal of Applied Psychology, 95, 977-983. doi: 10.1037/a0019462

Fritz, C., Ellis, A.M., Demsky, C.A., Lin, B.C., \& Guros, F. (2013). Embracing work breaks: Recovering from work stress. Organizational Dynamics, 4, 274-280. doi: 10.1016/j.orgdyn.2013.07.005 
Fritz, C., \& Sonnentag, S. (2005). Recovery, health, and job performance: Effects of weekend experiences. Journal of Occupational Health Psychology, 10, 187-199. doi: $10.1037 / 1076-8998.10 .3 .187$

Fritz, C., \& Sonnentag, S. (2006). Recovery, well-being, and performance-related outcomes: The role of workload and vacation experiences. Journal of Applied Psychology, 91, 936-945. doi: 10.1037/0021-9010.91.4.936

Gable, S.L., Reis, H.T., Impett, E.A., \& Asher, E.R. (2004). What do you do when things go right? The intrapersonal and interpersonal benefits of sharing positive events. Journal of Personality and Social Psychology, 87, 228-245. doi: 10.1037/00223514.87 .2 .228

Geurts, S.A.E., \& Sonnentag, S. (2006). Recovery as an explanatory mechanism in the relation between acute stress reactions and chronic health impairment. Scandinavian Journal of Work, Environment \& Health, 32, 482-492. doi: 10.5271/sjweh.1053

Griffin, M.A., \& Neal, A. (2000). Perceptions of safety at work: A framework for linking safety climate to safety performance, knowledge, and motivation. Journal of Occupational Health Psychology, 5, 347-358. doi: 10-1037//1076-8998.5.3.347

Hagger, M.S., Wood, C., Stiff, C., \& Chatzisarantis, N.L.D. (2010). Ego depletion and the strength model of self-control: A meta-analysis. Psychological Bulletin, 136, 495-525. doi: 10.1037/a0019486

Hahn, V.C., Binnewies, C., Sonnentag, S., \& Mojza, E.J. (2011). Learning how to recover from job stress: Effects of a recovery training program on recovery, 
recovery-related self-efficacy, and well-being. Journal of Occupational Health Psychology, 16, 202-216. doi: 10.1037/a0022169

Halbesleben, J.R.B. (2010). The role of exhaustion and workarounds in predicting occupational injuries: A cross-lagged panel study of health care professionals Harrison, D., Newman, D.A., \& Roth, P.L. (2006). How important are job attitudes? Meta-analytic comparisons of integrative behavioral outcomes and time sequences. 49, 305-325. doi: 10.5465/AMJ.2006.20786077

Higgins, T.E. (1997). Beyond pleasure and pain. American Psychologist, 52, 1280-1300. doi: 10.1037/0003-066X.52.12.1280

Hobfoll, S.E. (1989). Conservation of resources: A new attempt at conceptualizing stress. American Psychologist, 44, 513-524. doi: 10.1037/0003-066X.44.3.513

Hofmann, D.A., Jacobs, R., \& Landy, F. (1995). High reliability process industries: Individual, micro, and macro organizational influences on safety performance. Journal of Safety Research, 26, 131-149. doi: 10.1016/0022-4375(95)00011-E

Hogan, J., \& Foster, J. (2013). Multifaceted personality predictors of workplace safety performance: More than conscientiousness. Human Performance, 26, 20-43. doi: $10.1080 / 08959285.2012 .736899$

Hu, L. T., \& Bentler, P. M. (1999). Cutoff criteria for fit indexes in covariance structure analysis: Conventional criteria versus new alternative. Structural Equation Modeling, 6, 1-55. doi:10.1080/10705519909540118 
Inness, M., Turner, N., Barling, J., \& Stride, C.B. (2010). Transformational leadership and employee safety performance: A within-person, between-jobs design. Journal of Occupational Health Psychology, 15, 279-290. doi: 10.1037/a0019380

Jiang, L., Yu, G., Li, Y., \& Li, F. (2010). Perceived colleagues’ safety knowledge/behavior and safety performance: Safety climate as a moderator in a multilevel study. Accident Analysis and Prevention, 42, 1468-1476. doi: 10.1016/j.aap.2009.08.017

Judge, T.A., Thorensen, C.J., Bono, J.E., \& Patton, G.K. (2001). The job satisfaction-job performance relationship: A qualitative and quanitative review. Psychological Bulletin, 127, 376-407. doi: I0.1037//0033-2909.I27.3.376

Kanfer, R., \& Ackerman, P.L. (1989). Motivation and cognitive abilities: An integrative/aptitude-treatment interaction approach to skill acquisition. Journal of Applied Psychology Monograph, 74, 657-690. doi: 10.1037/0021-9010.74.4.657

Kaufman, B.K., Cigularov, K.P., Chen, P., Hoffmeister, K., Gibbons, A.M., \& Johnson, S.K. (2014). Interactive effects of leader justice and support for safety on safety performance. Journal of Organizational Effectiveness: People and Performance, 1, 296-315. doi: 10.1108/JOEPP-05-2014-0023

Kearny, G.D., Rodriguez, G., Quandt, S.A., Arcury, J.T., \& Arcury, T.A. (2015). Work safety climate, safety behaviors, and occupational injuries of youth farmworkers in North Carolina. American Journal of Public Health, 105, 1336-1344 
Kinicki, A.J., McKee-Ryan, F.M., Schriesheim, C.A., \& Carson, K.P. (2002). Assessing the construct validity of the Job Descriptive Index: A review and meta-analysis. Journal of Applied Psychology, 87, 14-32. doi: 10.1037//0021-9010.87.1.14

Kline, R.B. (2011). Principles and Practices of Structural Equation Modeling (3rd edition). New York: The Guilford Press.

Konda, S., Reichard, A.A., \& Tiesman, H.M. (2012). Occupational injuries among U.S. correctional officers, 1999-2008. Journal of Safety Research, 43, 181-186. doi: 10.1016/j.jsr.2012.06.002

LaPierre, L.M., Hammer, L.B., Truxillo, D.M., \& Murphy, L.A. (2012). Family interference with work and workplace cognitive failure: The mitigating role of recovery experiences. Journal of Vocational Behavior, 81, 227-235. doi: 10.1016/j.jvb.2012.07.007

Leigh, P.J. (2011). Economic burden of occupational injury and illness in the United States. The Milbank Quarterly, 89, 728-772. doi: 10.1111/j.14680009.2011.00648.x

Locke, E.A., \& Latham, G.P. (2002). Building a practically useful theory of goal setting and task motivation. American Psychologist, 57, 705-717. doi: 10.1037//0003066X.57.9.705

Meijman, T.F., \& Mulder, G. (1998). Psychological aspects of workload. In P. J. D. Drenth, H. Thierry \& C. J. W. de (Eds.), Handbook of work and organizational psychology (Vol. 2, pp. 5-33). Hove, England: Psychology Press 
Meyer, J.P., Stanley, D.J., Herscovitch, L., \& Topolnytsky, L. (2002). Affective, continuance, and normative commitment to the organization: A meta-analysis of antecedents, correlates, and consequences. Journal of Vocational Behavior, 61, 20-52. doi: 10.1006/jvbe.2001.1842

Muraven, M., \& Baumeister, R.F. (2000). Self-regulation and depletion of limited resources: Does self-control resemble a muscle? Psychological Bulletin, 126, 247259. doi: 10.1037//0033-2909.126.2.247

Nahrgang, J.D., Morgeson, F.P., \& Hofmann, D.A. (2011). Safety at work: A metaanalytic investigation of the link between job demands, job resources, burnout, engagement, and safety outcomes. Journal of Applied Psychology, 96, 71-94. doi: $10.1037 / \mathrm{a} 0021484$

Neal, A., \& Griffin, M.A. (2006). A study of the lagged relationships among safety climate, safety motivation, safety behavior, and accidents at the individual and group levels. Journal of Applied Psychology, 91, 946-953. doi: 10.1037/00219010.91 .4 .946

Neal, A., Griffin, M.A., \& Hart, P.M. (2000). The impact of organizational climate on safety climate and individual behavior. Safety Science, 34, 99-109.

Netemeyer, R.G., Boles, J.S., \& McMurrian, R. (1996). Development and validation of work-family conflict and family-work conflict scales. Journal of Applied Psychology, 81, 400-410. doi: 10.1037/0021-9010.81.4.400 
Ng, T.W.H., \& Feldman, D.C. (2008). The relationship of age to ten dimensions of job performance. Journal of Applied Psychology, 93, 392-423. doi: 10.1037/00219010.93 .2 .392

Obidoa, C., Reeves, D., Warren, N., Reisine, S., \& Cherniack, M. (2011). Depression and work family conflict among corrections officers. Journal of Occupational and Environmental Medicine, 53, 1294-1301. doi: 10.1097/JOM.0b013e3182307888

Olson, R. (201). Motivational traps. The Behavior Analyst Today, 11, 117-127.

Park, Y., \& Fritz, C. (2015). Spousal recovery support, recovery experiences, and life satisfaction crossover among dual-earner couples. Journal of Applied Psychology, 100, 557-566. doi: 10.1037/a0037894

Pereira, D., \& Elfering, A. (2014). Social stressors at work and sleep during the weekends: The mediating role of psychological detachment. Journal of Occupational Health Psychology, 19, 85-95. doi: 10.1037/a0034928

Podsakoff, P.M., MacKenzie, S.B., Lee, J.-Y., \& Podsakoff, N.P. (2003). Common method biases in behavioral research: A critical review of the literature and recommended remedies. Journal of Applied Psychology, 88, 879-903. doi: $10.1037 / 0021-9010.88 .5 .879$

Preacher, K.J., \& Hayes, A.F. (2004). SPSS and SAS procedures for estimating indirect effects in simple mediation models. Behavior Research Methods, Instruments \& Computers, 36, 717-731. 
Probst, T.M., \& Brubaker, T.L. (2001). The effect of job insecurity on employee safety outcomes: Cross sectional and longitudinal explorations. Journal of Occupational Health Psychology, 6, 139-159. doi: 10.1037//1076-8998.6.2.139

Reason, J., Parker, D., \& Lawton, R. (1998). Organizational controls and safety: The varieties of rule-related behaviour

Rothbard, N.P., \& Wilk, S.L. (2011). Waking up on the right or wrong side of the bed: Start-of-day workday mood, work events, employee affect, and performance. Academy of Management Journal, 54, 959-980. doi: 10.5465/amj.2007.0056

Salanova, M., Lorente, L., \& Martínez, I.M. (2012). The dark and bright sides of selfefficacy in predicting learning, innovative and risky performances. The Spanish Journal of Psychology, 15, 1123-1132. doi:

10.5209/rev_SJOP.2012.v15.n3.39402

Schneider, B. (1990). Organizational climate and culture: Pfeiffer.

Schwarz, N., \& Clore, G.L. (2003). Mood as information: 20 years later. Psychological Inquiry, 14, 296-303.

Segerstrom, S.C., Stanton, A.L., Alden, L.E., \& Shortridge, B.E. (2003). A multidimensional structure for repetitive thought: What's on your mind, and how, and how much? Journal of Personality and Social Psychology, 85, 909-921. doi: 10.1037/0022-3514.85.5.909

Shrout, P. E., \& Bolger, N. (2002). Mediation in experimental and nonexperimental studies: New procedures and recommendations. Psychological Methods, 7, 422445. doi: 10.1037/1082-989X.7.4.422 
Singer, J.D., \& Willett, J.B. (2003). Applied longitudinal data analysis: Modeling change and event occurrence: Oxford University Press.

Smith, M.J., \& Carayon, P. (2011). Controlling occupational safety and health hazards. In J. C. Quick \& L. E. Tetrick (Eds.), Handbook of Occupational Health Psychology. Washington, D.C.: American Psychological Association.

Smith, T.D., \& DeJoy, D.M. (2012). Occupational injury in America: An analysis of risk factors using data from the General Social Survey (GSS). Journal of Safety Research, 43, 67-74. doi: 10.1016/j.jsr.2011.12.002

Sobel, M. E. (1982). Asymptotic confidence intervals for indirect effects in structural equation models. Sociological Methodology, 13, 290-312.

Sonnentag, S., Kuttler, I., \& Fritz, C. (2010). Job stressors, emotional exhaustion, and need for recovery: A multi-source study on the benefits of psychological detachment. Journal of Vocational Behavior, 76, 355-365. doi:

10.1016/j.jvb.2009.06.005

Sonnentag, S. (2012). Psychological detachment from work during leisure time: The benefits of mentally disengaging from work. Current Directions in Psychological Science, 21, 1-5. doi: 10.1177/0963721411434979

Sonnentag, S., Arbeus, H., Mahn, C., \& Fritz, C. (2014). Exhaustion and lack of detachment from work during off-job time: Moderator effects of time pressure and leisure experiences. Journal of Occupational Health Psychology, 19, 206216. doi: $10.1037 / \mathrm{a} 0035760$ 
Sonnentag, S., \& Bayer, U. (2005). Switching off mentally: Predictors and consequences of psychological detachment from work during off-job time. Journal of Occupational Health Psychology, 10, 393-414. doi: 10.1037/1076-8998.10.4.393

Sonnentag, S., Binnewies, C., \& Mojza, E.J. (2008). "Did you have a nice evening?" A day-level study on recovery experiences, sleep and work-relevant affect. Journal of Applied Psychology, 93, 674-684. doi: 10.1037/0021-9010.93.3.674

Sonnentag, S., \& Fritz, C. (2007). The recovery experience questionnaire: Development and validation of a measure for assessing recuperation and unwinding from work. Journal of Occupational Health Psychology, 12, 204-221. doi: 10.1037/10768998.12.3.204

Sonnentag, S., \& Fritz, C. (2014). Recovery from job stress: The stressor-detachment, model as an integrative framework. Journal of Organizational Behavior. doi: 10.1002/job.1924

Sonnentag, S., \& Fritz, C. (in preparation). Recovery from work The SAGE Handbook of Industrial, Work \& Organizational Psychology.

Sonnentag, S., \& Grant, A.M. (2012). Doing good at work feels good at home, but not right away: When and why perceived prosocial impact predicts positive affect. Personnel Psychology, 65, 495-530. doi: 10.1111/j.1744-6570.2012.01251.x

Swenson, D.X., Waseleski, D., \& Hartl, R. (2008). Shift work and correctional officers: Effect and strategies for adjustment. Journal of Correctional Health Care, 14, 299-310. doi: 10.1177/1078345808322585 
Synder, L.A., Krauss, A.D., Chen, P.Y., Finlinson, S., \& Huang, Y.-H. (2011). Safety performance: The mediating role of safety control. Work, 40, 99-111. doi: 10.3233/WOR-2011-1210

ten Brummelhuis, L.L., \& Bakker, A.B. (2012). Staying engaged during the week: The effect of off-job activties on next day work engagement. Journal of Occupational Health Psychology, 17, 445-455. doi: 10.1037/a0029213

Tett, R.P., \& Meyer, J.P. (1993). Job satisfaction, organizational commitment, turnover intention, and turnover: Path analysis based on meta-analytic findings. Personnel Psychology, 45, 259-293.

Trougakos, J.P., \& Hideg, I. (2009). Momentary work recovery: The role of within-day work breaks. In S. Sonnentag, P. L. Perrewe \& D. C. Ganster (Eds.), Current perspectives on job-stress recovery (pp. 37-84). Bingley, UK: Emerald.

Turner, N., Herschcovis, M.S., Reich, T.C., Totterdell, P. (2014). Work-family interference, psychological distress, and workplace injuries. Journal of Occupational and Organizational Psychology, 87, 715-732. doi: 10.1111/joop.12071

Tyler, J.M., \& Burns, K.C. (2008). After depletion: The replenishment of the self's regulatory resources. Self and Identity, 7, 305-321. doi: $10.1080 / 15298860701799997$

Vancouver, J.B., Thompson, C.M., Tischner, C., \& Putka, D.J. (2002). Two studies examining the negative effect of self-efficacy on performance. Journal of Applied Psychology, 87, 506-516. doi: 10.1037//0021-9010.87.3.506 
Vinodkumar, M.N., \& Bhasi, M. (2010). Safety management practices and safety behaviour: Assessing the mediating role of safety knowledge and motivation. Accident Analysis and Prevention, 42, 2082-2093. doi: 10.1016/j.aap.2010.06.021

Volman, F.E., Bakker, A.B., \& Xanthopoulou, D. (2013). Recovery at home and performance at work: A diary study on self-family facilitation. European Journal of Work and Organizational Psychology, 22, 218-234. doi:

10.1080/1359432X.2011.648375

Volmer, J., Binnewies, C., Sonnentag, S., \& Niessen, C. (2012). Do social conflicts with customers at work encroach upon our private lives? A diary study. Journal of Occupational Health Psychology, 17, 304-315. doi: 10.1037/a0028454

Vroom, V.H. (1964). Work and motivation. New York, NY: John Wiley \& Sons.

Wallace, C., \& Chen, G. (2006). A multilevel integration of personality, climate, selfregulation, and performance. Personnel Psychology, 59, 529-557. doi: 10.1111/j.1744-6570.2006.00046.x

Zapf, D., Dormann, C., \& Frese, M. (1996). Longitudinal studies in organizational stress research: a review of the literature with reference to methodological issues. Journal of Occupational Health Psychology, 1, 145-169.

Zohar, D. (1980). Safety climate in industrial organizations: theoretical and applied implications. Journal of Applied Psychology, 65, 96-102. doi: 10.1037/00219010.65.1.96 
Zohar, D. (2000). A group-level model of safety climate: Testing the effect of group climate on microaccidents in manufacturing jobs. Journal of Applied Psychology, 85, 587-596. doi: 10.1037//0021-9010.85.4.587

Zohar, D. (2003). The influence of leadership and climate. In D.A. Hofmann \& L.E. Tetrick (Eds.), Health and Safety in Organizations: A Multilevel Perspective (pp. 201-230).

Zohar, D. (2010). Thirty years of safety climate research: Reflections and future directions. Accident Analysis and Prevention, 42, 1517-1522. doi: 10.1016/j.aap.2009.12.019

Zohar, D. (2011). Safety climate: Conceptual and measurement issues. In J.C. Quick \& L.E. Tetrick (Eds.), Handbook of Occupational Health Psychology (pp. 141-164). Washington, D.C.: American Psychological Association.

Zohar, D., \& Luria, G. (2005). A multilevel model of safety climate: Cross-level relationships between organization and group-level climate. Journal of Applied Psychology, 90, 616-628. doi: 10.1037/0021-9010.90.4.616

Zohar, D., Huang, Y., Lee, J., \& Robertson, M. (2014). A mediation model linking dispatcher leadership and work ownership with safety climate as predictors of truck driver safety performance. Accident Analysis and Prevention, 62, 17-25. doi: 10.1016/j.aap.2013.09.005 


\author{
Appendix: List of Measures
}

\title{
Cognitive Recovery
}

\section{Psychological Detachment}

1. I forgot about work.

2. I didn't think about work at all.

3. I distanced myself from work.

4. I got a break from the demands of work.

\section{Positive Work Reflection}

1. I realized what I like about my job.

2. I thought about the positive aspects of my job.

3. I considered the positive aspects of my job.

\section{Negative Work Reflection}

1. I considered the negative aspects of my work.

2. It became clear to me what I don't like about my work.

3. I was aware of what is negative about my work.

\section{Workplace Safety}




\section{Safety Compliance Motivation}

1. I felt that adhering to safety procedures was worthwhile.

2. I believed that it was important to always use safe/standard work procedures.

3. I believed that it was important to consistently use the correct personal protective equipment.

4. I felt that it was worthwhile to use my personal protective equipment in the defined areas.

5. I felt that adhering to safe procedures was important in my job.

\section{Safety Participation Motivation}

1. I felt that it was worthwhile to be involved in the development of safe work practices.

2. I believed that it was important to promote a safety program.

3. I felt that it was important to encourage others to use safe practices.

4. I believed that it was worthwhile to put extra effort into maintaining safety.

5. I felt that it was worthwhile to volunteer for safety- related tasks.

6. I believed that it was important to help my coworkers in unsafe or hazardous conditions.

\section{Safety Compliance}


1. I used all the necessary safety equipment to do my job.

2. I used the correct safety procedures for carrying out my job.

3. I ensured the highest levels of safety when I carried out my job.

\section{Safety Participation}

1. I promoted the safety program within the organization.

2. I put in extra effort to improve the safety of the workplace.

3. I voluntarily carried out tasks or activities that help to improve workplace safety.

\section{Perceptions of Safety Climate (CO frame of reference)}

1. My direct supervisor discussed with us how to improve safety.

2. My direct supervisor used explanations (not just compliance) to get us to act safely.

3. My direct supervisor refused to ignore safety rules when work fell behind schedule.

4. My direct supervisor was strict about working safely even when we were tired or stressed.

5. My direct supervisor complimented employees who paid special attention to safety.

6. My direct supervisor frequently talked about safety issues throughout the work week.

Perception of Safety Climate (Supervisor frame of reference) 
1. I discussed with my employees how to improve safety.

2. I used explanations (not just compliance) to get my employees to act safely.

3. I refused to ignore safety rules when work fell behind schedule.

4. I was strict about working safely even when my employees were tired or stressed.

5. I complimented employees who paid special attention to safety.

6. I frequently talked about safety issues throughout the work week.

\section{Accidents and Injuries}

When answering the following questions, please think about the last 3 months.

1. Have you had any injuries at work that required you to miss work on following shifts? (more serious sprains and cuts, muscle or joint pain, or fractures requiring recovery time or medical treatment)

Response options: 1 (No missed days); 2 (Yes, 1 day); 3 (Yes, 2 days); 4 (Yes, 3-5 days);

5 (Yes, 6-10 days); 7 (Yes, 10 or more)

2. In the past 3 months have you filed a worker's compensation claim?

Response options: 1 (Yes); 2 (No) 